\title{
Pain assessment in nursing home residents with dementia
}

Citation for published version (APA):

Zwakhalen, S. M. G. (2007). Pain assessment in nursing home residents with dementia. [Doctoral Thesis, Maastricht University]. Maastricht University. https://doi.org/10.26481/dis.20071212sz

Document status and date:

Published: 01/01/2007

DOI:

$10.26481 /$ dis.20071212sz

Document Version:

Publisher's PDF, also known as Version of record

\section{Please check the document version of this publication:}

- A submitted manuscript is the version of the article upon submission and before peer-review. There can be important differences between the submitted version and the official published version of record.

People interested in the research are advised to contact the author for the final version of the publication, or visit the DOI to the publisher's website.

- The final author version and the galley proof are versions of the publication after peer review.

- The final published version features the final layout of the paper including the volume, issue and page numbers.

Link to publication

\footnotetext{
General rights rights.

- You may freely distribute the URL identifying the publication in the public portal. please follow below link for the End User Agreement:

www.umlib.nl/taverne-license

Take down policy

If you believe that this document breaches copyright please contact us at:

repository@maastrichtuniversity.nl

providing details and we will investigate your claim.
}

Copyright and moral rights for the publications made accessible in the public portal are retained by the authors and/or other copyright owners and it is a condition of accessing publications that users recognise and abide by the legal requirements associated with these

- Users may download and print one copy of any publication from the public portal for the purpose of private study or research.

- You may not further distribute the material or use it for any profit-making activity or commercial gain

If the publication is distributed under the terms of Article $25 \mathrm{fa}$ of the Dutch Copyright Act, indicated by the "Taverne" license above, 


\section{Pain assessment in nursing home residents with dementia}




\section{Colophon}

Title: Pain assessment in nursing home residents with dementia.

Sandra MG Zwakhalen. Thesis Maastricht University

Cover: the drawing used on the cover was made by Gepko Roggeveen, who is a visual artist. This drawing is one of a series of thirty. These drawings were made with the special thought to gave all demented elderly people a face. Out of consideration for those who can speak not for themselves.

Lay-out: Inge en Hans Duimel

Printed by: Elsevier, gezondheidszorg

(C) Sandra MG Zwakhalen, Maastricht, 2007

ISBN 978-90-3522270-9

Studies in this thesis have been supported by Grant No. 940-31-087 of the Netherlands organisation for health research and development (ZON-MW).

Financial support for printing this thesis has been kindly provided by the International Stichting Alzheimer Onderzoek (ISAO), P. Vosters OG., Elsevier gezondheidszorg. 


\title{
Pain assessment in nursing home residents with dementia
}

\author{
PROEFSCHRIFT \\ Ter verkrijging van de graad van doctor aan de Universiteit Maastricht, \\ op gezag van de Rector Magnificus, Prof. Mr. G.P.M.F. Mols, \\ volgens het besluit van het College van Decanen, \\ in het openbaar te verdedigen \\ op woensdag 12 december 2007 om 16:00 uur
}

door

SANDRA MARIA GABRIELLA ZWAKHALEN 


\section{PROMOTORES :}

Prof. dr. J.P.H. Hamers

Prot. dr. M.P.F. Berger

\section{BEOORDELINGSCOMMISSIE:}

Prof. dr. J.W.S. Vlaeyen (voorzitter)

Prof. dr. R. de Wit

Prof. dr. E.J.A. Scherder

Prof. dr. ir. H.C.W. de Vet

Prof. dr. G.I.J.M. Kempen 


\section{CONTENTS}

$\begin{array}{ll}\text { Prologue } & 7\end{array}$

Chapter $1 \quad$ General introduction

Chapter $2 \quad$ Nursing staffs knowledge and beliefs 23 about pain in elderly nursing home residents with dementia

Chapter 3 Pain in elderly people with severe dementia: A systematic review of behavioural pain assessment tools

Chapter 4 The psychometric quality and clinical usefulness of three pain assessment tools for elderly people with dementia

Chapter 5 Improving the clinical usefulness of a behavioural pain scale for older people with dementia

Chapter 6 The prevalence of pain in nursing home residents with dementia measured using an observational pain scale

Chapter $7 \quad$ General discussion

Chapter 8

Summary

Samenvatting

146

Dankwoord

150

About the author 


\section{PROLOGUE}

A case report

$7 \mathrm{rs}$ B. is an 81-year-old woman who was aclmitted to the nursing bome about one year 11 ago. She was diagnosed with a progressive form of Alzbeimer's disease and right now' ber cognitive abilities are very limited due to the dementia. Therefore, she is not able to respond to simple questions. Her communicative abilities are also very limited. Words don't make sense anymore; sometimes she mumbles. She bas multiple chronic severe illnesses that keep ber more and more bed-ridden and make ber more dependent on others. She bas a bistory of astbma, diabetes and artbritis. Because of the time she was spending in bed she started to develop pressure ulcers. Since ber admission last year, she has lost over 10\% of ber body weight. In the beginning, nurses thought she was baving difficulties with the changes in her environment. During the past year cognitive functioning bas declined, bowever, and she bas started to witbdraw from social activities. During morning care, nurses noted that Mrs. B. bad a constant facial expression and looked extbausted, initially assumed to be related to the asthmatic bistory. They' also reported that she was repeatedly physically' aggressive during care, but they related that aspect to the dementia process itself. Sometimes she would become so defensive that it was impossible to bathe ber. Those moments, when she refused to let the staff come near her, bave occurred more frequently as of late.

Her family started to worry and brought their alarm to the attention of one of the nurses on the ward. In an evaluation with the nurses the family addressed these behavioural problems and the physical decline of their mother, and identified pain as the most likely cause.

Mrs B. was considered to be in pain. The question now arises as to how this pain can objectively be determined and evaluated. The assessment of pain in elderly people with severe dementia is the topic of this thesis. 
Chapter 1

General introduction 


\section{INTRODUCTION}

This thesis addresses a problem, a subjective feeling that a lot of people feel

1 they can relate to, namely pain. Pain has a great impact on daily living and is associated with suffering. Everyone experiences pain once in a while and everyone knows what we mean when we talk about pain. But when we are asked to describe what pain is, suddenly it's not that simple anymore. Imagine one of the extra complexities pcople with severe dementia have to deal with when they only have a limited ability to communicate their pain. How can they express their feelings, their pain, and how can we, as health care workers, be sure that pain cues are interpreted correctly? Pain assessment scales may be a possible solution and therefore a key to better pain management. A solid pain assessment scale is definitely the first step towards better treatment and is needed in daily clinical practice. However, although the assumption that better assessment leads to better treatment sounds logical, it still needs to be proven. Before this can be done, we have to make sure that we have a psychometrically reliable and clinically useful scale that can be implemented in daily practice.

The first chapter of this thesis will provide a general background on pain in elderly people with dementia. It will specify the overall aim and present an overview of the thesis.

\section{Area of researcb: elderly people with dementia living in Dutch nursing bomes}

Elderly people have been defined by demographers, insurers and employers as those aged 65 and older.' However, it should be noted that the group of elderly people can be very heterogeneous and may include a broad age group ranging from the younger elderly of 60-65, up to those older than 100 years of age, all of whom represent completely different health problems. With the increasing number of people over 65 in industrialized countries, clinicians will be treating more older people than in the past and will have to anticipate absent, atypical or exacerbated presentation of acute or chronic pain. ${ }^{2}$ In the Netherlands, people aged 65 and older comprise $14.5 \%$ of the Dutch population. ${ }^{3}$ Of the people in this age category, over $2.7 \%$ live in nursing homes. ${ }^{+}$Nursing homes offer complex care to very frail elderly people who have physical and/or psychogeriatric disorders that affect self-care, mobility, continence and cognitive functioning. ${ }^{5}$ Nursing home care in the Netherlands differs from other countries in that the staff includes nursing home physicians (one full-time doctor per hundred patients), along with physical therapists, occupational therapists, speech therapists and psychologists, all of whom are employed by the nursing home. Nursing homes have separate wards for rehabilitation, long-term physical care and patients with Alzheimer's disease.' In 2004 there were approximately 342 nursing homes in the Netherlands. "These nursing homes care for over 30,000 of the 220,000 elderly people with dementia living in the Netherlands. ${ }^{5}$

Dementia is the most frequently encountered diagnosis in psycho-getiatric patients. ${ }^{7}$ Dementia, caused by a variety of conditions, is defined as a complex of symptoms characterized by progressive global deterioration of cognitive 
functioning." The probability of suffering from dementia increases with advancing age, with an incidence of approximately $1 \%$ at the age of 65 and $25 \%$ at the age of 85." Multiple co-morbid conditions are common in patients with dementia and these patients often receive complex medication regimens." Dementia leads to a substantial individual, family and societal burden." The progressive decline has a great impact on everyone involved in the process of caregiving.

\section{Pain in elderly with dementia: a complex phenomenon}

Pain is a subjective phenomenon, not a well-defined disease state that can be ascertained by objective diagnostic tests ${ }^{12}$ Pigeon et al. ${ }^{13}$ stated that pain is always a subjective and complex response, and different people may react to the same stimulus in different ways, or the same person may react differently in different situations or at different moments. Pain is defined by the International Association of Pain (IASP) ${ }^{14}$ as 'an unpleasant sensory and emotional experience associated with actual or potential tissue damage or described in terms of such damage'. The IASP noted on their website that the inability to communicate verbally does not negate the possibility that an individual is experiencing pain and is in need of appropriate pain-relieving treatment. Another frequently used definition of pain is 'pain is whatever the experiencing person says it is and whenever he/she says it does'. 'This definition by McCaffery ${ }^{15}$ is often used in clinical practice and guides health care professionals in their direct view towards pain. This definition puts the emphasis even more strongly on verbal expression than does the definition from the IASP and, consequently, the first impression might be that this definition is less useful in the most vulnerable people with extreme verbally limited abilities to communicate. However, with a slight adaptation, the definition by McCaffery is also applicable for a noncommunicative population. Therefore, our adapted definition of pain is: 'pain is whatever the experiencing person expresses it is and whenever he/ she expresses it does'. This definition focuses on expression, which can be verbal or nonverbal. Furthermore, it highlights the importance and responsibility of the observer, which is of major importance in pain assessment in non-verbal populations. The internal pain experienced is communicated through external signs. An external rater observes these signs (influenced by the method through which signs are observed) and interprets them (influences by rater-specific factors). The result is the external raters' pain assessment. ${ }^{16}$

Most studies show that older people have higher rates of pain prevalence. ${ }^{17}$, 18 This is not surprising, since older people are more at risk of experiencing pain. They have more painful pathology due to the increased incidence of chronic medical conditions such as musculoskeletal, cardiovascular and respiratory diseases."

Reported pain prevalence rates vary enormously and range between 50 and $86 \%$, studies and across age groups, and may also depend on the type of pain scale used..$^{22}$ 
Scarcer still is the scientific knowledge about pain prevalence in elderly nursing home people with dementia. Often they have multiple physical complaints increasing the risk of pain. But because of the absence of adequate diagnostic instruments, pain prevalence rates can only be roughly estimated at between 28 and $83 \% .{ }^{23} 28$

The conscquences of persistent pain are numerous. Depression, anxiety, decreased socialization, sleep disturbance, impaired ambulation, and increased health care utilization and costs have all been found to be associated with the presence of pain in older people. ' Hence, it can be stated that under-treated pain affects quality of life negatively.

People with dementia are asked about their pain less frequently as compared to non-impaired elderly people. Hospitalized elderly patients with hip fractures were not assessed and reassessed as recommended and there was significantly lower pain rating for patients with dementia. ${ }^{29}$ Even more worrying is the fact that people with dementia receive fewer analgesics and thus less optimal treatment as compared to elderly people without a dementia diagnosis. Increased level of cognitive dysfunction is associated with decreased levels of cardiovascular and analgesic medications, along with the use of fewer prescribed medications. ${ }^{31}$ Horgas and Tsai ${ }^{31}$ found similar results in prescribed and administered analgesic medication, both in number and dosage. Pickering et al. ${ }^{32}$ compared the analgesic consumption for residents with Alzheimer's disease and non-demented individuals. Although analgesic consumption for acute pain was not significantly different between both groups, chronic analgesic pain consumption was significantly lower in Alzheimer's residents than in nondemented residents. Even in situations such as undergoing hip surgery " elderly people receive a considerably lower dosage of analgesics postoperative. Won et al..$^{33}$ stated that increased cognitive impairment together with being over 85 years old, male and of non-white ethnicity are predictors of poor analgesic administration. This would make a lot of elderly people with dementia a highrisk population for undertreatment.

It cannot be stated enough that the nursing home staff plays an important role in almost all care giving decision-making processes. Therefore, another factor that might contribute to the complexity of pain and assessment is their attitude and knowledge. Lack of knowledge about pain and its treatment has been viewed as an important barrier to effective pain management in several studies. ${ }^{\text {p.p }}$, ${ }^{+1}$ Of concern is the fact that studies show inadequate knowledge about pain treatment and, for instance, about the risk of addiction. ${ }^{3.1,35}$ Information on attitudes and knowledge of nursing staff in working with elderly people with dementia is, however, still limited, but if nurses' behaviour is indeed affected by their knowledge and beliefs about pain in elderly people with dementia, this should be a matter of concern. 
Metbods to assess pain in elderly nursing bome residents with dementia

Research into pain distinguishes between pain measurement and assessment. Measurement refers to the application of some form of metrics to a specific element. Usually this is intensity of pain. Assessment is a much broader endeavour, which encompasses the measurement of the interplay of different factors in pain experienced. ${ }^{36}$ Thus, pain measurement usually refers to describing the uni-dimensional aspect of pain measurement, while pain assessment refers to the multi-dimensional measurement of pain. ${ }^{37}$ Assessment of pain is, therefore, usually more comprehensive and includes not only pain intensity, but also affective and/or cognitive components of pain.

Assessment of pain requires the availability of well-validated measurement instruments, and it is not until measurement instruments are available that assessment strategies can develop. ${ }^{36}$ However, the terms 'measurement' and 'assessment' are often used simultaneously. This thesis will emphasize mostly that aspect of pain measurement that is concerned with pain detection and pain intensity. Pain intensity is defined as the quantitative estimate of the severity or magnitude of perceived pain. ${ }^{3 k}$ It is the most frequently assessed component of pain. ${ }^{30}$

Different methods have been developed to measure pain in elderly people with dementia, including patient's self-report, observational methods and physiological reactions. "Unfortunately, there are no manifestations of pain that are exclusive markers of the experience or not subject to observer doubts about credibility. ${ }^{41}$

Self-reporting is often referred to as the 'gold standard' in pain assessment. Self-report scales require the capacity to understand the task and to communicate the experienced pain sensation. A broad range of self-report scales is currently available to assess pain in the elderly. Most of these self-report scales have been developed for and tested in different settings before being used among elderly people with dementia. ${ }^{30}$ Commonly used measures of pain intensity include Visual Analogue Scales (VAS), Verbal Rating Scales (VRS), Numeric Rating Scales (NRS) and Facial Pain Scales (FPS). ${ }^{3 \prime \prime}, 2$

Studies have repeatedly demonstrated that mildly or moderately demented elderly people are capable of and successful in using self-report scales and are able to communicate about their pain. ${ }^{23,25,43.47}$ In general it can be stated that most people with mild and moderate dementia can use self-report in a reliable and valid way, although tool selection does require special attention. The American Geriatric Society (AGS) also recommends that for this group, pain should be assessed by asking the patient directly'. Some studies have even shown that some residents with severe cognitive impairment are still capable of using one or more simple self-report scales. ${ }^{46,+4,+4)}$

Studies confirmed the validity and reliability of patients self-reports. ${ }^{6.8}+5,48,50$ However, recalling pain seems to create a greater risk of reduced reliability given 
the lower reliability coefficients in cognitively impaired people. ${ }^{45,49}$

While the VDS, CAS and NRS present high completion rates in most studies 4, in $; 3$, the VAS consistently demonstrates high lowest-completion rates or high numbers of failures, and is therefore not recommended in elderly people with dementia. ${ }^{25,+3}$

Observational methods focus upon non-verbal, obscrvable signs of pain that are often in the involuntary, non-deliberate domain." Behavioural observation methods include observation of changes in sleep, appetite, physical activity, mobility and facial/body language. Dementia may affect the ability to communicate, impairing expression of pain, thus presenting a substantial barrier to pain assessment and management ${ }^{54}$, especially at a more advanced stage. In this stage of dementia, when elderly persons are severely impaired and often not able to communicate by words, behavioural pain assessment methods become more useful and important.

In contrast to self-report procedures, observational methods of assessing pain tend to rely on more automatic forms of pain expression and communication. These automatic forms of pain communication are sometimes more difficult to decode and interpret than self-report information. On the other hand, due to their reflexive automaticity, non-verbal behaviours are more likely to be preserved in situations where higher mental processes are compromised." Observational tools have received a great deal of attention in the last decade. This has resulted in a considerable increase in observational tools to assess pain in elderly with severe dementia. These scales will be reviewed extensively in Chapter 2 of this thesis.

Physiological measures, like heart rate or blood pressure, are typically markers for acute pain and may provide information in combination with other indicators (e.g., behaviour). Research on physiological measures is limited. Autonomic responses to pain are difficult to discriminate physiologically from other states of arousal or distress."11 Furthermore, this method has major practical limitations and is therefore not useful in clinical practice.

Regardless of which method of pain assessment is used, the way to adequate assessment is often complicated by the many barriers specific to this target group. Dementia can be characterized by memory loss, personality changes and loss of other functions such as judgement, abstract thinking and language skills, which can affect the assessment. Residents with dementia may express their pain in ways that are quite different from those of elderly people without dementia.5. As a result of these problems, which affect almost all dementia residents, pain in this population is extremely difficult to assess.

\section{Overall aim of the study}

In the last decade, research on pain in elderly nursing home residents with limited ability to express their pain has received more attention. While most 
studies focused on developing their own new pain assessment tool, we have tried to benefit from the lessons of others and started to examine the availability of the existing pain assessment scales, the psychometric qualities and their implication for clinical practice. Therefore, we conducted several studies to gain more insight into pain assessment in elderly nursing home people with dementia.

The overall aim of the research in this thesis is

(1) to gain more insight into nurses' knowledge and attitudes towards pain in elderly nursing home residents as a possible factor influencing undertreatment

(2) to gain more insight into pain assessment in elderly people with dementia

(3) to make sure that a clinically useful and psychometrically sound observational assessment scale becomes available for daily use in measuring pain in Dutch nursing homes and to investigate the psychometric qualities; and

(4) to measure pain prevalence using an observational scale.

\section{OUTLINE OF THIS THESIS}

This thesis comprises seven chapters and is organized as follows. The current chapter presents the general introduction, which provides background information and the outline of the thesis.

Chapter 2 describes an important issue that relates to pain, namely knowledge and beliefs. Knowledge deficits and beliefs among nurses influence their behaviour in pain assessment and management. The research in this chapter will report the results of a survey using a questionnaire that was developed to measure nursing-staff knowledge and beliefs about pain in elderly people with dementia.

Chapter 3 presents a systematic review. The aim of this review is to present an overview of the available behavioural pain assessment scales, specially developed to assess pain in elderly people with dementia, and to evaluate the psychometric qualities and clinical usefulness of these tools. One of the major findings of this review was that Pain Assessment IN Advanced Dementia (PAINAD) scale, Pain Assessment Checklist for Seniors with Limited Ability to Communicate (PACSLAC), and DOLOPLUS-2 showed promising psychometric qualities, though they required further testing.

Therefore, in addition, Chapter 4 will describe the psychometric testing of these three pain assessment scales in nursing home practice, using potentially painful situations. In the two previous studies we have shown that the Pain Assessment Checklist for Seniors with Limited Ability to Communicate 
(PACSLAC) demonstrates high validity and reliability, although it could be refined to reduce the number of scale items and increase the homogeneity and usefulness of the scale.

Chapter 5 describes the process of item reduction as part of the construction of the Dutch version of the PACSLAC scale (named PACSLAC-D) to assess pain in Dutch older nursing home residents with dementia.

Chapter 6 explores the prevalence of pain in nursing home residents with dementia as measured by the PACSLAC-D during morning care and identifies the association with possible (personal) characteristics/health conditions.

Finally, the main findings and implications of the previous chapters will be discussed in Chapter 7.

Due to the fact that Chapters 2 through 6 in this thesis are based on articles published or submitted to scientific journals, some overlap between the chapters is inevitable. In this thesis, the terms patient and resident are both used indiscriminately, guided by the preference of the journal to which the article was submitted.

\section{REFERENCES}

1. AGS Panel on Persistent Pain in Older Persons. The management of persistent pain in older persons. Journal of the American Geriatrics Society. 2002;50 (6 Suppl):S205-224.

2. Pickering G. Age differences in clinical studies. In: Gibson SJ, Weiner DK, 1eds. Pain in older persons. Seattle: IASP Press; 2005:67-87.

3. CBS. http://statline.cbs.nl $/$ StatWeb $/$ table.asp?PA $=60035$ ned $\& D 1=0,49 \& D 2=$ $a \& D 3=a \& D 4=0,5-6 \& D 5=4,(1-1)-1 \& D M=S L N L \& L A=n l \& T T=2.2007$.

4. Hoek JF, Penninx BW, Ligthart GJ, Ribbe NWW. Health care for older persons, a country profile: The Netherlands. Journal of the American Geriatrics Society. 2000;48(2):214-217.

5. Schols JM, van der Schriek-van Meel C. Day care for demented elderly in a dairy farm setting: positive first impressions. Journal of the American Medical Directors Association. 2006;7(7):456-459.

6. Giesbers H. Aantal verpleeghuizen per gemeente 2004. ( The number of nursing homes per local authority in 2004). Bilthoven: RIVM; 2005.

7. Schols JM, Crebolder HF, van Weel C. Nursing home and nursing home physician: the Dutch experience. Journal of the American Medical Directors Association. 2004;5(3):207-212.

8. Patterson CJ, Gauthier S, Bergman $\mathrm{H}$, et al. The recognition, assessment and management of dementing disorders: conclusions from the Canadian Consensus Conference on Dementia. CMAJ Canadian Medical Association Journal. 1999;160(12 Suppl):S1-15.

9. Jorm AF, Henderson S, Scott R, Mackinnon AJ, Korten AE, Christensen H. The disabled elderly living in the community: care received from family and formal services. Med J Aust. Mar 15 1993;158(6):383-385, 388. 
10. Schubert CC, Boustani M, Callahan CM, et al. Comorbidity profile of dementia patients in primary care: are they sicker? Journal of the American Geriatrics Society. 2006;54(1):104-109.

11. Boustani M, Peterson B, Hanson I, Harris R, Lohr KN. Screening for dementia in primary care: a summary of the evidence for the U.S. Preventive Services Task Force. Annals of Internal Medicine. 2003;138(11):927-937.

12. Von Korff M, LeResche L. Epidemiology of pain. In: Merskey H, Loeser J, D., Dubner R, eds. The paths of pain 1975-2005. Seattle: IASP Press; 2005:339-352.

13. Pigeon HM, McGrath PJ, Lawrence J, MacMurray SB. Nurses' perceptions of pain in the neonatal intensive care unit. Journal of Pain \& Symptom Management. 1989;4(4):179-183.

14. Classification of chronic pain. Descriptions of chronic pain syndromes and definitions of pain terms. Prepared by the International Association for the Study of Pain, Subcommittee on Taxonomy. Pain Suppl. 1986;3:S1-226.

15. McCaffery M, Beebe A. Pain: Clinical Manual for Nursing Practice. St. Louis: CV Mosby Company; 1989.

16. Snow AL, O'Malley KJ, Cody M, ct al. A conceptual model of pain assessment for noncommunicative persons with dementia. Gerontologist. 2004;44(6):807817.

17. Crook J, Rideout E, Browne (j. The prevalence of pain complaints in a general population. Pain. 1984;18(3):299-314.

18. Elliott AM, Smith BH, Penny KI, Smith WC, Chambers WA. The epidemiology of chronic pain in the community. Lancet. 1999;354(9186):1248-1252.

19. Feldt KS, Ryden MB, Miles S. Treatment of pain in cognitively impaired compared with cognitively intact older patients with hip-fracture. Journal of the American Geriatrics Society. 1998;46(9):1079-1085.

20. Brattberg G, Parker MG, Thorslund M. The prevalence of pain among the oldest old in Sweden. Pain. 1996;67(1):29-34.

21. Horgas AL, Dunn K. Pain in nursing home residents. Comparison of residents' self-report and nursing assistants' perceptions. Incongruencies exist in resident and caregiver reports of pain; therefore, pain management education is needed to prevent suffering. Journal of Gerontological Nursing. 2001;27(3):44-53.

22. Gagliese L, Katz J. Age differences in postoperative pain are scale dependent: a comparison of measures of pain intensity and quality in younger and older surgical patients. Pain. 2003;103(1-2):11-20.

23. Parmelee PA, Smith B, Katz IR. Pain complaints and cognitive status among elderly institution residents. Journal of the American Geriatrics Society. 1993;41(5):517-522.

24. Sengstaken EA, King SA. The problems of pain and its detection among geriatric nursing home residents. Journal of the American Geriatrics Society. 1993;41(5):541-544.

25. Ferrell $B \Lambda$, Ferrell BR, Rivera L. Pain in cognitively impaired nursing home patients. Journal of Pain \& Symptom Management. 1995;10(8):591-598.

26. Wagner AM, Goodwin M, Campbell B, et al. Pain prevalence and pain treatments for residents in Oregon nursing homes. Geriatric Nursing. 1997;18(6):268-272.

27. Weincr D, Peterson B, Ladd K, McConnell E, Keefe F. Pain in nursing home residents: an exploration of prevalence, staff perspectives, and practical aspects 
of measurement. Clinical Journal of Pain. 1999;15(2):92-101.

28. McClean WJ, Higginbotham NH. Prevalence of pain among nursing home residents in rural New South Wales. Med J Aust. Jul 1 2002;177(1):17-20.

29. Herr K, Titler MG, Schilling MII, et al. Evidence-based assessment of acute pain in older adults: current nursing practices and perceived barriers. Clinical Journal of Pain. 2004;20(5):331-340.

30. Schmader KE, Hanlon JT, Fillenbaum GG, Huber M, Pieper C, Horner R. Medication use patterns among demented, cognitively impaired and cognitively intact community-dwelling elderly people. Age \& Ageing. 1998;27(4):493-501.

31. Horgas AL, Tsai PF. Analgesic drug prescription and use in cognitively impaired nursing home residents. Nursing Research. 1998;47(4):235-242.

32. Pickering G, Jourdan D, Dubray C. Acute versus chronic pain treatment in Alzhcimer's disease. European Journal of Pain: Ejp. 2006;10(4):379-384.

33. Won A, Lapane K, Gambassi G, Bernabei R, Mor V, Lipsitz I.A. Correlates and management of nonmalignant pain in the nursing home. SAGE Study Group. Systematic Assessment of Geriatric drug use via Epidemiology. Journal of the American Geriatrics Society. 1999;47(8):936-942.

34. Jones KR, Fink R, Pepper G, et al. Improving nursing home staff knowledge and attitudes about pain. Gerontologist. 2004;44(4):469-478.

35. Sloman R, Ahern M, Wright A, Brown L. Nurses' knowledge of pain in the elderly. Journal of Pain \& Symptom Management. 2001;21(4):317-322.

36. McGrath PJ, Unruh AM. Pain in children and adolescents. Vol 1. Amsterdam: Elsevier; 1987.

37. De Wit R. Pijnmeting en pijnbeoordeling. In: Passchier J, Trijsburg RW, de Wit R, Eerdsmans-Dubbet SIC, eds. Psychologie van onbegrepen pijn. Assen: Van Gorcum; 1998:28-45.

38. Jensen MP, Karoly P. Self-report scales an procedures for assessing pain in adults. In: Turk DC, Melzack R, eds. Handbook of Pain Assessment. 2 ed. New YorkLondon: The Guildford Press; 2001:15-35.

39. Gagliese L. Assessment of pain in elderly people. In: Turk DC, Melzack R, eds. Handbook of Pain Assessment. 2 ed. New York-London: The Guildford Press; 2001:119-134.

40. Hadjistavropoulos $\mathrm{T}$, von Baeyer $\mathrm{C}$, Craig $\mathrm{KD}$. Pain assessment in persons with limited abilities to comminicate. In: Turk DC, Melzack R, eds. Handbook of Pain Assessment. 2 ed. New York- London: The Guidfors Press; 2001:134-153.

41. Hadjistavropoulos $\mathrm{T}$, Craig $\mathrm{KD}$. A theoretical framework for understanding selfreport and observational measures of pain: a communications model. Behaviour Research \& Therapy. 2002;40(5):551-570.

42. Herr KA, Garand L. Assessment and measurement of pain in older adults. Clinics in Geriatric Medicine. 2001;17(3):457-478.

43. Herr KA, Mobily PR. Comparison of selected pain assessment tools for use with the elderly. Applied Nursing Research. 1993;6(1):39-46.

44. Manz BD, Mosier R, Nusser-Gerlach MA, Bergstrom N, Agrawal S. Pain assessment in the cognitively impaired and unimpaired elderly. Pain Management Nursing. 2000;1(4):106-115. 
45. Chibnall JT, Tait RC. Pain assessment in cognitively impaired and unimpaired older adults: a comparison of four scales. Pain. 2001;92(1-2):173-186.

46. Closs SJ, Barr B, Briggs M, Cash K, Seers K. A comparison of five pain assessment scales for nursing home residents with varying degrees of cognitive impairment. Journal of Pain \& Symptom Management. 2004;27(3):196-205.

47. Kaasalainen S, Crook J. An exploration of seniors' ability to report pain. Clinical Nursing Research. 2004;13(3):199-215.

48. Pautex S, Herrmann F, Le Lous P, Fabjan M, Michel JP, Gold G. Feasibility and reliability of four pain self-assessment scales and correlation with an observational rating scale in hospitalized elderly demented patients. Journals of Gerontology Series A-Biological Sciences \& Medical Sciences. 2005;60(4):524-529.

49. Krulewitch H, London MR, Skakel VJ, Lundstedt GJ, Thomason H, BrummelSnith K. Assessment of pain in cognitively impaired older adults: a comparison of pain assessment tools and their use by nonprofessional caregivers. Journal of the American Geriatrics Society. 2000;48(12):1607-1611.

50. Herr KA, Spratt K, Mobily PR, Richardson G. Pain intensity assessment in older adults: use of experimental pain to compare psychometric properties and usability of selected pain scales with younger adults. Clinical Journal of Pain. 2004:20(4):207-219.

51. Hadjistavropoulos T, LaChapelle DL, MacLeod FK, Snider B, Craig KD. Measuring movement-exacerbated pain in cognitively impaired frail elders. Clinical Journal of Pain. 2000;16(1):54-63.

52. Scherder EJ, Bouma A. Visual analogue scales for pain assessment in Alzheimer's disease. Gerontology. 2000;46(1):47-53.

53. Scherder EJ, Slaets J, Deijen JB, et al. Pain assessment in patients with possible vascular dementia. Psychiatry. 2003;66(2):133-145.

54. Frampton M. Experience assessment and management of pain in people with dementia. Age Ageing. May 2003;32(3):248-251.

55. Herr K, Decker S. Assessment of pain in older adults with severe cognitive impairment. Annals of Long-Term Care: Clinical Care and Aging. 2004;12(4):46-52. 


\section{Chapter 2}

Nursing staff knowledge and beliefs about pain in elderly nursing home residents with dementia

This chapter was published as:

Zwakhalen SMG, Hamers JPH, Peijnenburg RHA, Berger MFP. Nursing staff knowledge and beliefs about pain in elderly nursing home residents with dementia. Pain Research and Management. 2007; 12 (3):177-184. 
ging is known to be associated with a high prevalence (up to $80 \%$ ) of
persistent pain among residents of nursing homes. With high pain
prevalence rates, nursing home residents are at risk for undertreatment.
Knowledge deficits and beliefs among nurses influence staff behaviour in pain
assessment and management. We aimed to develop a psychometrically sound
questionnaire and to gather information about knowledge and beliefs of nursing
staff regarding various aspects of pain in elderly patients with dementia. In
addition, the differences among several categories of nurses (based on
cducational level and work experience) with respect to beliefs about pain were
investigated.
Participants were 123 staff members of psycho-geriatric wards in two
nursing homes in the Netherlands (with a mean of 11.4 years of experience).
Their results were compared with those of two groups of nurses, one consisting
of 25 RN, PhD students in nursing science and one of 20 trainee pain nurse
specialists. The main findings indicate that nursing home staff respondents
showed knowledge deficits about several aspects of pain, even though they were
satisfied about the way pain was assessed and treated at their wards. Specific
know-ledge deficits were found regarding pain treatment and medication in
elderly nursing home residents. Staff educational level seemed to influence their
beliefs and knowledge about pain in elderly nursing home patients. 


\section{INTRODUCTION}

Dain is highly prevalent among nursing home residents ${ }^{1 \cdot 5}$, with rates 1 sometimes estimated to be as high as $80 \%{ }^{\circ}$. The consequences of persistent pain are numerous and include depression, sleep disturbances, anxiety, and disruptive or aggressive behaviour. $.^{6 .}-$ Moreover, untreated pain decreases quality of life.

Nurses play an important role in decision-making processes and effective pain management among patients." In daily practice, it is often a nurse who decides when analgesics that have been prescribed for administration 'as needed' are distributed, and in what dosage. Previous research has identified certain knowledge deficits and incorrect beliefs among nurses with regard to pain assessment and management, and lack of knowledge about pain and its treatment has been mentioned as an important barrier to effective pain management." There is some literature about knowledge and beliefs among nursing staff about pain in elderly people ${ }^{11,12}$, and specifically in elderly residents of long-term care facilities. ${ }^{31,13,14}$ As part of an intervention study to improve pain practices in nursing homes, Jones et al." developed attitude scales by modifying two pre-existing questionnaires in order to align them with the geriatric pain management guidelines and the nursing home environment. The final scales included general pain biases and attitudes; general beliefs about aging; beliefs and attitudes about the role of religion, culture and gender; pain medication attitudes; and communicational issues. Jones et al. " identified notable knowledge deficits in the areas of pharmacology, drug addiction and dependence, side effect management, and the effectiveness of non pharmacologic management-strategy. Other knowledge deficits and misconceptions are related to pain assessment and can lead nurses to undervalue reports of pain by residents. Similarly, Sloman and colleagues" confirmed that there was a significant deficit in knowledge regarding the experience of pain and its management in older adults in a sample of registered nurses (RNs) surveyed using a 14 item questionnaire.

It is even more difficult to obtain a clear picture for the more specific group of older nursing home residents with dementia, because relevant literature information is very scarce. ${ }^{15}$ Kovach et al. ${ }^{15}$ used a qualitative approach to describe nurses' perceptions regarding the assessment and treatment of pain in patients with late-stage dementia. These nurses expressed some concerns both about misuse and under use of medications.

Previous research in other nursing areas (palliative and paediatric care) has revealed that nurses have certain knowledge deficits and misconceptions about a number of issues. ${ }^{16.24}$ These issues also relate to analgesics, side effects of medication, pain assessment, as well as aspects of the aging process. For example, pharmacological management of pain remains an area in which nurses lack the necessary knowledge to provide optimal treatment. ${ }^{10,19}$ Nurses also seem 
to have certain knowledge deficits and negative beliefs about the use of opioids during a diagnostic phase and about the risk of possible addiction..$^{25}$ While addiction caused by using opioids for pain relief is rare ${ }^{2 h}$, nurses seem to overestimate its risk. Closs ${ }^{12}$ also reported on misconceptions about the pharmacological treatment of pain in elderly patients, and Lander ${ }^{27}$ found that nurses were very concerned about the possibility of addiction to medications. Meanwhile, nurses play a major role in effective pain management and are confronted on a daily basis with tasks that relate to various aspect of pain.

Researchers have focused on the influence of nurses' characteristics, such as work experience and educational level, on their knowledge about and attitude towards pain. These factors have been reported to relate to what nurses know and believe about pain. ${ }^{13,28}$ It has also been reported that nurses learn about pain assessment and treatment through work experience. ${ }^{2 y}$ Hamers et al..$^{24}$ examined the influence of expertise on nurses' pain assessment and decisions regarding pharmacological interventions in children. Expertise relates to both the knowledge and experience one acquires over time." Hamers et al. found that expertise had a distinct impact on both the nurses' confidence in their decisions and the decision to administer analgesics. They suggested that experienced nurses were most confident and were most inclined to administer analgesics to children. Furthermore, Gibbs ${ }^{13}$ showed that lack of education among nurses was reflected in the way they responded to questions about pain management.

Since specific research into nurses' knowledge and beliefs about pain in elderly people with dementia is lacking, it remains unclear what nurses know about pain among such nursing home residents. Furthermore, the relationship of experience and level of education with pain management knowledge in this context remains to be investigated. Therefore, the present study was designed to develop a psychometrically sound questionnaire and explore the knowledge and beliefs about various aspects of pain among nursing staff working with elderly nursing home residents with dementia. In particular, we aimed to develop and conduct initial testing of a questionnaire to assess knowledge and beliefs about pain in elderly nursing home residents, gather information about knowledge and beliefs among nursing home staff regarding various aspects of pain in elderly residents with dementia, and investigate the differences among several categories of nursing staff (based on educational level and work experience) with respect to beliefs about pain in elderly nursing home patients with dementia.

\section{METHODS}

\section{Design}

A cross-sectional study design was used to develop a questionnaire and to evaluate nursing staff knowledge and beliefs about pain in elderly nursing home patients with dementia. The study was based on the assumption that nurses' 
knowledge and beliefs about pain in elderly nursing home residents with dementia affect nurse behaviour. ${ }^{14}$ It was hypothesized that previous work experience and educational level would be predictive of a higher level of knowledge about pain and its management.

\section{Context}

Nursing homes offer complex care to very frail elderly people who have physical and/or psycho-geriatric disorders that affect self-care, mobility, continence and cognitive functioning. ${ }^{31} \mathrm{Of}$ the 220,000 elderly people with dementia, more than 30,000 reside in approximately 330 nursing homes in the Netherlands. ${ }^{31}$ Nurses are the largest group of health care professionals providing continuity of care to older adults in both acute and community settings. ${ }^{11}$ In Dutch nursing homes, care is provided by RNs together with a large number of nursing assistants (NAs).

\section{Participants}

Data were collected in two nursing homes in the Netherlands. All nursing staff (RNs and NAs) from the psycho-geriatric wards of the two nursing homes $(\mathrm{n}=167)$ were invited to participate in this survey. The questionnaire was returned by $74 \%$ of the nursing home staff $(n=123)$. All 123 participants (109 women and 14 men) were specialized in the care of elderly nursing home patients (mean number of years of experience $=11.4 ; \mathrm{SD}=8.9$ years). Their average age was 36.7 years $(S D=10.5)$. Table 1 summarizes the demographics of the three groups of respondents.

To investigate the differences in responses based on nurses' educational level, the group was compared with two additional groups, consisting of a convenience sample of $25 \mathrm{PhD}$ students in nursing science and a group of 20 registered nurses in training to become pain nurse specialists.

\section{Data collection}

Since, to our best knowledge, no questionnaire was available to assess nursing staff knowledge and beliefs about pain in elderly nursing home residents with dementia, we developed such a questionnaire. The first part of the questionnaire focused on demographic information, including gender, age, educational level and number of years of work experience. The second part included 34 statements about pain whose content was derived from the literature and from existing questionnaires designed to measure knowledge and attitudes about pain in other settings. ${ }^{11}$ 12, 14, 15, 17.23 Face validity was established by asking two pain experts and four nurses working in nursing homes to review the questionnaire. Respondents were asked to respond to the statements on a five-point Likert scale ( $1=$ completely disagree, $2=$ disagree to some extent, $3=$ no opinion, $4=$ agree to some extent, $5=$ completely agree). 
Table 1 Characteristics of the respondents

\begin{tabular}{|c|c|c|c|}
\hline Variable & $\begin{array}{l}\text { Group } 1 \\
n=123\end{array}$ & $\begin{array}{c}\text { Group } 2 \\
n=25\end{array}$ & $\begin{array}{c}\text { Group } 3 \\
n=20\end{array}$ \\
\hline Age, mean (SD; range) & $36.7(10.5 ; 16-61)$ & $38.6(9.5 ; 25-63)$ & $36.2(8 ; 24.51)$ \\
\hline Fcmale $\%(n=)$ & $88.6(109)$ & $84(21)$ & $60(12)$ \\
\hline Male $\%(n=)$ & $11.4(14)$ & $16(4)$ & $40(8)$ \\
\hline \multicolumn{4}{|l|}{ Job title $\%(n=)$} \\
\hline nursing assistant & $15.4(19)$ & & \\
\hline Caregiver & $80.5(99)$ & & \\
\hline RN & $4.1(5)$ & & \\
\hline
\end{tabular}

$\mathrm{RN}$

$100(20)$

$\mathrm{RN}$, trainee pain nurse specialist

$\mathrm{RN}, \mathrm{PhD}$ student

$100(25)$

Years of experience, mean (SD; range) $11.4(8.9 ; 0-34) \quad 14.4(10 ; 4-43) \quad 14.8(8 ; 3-26)$

$<5$ years of experience $\%(\mathrm{n}=) * \quad 38.2(47) \quad 20(5) \quad 10(2)$

$>=5$ years of experience $\%(n=)^{*} \quad 58.5(72) \quad 80(20) \quad 55(11)$

Years of experience in gerontology,

mean (SD; range)

$8.5(7,6 ; 0-30) \quad 0.5(1.3 ; 0-5) \quad 1(1.7 ; 0-5)$

Hours of employment per week

mean (SD; range)

$29.1(6.7 ; 10-36) \quad 41.9(6.8 ; 35-60) \quad 35.7(4.7 ; 24-40)$

* Data missing from some respondents. Group 1: Nursing home staff; group 2: Nurses working on their $\mathrm{PhD}$; group 3: Trainee pain nurse specialists. RN means Registered nurse

\section{Procedures}

In each nursing home, a contact person was designated who was responsible for distributing and collecting the questionnaires. A cover information letter detailing the procedure was attached to the questionnaire, and participants were asked to respond within two weeks. After these two weeks, participants were reminded about returning the questionnaire and were given another two weeks to return it. Permission to conduct the study was obtained from the directors of the nursing homes. Nursing staff participated in this study on a voluntary basis and the information that was obtained was anonymous. 
Data analysis

Descriptive statistics were generated about the characteristics of the nursing staff. We performed a Principal Components Analysis (PCA) in order to refine the scale (as a part of the scale development) and to investigate its underlying factor structure. Furthermore internal consistency analyses were carried out for the remaining subscales and the total scale in order to investigate the homogeneity of the scale. The responses to statements on participants' knowledge and beliefs about pain in the elderly nursing home patients were examined by calculating percentages of extent of agreement with each statement. Since the data were not normally distributed, non-parametric MannWhitney $U$ tests were used to investigate whether there was a significant difference in the responses of the nurses among the three study groups. Because of the risk of type-I errors, a Bonferonni corrected alpha $(0.05 / 17$ items $=0.003$ ) was used to correct for multiple testing.

\section{RESULTS}

\section{Development of the questionnaire}

A PCA was used to create the final questionnaire scale and to investigate its underlying factor structure. The number of factors was determined by means of eigenvalues and scree tests. Items were retained if the Measure of Sampling Adequacy (MSA) was $>.5$ and the communality of an item was $>.4$. Because subscales correlated, Oblimin rotation was used. Item-total correlations were calculated for all items that were retained after the PCA. Items with an item-total correlation below 0.2 were removed. Internal consistency was analysed for the remaining subscales and the complete scale. Based on these criteria, 17 of the 34 items remained in the final scale. Table 2 presents the Cronbach's alpha values resulting from the internal consistency analyses and psychometric statistics with factor loadings of the 17-item final questionnaire. The four-component solution explained $54.4 \%$ of the variance. The first factor explained $23.9 \%$, the second factor $12.4 \%$, the third factor $10.1 \%$ and the fourth factor $7.9 \%$ of the variance. The findings of the PCA showed that the first factor related to knowledge about the pain experience of older compared to younger people, the second to pain management at the ward, the third to pain medication and the last to pain and pain treatment in older adults. Although knowledge and belief are two closely related constructs, the 17 items remaining in the final scale, with the exception of the second factor, mostly measured knowledge. These items are presented in Table 2. 


\section{Nursing bome staff knowledge and beliefs}

Knowledge and beliefs about pain in elderly nursing home residents with dementia among the 123 nursing home staff were investigated by calculating percentages of extent of agreement or disagreement (based on a five-point Likert scale). Table 3 presents the participants' responses $(n=123)$. Nursing home staff responses showed a wide variance. All items had 5 possible responses (minimum $1=$ completely disagree; maximum $5=$ completely agree), except for "where I work, pain is correctly assessed " (2-5), "where I work, pain is treated correctly" (2-5), "pain medication works longer in the elderly than in young people" (1-4) and "administering pain medication should be postponed as long as possible, because a patient with dementia should receive as little pain medication as possible" (1-4).

Most questions of the first factor contrasted aspects of pain in elderly people with corresponding aspects in younger people. Responses varied, but the majority of respondents correctly reported that elderly patients do not experience less pain and that they do not experience pain less intensely than younger patients. When respondents were asked if they thought assessing pain was a matter of guessing, their responses showed a very decisive disagreement with this statement.

A large majority of nursing home staff were convinced that pain was being correctly assessed (83\%) and treated (83\%) at their ward, and that there was a great deal of attention paid to pain in dementia patients $(80 \%)$.

The largest percentage of "no opinion" (response option 3 on the five-point Likert scale) responses were found on questions about medication aspects (factor 3), including side effects and risk of addiction. Furthermore, there was a lack of unanimity among respondents about the question whether medication should be administered when necessary, rather than according to a fixed schectule.

Questions that were part of the last factor, (beliefs regarding pain and pain treatment in the elderly), led to the greatest diversity of responses. There was a lack of consensus about the items "pain is a part of the aging process", "older people are affected by pain more often than younger people" and "pain medication easily leads to addiction among the elderly". Only approximately onc-third of the respondents were awate of the fact that older people are affected more often by pain than younger people (i.e., that incidence rates of chronic pain are known to be higher for elderly than for younger people). 
Table 2. Factor structure and internal consistency of the questionnaire

Questionnaire items*

\section{Component}

One Two Three Four

1 Older people experience pain less intensely than younger people

2 Pain medication works better in young people than in the elderly

3 Pain medication works longer in the elderly than in young people

4 Pain medication has more side effects in the elderly than in younger people

5 Dementia patients experience less pain than nondementia patients

6 Assessing pain in a dementia patient is a matter of guessing

7 Where I work, pain is assessed correctly

0.86

0.84

9 Where I work, much attention is given to pain in dementia patients

0.81

10 Pain medication should only be administered to patients suffering from severe pain

necessary', rather than according to a fixed schedule

13 Adminstering pain medication should be postponed as long as possible, because dementia patients should receive as little pain medication as possible

\section{Data analysis}

\begin{tabular}{lllll}
\hline Chronbach's alpha (total scale, 17 items .782) & 0.74 & 0.80 & 0.68 & 0.58 \\
Eigenvalue & 4.06 & 2.11 & 1.72 & 1.35 \\
Kaiser-Meyer-Olkin Measure of Sampling Adequacy & 0.73 & & & \\
Bartlett's Test of Sphericity Significance & 0.00 & & &
\end{tabular}

*Factor loadings $>.30$ are presented Extraction Method: Principal Component Analysis. Rotation Method: Oblimin 


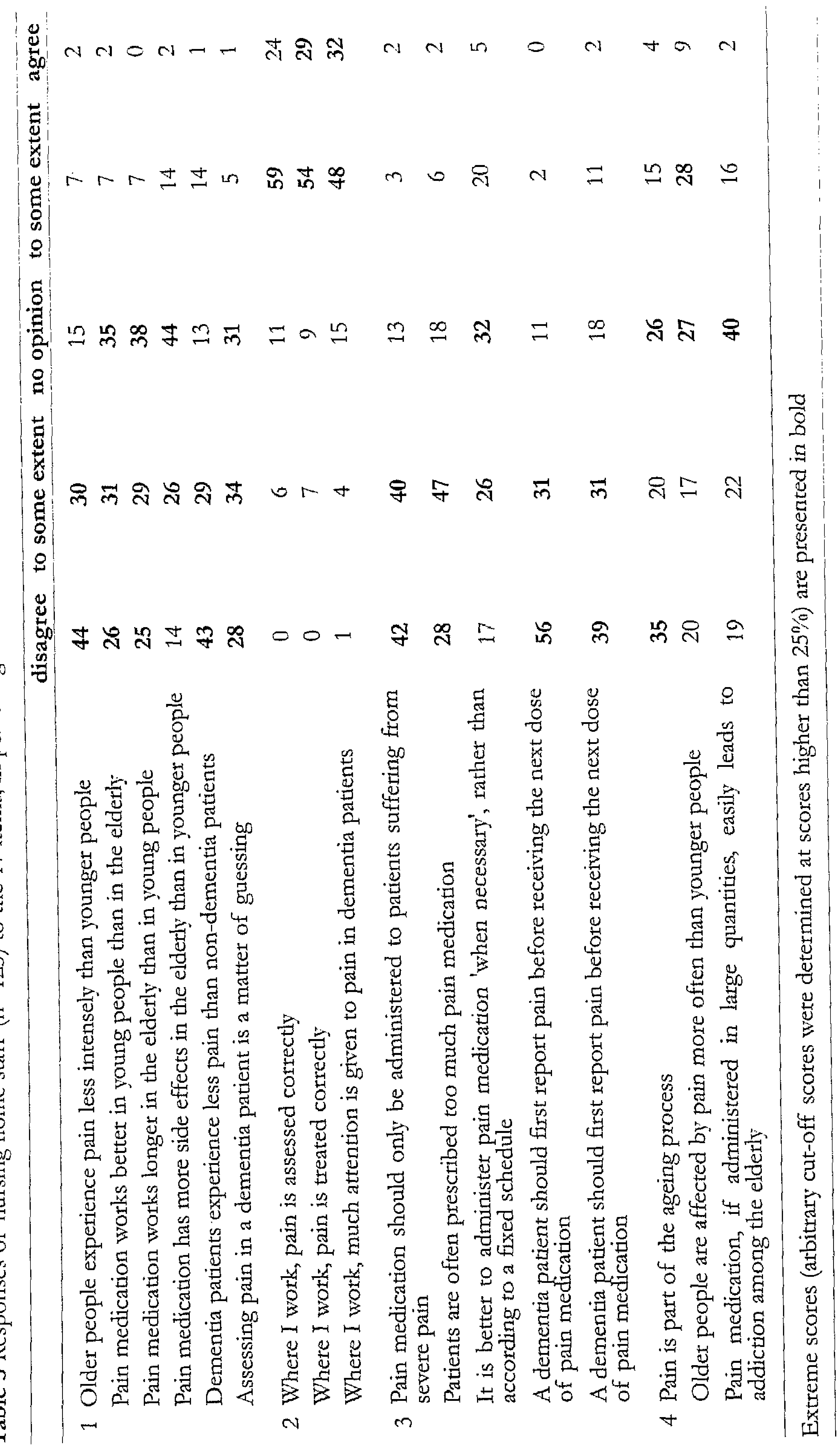


Differences among groups

The second research question referred to the differences between nurses with a higher educational background (a group of $25 \mathrm{PhD}$ students in nursing science and a group of 20 trainee pain nurse specialists) and regular nursing home staff $(\mathrm{n}=123)$.

Although the group of trainee pain nurse specialists was not very large $(n=20)$, their responses about pain in elderly people with dementia seemed to differ from those of the nursing home staff. Using an alpha of $0.003,8$ of the 17 items showed a significant difference. These items are presented in Table 4.

The trainee pain nurse specialists had more realistic beliefs and knowledge about pain in this patient group, beliefs that were in agreement with the literature and the current state of the art. Significant differences between the groups were most often related to issues of pain medication. All trainee pain nurse specialists disagreed with the statement "Pain medication should only be administered to patients suffering from severe pain" (median 1; minimum 1, maximum 1). The responses of the group of trainee pain nurse specialists also showed greater consensus, whereas the answers of regular nursing home staff varied more widely (ranging from 1 to 5). While none of the trainee pain nurse specialists agreed that it is better to administer pain medication only 'when necessary', rather than according to a fixed schedule, a large number of nursing home nurses agreed with this statement, not recognizing the value of fixed regular analgesia. Findings also indicated that the nursing home staff respondents were more anxious about the risk of addiction than the trainee pain nurse specialists. For example, there was a significant difference in the response to the statement that "pain medication if administered in large quantities easily leads to addiction among the elderly": between the trainee pain nurse specialists (median 1; minimum 1, maximum 3) and the nursing home staff (median 3; minimum 1, maximum 5).

A second comparison included the scores of those who attended higher education in nursing ( $\mathrm{PhD}$ students in nursing science) and the group of 123 regular nursing home staff. Findings presented in Table 4 show that the group of nursing home staff respondents had higher scores on all items belonging to the second factor, referring to pain management at the ward. The comparison between these two groups also revealed significant differences in beliefs about pain medication, mostly relating to the same issues as in the comparison between nursing home staff and trainee pain nurse specialists. Table 4 presents a complete overview of the significant differences among all respondent groups.

A final comparison was made between highly experienced nursing staff and less experienced nursing staff working in nursing homes. From the total group of 123 nursing home respondents, we created two subgroups, one with less than 5 years of experience in working $(n=47)$ and one with five or more years of experience $(n=72)$. Using an alpha of 0.003 , no significant or nearly significant differences in responses between these two subgroups were found. 
Table 4 Significant differences in knowledge and attitude about pain among groups

Median Scores
$\begin{gathered}\text { group } 1 \text { group } 2 \text { group } 3 \\ n=123 \quad n=25 \\ n=20\end{gathered}$

\section{Group 1 compared with group 3}

Where I work, much attention is given to pain in dementia patients

Pain medication works longer in the elderly than in young people

Pain medication has more side effects in the elderly than in younger people

$3.0 \quad .000$

$2.0 \quad 4.0 \quad .001$

It is better to administer pain medication 'when necessary', rather than according to a fixed schedule

Adminstering pain medication should be postponed as long as possible, because dementia patients should receive as little pain medication as possible

$3.0 \quad 4.0 \quad .000$

$\begin{array}{lll}2.0 & 1.0 \quad .000\end{array}$

$\begin{array}{lll}3.0 & 1.0 \quad .000\end{array}$

$\begin{array}{lll}1.0 & 1.0 \quad .001\end{array}$

A dementia patient should first report pain

before receiving the next dose of pain medication

Pain is a part of the ageing process

$\begin{array}{lll}2.0 & 1.0 \quad .003\end{array}$

Pain medication, if administered in large quantities, easily leads to addiction among the eldetly

$\begin{array}{lll}2.0 & 1.0 \quad .001\end{array}$

\section{Group 1 compared with group 2}

Where I work, pain is assessed correctly

\begin{tabular}{lll}
4.0 & 3.0 & .000 \\
4.0 & 3.0 & .000 \\
4.0 & 3.0 & .000 \\
2.0 & 1.0 & .000 \\
2.0 & 2.0 & .003 \\
3.0 & 1.5 & .000 \\
2.0 & 1.0 & .002 \\
3.0 & 2.0 & .000 \\
\hline
\end{tabular}

Where I work, pain is treated correctly
Where I work, much attention is given to pain in dementia patients

Older people experience pain less intensely than younger people

Pain medication works longer in the elderly than in young people

3.0

It is better to administer pain medication 'when necessary', tather than according to a fixed schedule A dementia patient should first report pain before receiving the next dose of pain medication Pain medication, if administered in large quantities, easily leads to addiction among the elderly

\section{Group 2 compared to group 3}

Pain medication works longet in the eldetly than in young people

$\begin{array}{lll}4.0 & 2.0 \quad .000\end{array}$

Pain medication has more side effects in the elderly than in younger people

$\begin{array}{lll}4.0 & 2.0 \quad .000\end{array}$

Group1: Nurses working in a nursing home; group 2: Highly educated nurses working on their PhD: group 3: 'Trainee pain nurse specialists. Higher scores represent a greater degree of agreement with statcment (response tange was 1-5). A non-parametric test (MannWhitney U test) was used to test for significant differences between groups Bonferonni corrected alpha $0,05 / 17=0,003$ 


\section{DISCUSSION}

The main findings of this study indicate that even though nursing home staff have deficits in knowledge related to pain, they are satisfied about the way pain is being assessed and treated at their ward. The respondents' educational level influences their beliefs and knowledge about pain in elderly nursing home patients. In particular, we found some evidence of knowledge deficits regarding pain treatment and medication in elderly nursing home residents. The lack of knowledge regarding issues of pain treatment was reflected in the large variety in responses and the high number of "no opinion" scores on these issues. There seemed to be a lack of consensus especially about statements relating to medication, such as "prescription when necessary, rather than according to a fixed schedule" or "pain medication, if administered in large quantities, easily leads to addiction". This might be the result of a lack of education among the participants but could also stem from the fact that pain treatment in elderly nursing home patients is an under-researched area. People with dementia have often been excluded from pain studies. ${ }^{32}$ As a result, little is known about the effects of analgesics on functional status and well-being of nursing home residents with chronic pain.3. The limited but important knowledge that is available may not reach the nurses and nursing assistants in the field. Our findings confirm that information is not sufficiently being disseminated to practicing staff.

When our nursing home staff respondents were asked about pain assessment and treatment at the place where they worked, they seemed very satisfied with the attention given to these and considered pain to be correctly assessed (over 80\%) and treated (over 80\%). The highest level of agreement among the respondents was found for the items of factor 2, "pain management at the ward". These findings are not only striking because they are highly inconsistent with the literature on pain assessment and treatment in elderly people with dementia, but also very worrisome because this assumption could lead to inadequate attention and undertreatment. Pain assessment among nursing home patients with dementia has been described as extremely difficult, and evidence of underassessment and undertreatment is available..$^{3 ., 35}$ Furthermore, nursing home staff do not use pain assessment tools to improve pain detection, and pain assessment depends on nurses' subjective impressions. Thus, it seems that pain assessment in people with severe dementia, with limited ability to communicate is sometimes a matter of guessing, even though only $5 \%$ of the participants agreed with this statement. Obviously, nursing home staff do not recognise the fact that pain assessment and management are often considered inadequate, so the risk of undertreatment remains. This is a major concern, which might also affect and undermine attempts to improve pain management and assessment. After all, if nursing home staff really underestimate the difficulties of identifying pain or overestimate their own 
abilities to do so, they might be less willing to invest in pain control and education programmes.

The nursing home staff in our sample had reasonable knowledge about pain issues relating to the first factor of our questionnaire, (knowledge about the experience of older compared to younger people). Nlthough there is some evidence that pain tolerance are different in people with Alzheimer's disease, ${ }^{36,37}$ this evidence is still limited and has been found for very specific groups of geriatric patients. Moreover, there is no evidence that the small differences in pain tolerance (identified in experimental investigations) have significant clinical implications. Therefore, until proof to the contrary is found, the safest approach is to assume that, on average, older people do not experience pain less intensely than younger people.

Our final 17-item questionnaire included many items derived from or similar to those of a pain knowledge questionnaire presented by Sloman et al. ${ }^{11}$ Our findings of knowledge deficits with respect to pain management are consistent with the results of the study by Sloman et al. ${ }^{11}$ However, we demonstrated a relationship between the nurses' level of experience and their knowledge of pain among elderly persons. We also found differences in responses between regular nursing home staff and a group of trainee pain nurse specialists. As part of their training to become pain nurse specialists, these individuals were more exposed to palliative care, and tended to have different beliefs and higher levels of knowledge about pain treatment. Thus, our findings show that educational level seems to influence nursing staff beliefs and knowledge about pain in elderly nursing home patients with dementia. The more highly educated nurses had better knowledge (i.e. in better agreement with current literature) and seemed more aware of several issues related to pain. This result is consistent with findings by Brunier ${ }^{28}$ who showed that Canadian nurses with a university education also scored significantly better than non-university nurses in a hospital setting. These findings support the view that there is a need not only for continuing education for nurses working in nursing homes, but also for more highly educated nurses to work in nursing home care.

In the present study, $\mathrm{PhD}$ students in nursing sciences, with no expertise in geriatrics compared to nursing home nurses, provided responses that were more consistent with the literature. An explanation for the differences between these groups might indicate that more highly educated nurses are more aware of pain as an aspect of the nursing process. Nurses attending higher education courses, and especially trainee pain nurse specialists, have increased pain education. Lack of education could contribute to low priority being given to pain management and misconceptions about pain.

Our study had certain limitations that need to be acknowledged. The relatively small number of respondents in the two groups used for comparison with the nursing home nurses $(n=20$ and $n=25$ ) places some limits on 
generalizability. Although our results should be interpreted with caution, they do suggest that there are differences between regular nursing home staff and more highly educated nurses in their responses to our statements. These differences were most obvious on aspects related to pain medication and treatment. The findings were convincing and consistent between the two independent samples of highly educated nurses compared to regular nursing home staff. Another issue concerning generalizability relates to the fact that our study took place in the Netherlands. Research is needed to examine the extent to which our findings generalize to other countries. Furthermore, even though the information was obtained anonymously, there is a possibility that nursing home staff responses are biased clue to aspects of social desirability with regard to items related to pain at work.

The pain knowledge and belief questionnaire, that we used, was constructed specifically for this study. Its internal consistency was satisfactory for newly developed scales and had an $\alpha$ greater than $0.7{ }^{36}$ However, when we calculated $\alpha$ for the subscales, factor 4 yielded mediocre scores $(\alpha=.58)$. Knowing that the value of an alpha depends on the number of items and because none of the items that loaded to the fourth factor met our statistical deletion criterion (item total correlation less than .2), we decided to retain all 3 items that loaded on the fourth factor.

Our intention was to construct a questionnaire to evaluate nursing staff knowledge and beliefs about pain in elderly nursing home residents with dementia. Reflecting on the questionnaire that ultimately remained after the item reduction process, it is debatable whether this questionnaire strictly refers to pain among dementia patients. More than half of the items in the questionnaire relate to nursing home patients in general, rather than to the more specific category of dementia patients. Although the final questionnaire covered a broader category of patients than originally intended, it demonstrated good internal consistency and a clear underlying factor structure.

\section{CONCLUSION}

Pain in elderly people with dementia represents a relatively new and fast developing research area, which has made important progress over the last decade. This has resulted in new research information, knowledge and several potentially clinically useful new pain scales" like the PACSLAC developed by Fuchs-Lacelle and Hadjistavropoulos, ${ }^{40}$ the PAINAD by Warden et al. ${ }^{11}$ and the DOLOPLUS by Wary et al..$^{\text {t2 }}$ Although having a valid, reliable and useful tool represents an important step forward, it is not the only factor contributing to adequate pain treatment. In the present study we found that many nursing home staff still show knowledge gaps or negative beliefs about pain in elderly people with dementia, which could contribute to inadequate assessment and treatment. Furthermore our study demonstrated that in a nursing area where care is 
provided by a large number of NAs, educational level is an important factor.

Pain is a highly relevant issue, impacting greatly on a person's abilities and quality of life. The dissemination of knowledge about pain assessment and management represents an extremely important task for leading nurses, researchers and policymakers. This knowledge needs to be made available to the nurses who have major responsibilities during the whole process of care. Nurses should also be made aware of the consequences of inadequately handling of pain problems.

It seems that basic nursing education is not sufficient to prepare nurses to cope with problems of pain and pain management in daily nursing home practice. Additional specialist education seems the most obvious method of accomplishing the required awareness and knowledge. Given the fact that there is evidence of certain misconceptions, the effects of knowledge deficits, misconceptions about pain management and relevant decision-making processes need to be further examined. We recommend a multi-disciplinary intervention that not only focuses on proper pain assessment, using the newly developed evidence-based scales, but also one that focuses on improved education and knowledge and on overcoming misconceptions.

\section{Acknowledgements}

We would like to thank all the staff of the participating nursing homes, $\mathrm{PhD}$ students at the European Academy of Nursing Science and the trainee pain nurse specialists at Leuven University (Belgium) for their co-operation to this study on pain knowledge and beliefs.

\section{REFERENCES}

1. Pautex S, Herrmann F, Le Lous P, Fabjan M, Michel JP, Gold G. Feasibility and reliability of four pain self-assessment scales and correlation with an observational tating scale in hospitalized elderly demented patients. Journals of Gerontology Series A-Biological Sciences \& Medical Sciences. 2005;60(4):524-529.

2. Blomqvist $K$, Hallberg IR. Recognising pain in older adults living in sheltered accommodation: the views of nurses and older adults. International Journal of Nursing Studies. 2001;38(3):305-318.

3. Weiner D, Peterson B, Ladd K, McConnell E, Keefe F. Pain in nursing home residents: an exploration of prevalence, staff perspectives, and practical aspects of measurement. Clinical Journal of Pain. 1999;15(2):92-101.

4. Ferrell $B \Lambda$. Pain evaluation and management in the nursing home. Annals of Internal Medicine. 1995;123(9):681-687.

5. Proctor WR, Hirdes JP. Pain and cognitive status among nursing home residents in Canada. Pain Res Manag. Fall 2001;6(3):119-125.

6. Feldt $\mathrm{KS}$, Warne MA, Ryden MBB. Examining pain in aggressive cognitively impaired older adults. Journal of Gerontological Nursing. 1998;24(11):14-22. 
7. A. G. S. Panel on Persistent Pain in Older Persons. The management of persistent pain in older persons. Journal of the American Geriatrics Society. 2002;50(6 Suppl):S205-224.

8. Hert KA, Mobily PR. Complexities of pain assessment in the elderly: Clinical considerations. Journal of Gerontological Nursing. 1991;17(4):12-19.

9. Katsma DL, Souza $\mathrm{CH}$. Elderly pain assessment and pain management knowledge of long-term care nurses. Pain Management Nursing. 2000;1(3):88-95.

10. Jones KR, Fink R, Pepper $G$, et al. Improving nursing home staff knowledge and attitudes about pain. Gerontologist. Aug 2004;44(4):469-478.

11. Sloman R, Ahern M, Wright A, Brown I. Nurses' knowledge of pain in the elderly. J Pain Symptom Manage. Apr 2001;21(4):317-322.

12. Closs SJ. Pain and elderly patients: a survey of nurses' knowledge and experiences. Journal of Advanced Nursing. 1996;23(2):237-242.

13. Gibbs G. Nurses in private nursing homes: a study of their knowledge and attitudes to pain management in palliative care. Palliative Medicine. 1995;9(3):245-253.

14. Mrozek JE, Werner JS. Nurses' attitudes toward pain, pain assessment, and pain management practices in long-term care facilities. Pain Manag Nurs. Dec $2001 ; 2(4): 154-162$.

15. Kovach CR, Griffie J, Muchka S, Noonan PE, Weissman DE. Nurses' perceptions of pain assessment and treatment in the cognitively impaired elderly. It's not a guessing game. Clin Nurse Spec. Sep 2000;14(5):215-220.

16. Hamers JP, Abu-Saad HH, van den Hout MA, Halfens RJ. Are children given insufficient pain-relieving medication postoperatively? Journal of Advanced Nursing. 1998;27(1):37-44.

17. Visentin M, Trentin $\mathrm{I}$, de Marco R, Zanolin E. Knowledge and attitudes of Italian medical staff towards the approach and treatment of paticnts in pain. Journal of Pain \& Symptom Management. 2001;22(5):925-930.

18. de Rond $M$, de Wit $R$, van Dam F. The implementation of a Pain Monitoring Programme for nurses in daily clinical practice: results of a follow-up study in five hospitals. Journal of Advanced Nursing. Aug 2001;35(4):590-598.

19. Clarke EB, French B, Bilodeau ML, Capasso VC, Edwards A, Empoliti J. Pain management knowledge, attitudes and clinical practice: the impact of nurses' characteristics and education. Journal of Pain \& Symptom Management. 1996;11(1):18-31.

20. McCaffery M, Ferrell BR. Nurses' knowledge of pain assessment and management: how much progress have we made? J Pain Symptom Manage. Sep 1997;14(3):175-188.

21. Hamers JP, Abu-Saad HH, Halfens RJ, Schumacher JN. Factors influencing nurses' pain assessment and interventions in children. Journal of Advanced Nursing. 1994;20(5):853-860.

22. de Rond ME, de Wit R, van Dam FS, van Campen BT, den Hartog YM, Klievink RM. A pain monitoring program for nurses: cffects on nurses' pain knowledge and attitude. Journal of Pain \& Symptom Management. 2000;19(6):457-467.

23. Langeveld N, Molenkamp C, Merks J. Pijn bij kinderen met kanker. Kennis en opvattingen van (kinder)verpleegkundigen. Verpleegkunde. 1996;11(1):3-11.

24. Hamers JP, van den Hout MA, Halfens RJ, Abu-Saad HH, Heijltjes AE. Differences in pain assessment and decisions regarding the administration of analgesics between 
novices, intermediates and experts in pediatric nursing. International Journal of Nursing Studies. 1997;34(5):325-334.

25. Broekmans S, Vanderschueren S, Morlion B, Kumar A, Evers G. Nurses' attitudes toward pain treatment with opioids: a survey in a Belgian university hospital. Int J Nurs Stud. Feb 2004;41(2):183-189.

26. Porter J, Jick H. Addiction rare in patients treated with narcotics. New England Journal of Medicine. 1980;302(2):123.

27. Lander J. Fallacies and phobias about addiction and pain. $\mathrm{Br} \mathrm{J}$ Addict. Jun 1990;85(6):803-809.

28. Brunier $G$, Carson MG, Harrison DE. What do nurses know and believe about patients with pain? Results of a hospital survey. J Pain Symptom Manage. Aug 1995;10(6):436-445.

29. Twycross A. Education about pain: a neglected area? Nurse Educ Today. Apr 2000;20(3):244-253.

30. Boshuizen HPA. The development of medical expertise. A cognitive psychological approach. Unpublished dissertation. University of Maastricht, The Netherlands.

31. Schols JM, van der Schriek-van Meel C. Day care for demented elderly in a dairy farm setting: positive first impressions. J Am Med Dir Assoc. Sep 2006;7(7):456-459.

32. Kovach CR, Weissman DE, Griffie J, Matson S, Muchka S. Assessment and treatment of discomfort for people with late-stage dementia. J Pain Symptom Manage. Dec 1999;18(6):412-419.

33. Won A, Lapane KL, Vallow S, Schein J, Morris JN, Lipsitz LA. I.ong-term effects of analgesics in a population of elderly nursing home residents with persistent nonmalignant pain. Journals of Gerontology Series A-Biological Sciences \& Medical Sciences. 2006;61(2):165-169.

34. Horgas AL, Tsai PF. Analgesic drug prescription and use in cognitively impaired nursing home residents. Nursing Research. 1998;47(4):235-242.

35. Loeb JL. Pain management in long-term care. American Journal of Nursing. 1999;99(2):48-52.

36. Scherder E, Oosterman J, Swaab D, et al. Recent developments in pain in dementia. BMJ. 2005;330(7489):461-464.

37. Benedetti F, Vighetti S, Ricco C, et al. Pain threshold and tolerance in Alzheimer's disease. Pain. 1999;80(1-2):377-382.

38. Kline P. The handbook of psychological testing. 2 ed. London: Routledge; 1999.

39. Zwakhalen SM, Hamers JP, Abu-Saad HH, Berger MP. Pain in elderly people with severe dementia: a systematic review of behavioural pain assessment tools. BMC Geriatrics. 2006;6:3.

40. Fuchs-Lacelle S, Hadjistavropoulos T. Development and preliminary validation of the pain assessment checklist for seniors with limited ability to communicate (PACSLAC) Pain Management Nursing. 2004;5(1):37-49.

41. Warden V, Hurley AC, Volicer L. Development and psychometric evaluation of the Pain Assessment in Advanced Dementia (PAINAD) scale. Journal of the American Medical Directors Association. 2003;4(1):9-15.

42. Wary B, Doloplus C. [Doloplus-2, a scale for pain measurement]. Soins Gerontol. Aug-Oct 1999(19):25-27. 


\section{Chapter 3}

Pain in elderly people with severe dementia: A systematic review of behavioural pain assessment tools people with severe dementia: a systematic review of behavioural pain assessment tools. BMC Geriatrics. 2006;6:3. 


\section{ABSTRACT}

$\mathrm{D}$ ain is a common and major problem among nursing home residents. The 1 prevalence of pain in elderly nursing home people is $40-80 \%$, showing that they are at great risk of experiencing pain. Since assessment of pain is an important step towards the treatment of pain, there is a need for manageable, valid and reliable tools to assess pain in elderly people with dementia. This systematic review jdentifies pain assessment scales for elderly people with severe dementia and evaluates the psychometric properties and clinical utility of these instruments. Relevant publications in English, German, French or Dutch, from 1988 to 2005, were identified by means of an extensive search strategy in Medline, Psychinfo and CINAHL, supplemented by screening citations and references, Quality judgement criteria were formulated and used to evaluate the psychometric aspects of the scales. Twenty-nine publications reporting on behavioural pain assessment instruments were selected for this review. Twelve observational pain assessment scales (DOLOPLUS2; ECPA; ECS; Observational Pain Behavior Tool; CNPI; PACSLAC; PAINAD; PADE; RaPID; Abbey Pain Scale; NOPPAIN; Pain assessment scale for use with cognitively impaired adults) were identified. Findings indicate that most observational scales are under development and show moderate psychometric qualities. Based on the psychometric qualities and criteria regarding sensitivity and clinical utility, we conclude that PACSLAC and DOLOPLUS2 are the most appropriate scales currently available. Further research should focus on improving these scales by further testing their validity, reliability and clinical utility. 


\section{BACKGROUND}

In the last decade, there has been a growing interest in pain among elderly 1 people. Pain among nursing home residents is a common and major problem. Statistics indicate that pain is twice as likely to occur in individuals aged 60 and older as in younger persons. ${ }^{1.3}$ The prevalence of pain in elderly nursing home residents is $40-80 \% \%^{+1.1}$, showing that they are at great risk of experiencing pain.

As in most countries, the population of individuals over the age of 65 in the Netherlands is growing fast. Demographic trends make it likely that in 2040, $22.9 \%$ of the population will belong to this category."

More than $50 \%$ of US nursing home residents have substantial cognitive impairment or dementia." This situation is comparable to that in European countries like Austria and the UK, where dementia has been found to occur in over $60 \%$ of the institutionalised population ${ }^{11,12}$ and in the Netherlands, where more than half of the nursing home residents have been diagnosed with dementia. ${ }^{13}$ This demographic data suggests that the volume of nursing home care required will increase and pain assessment will be a major challenge.

Dementia, caused by a variety of conditions, has been defined as a complex of symptoms characterized by progressive global deterioration of cognitive functioning. ${ }^{14}$ The impairment level is often categorized by means of Mini Mental State Examination (MMSE) scores. The MMSE assesses orientation, registration, attention and recall, and language..$^{15}$ Dementia causes serious and unique barriers to pain assessment and can be characterized by memory loss, personality changes and loss of other functions such as judgement, abstract thinking and language skills. Furthermore, common behaviours associated with pain may be absent or difficult to interpret. ${ }^{16}$ On the other hand, symptoms attributed to dementia may actually be an indication of pain. For example, aggressive behaviours may be a protective response by subjects who are not able to articulate their pain. ${ }^{17}$ Such behaviour, however, could also be mistaken for a symptom of dementia. As a result of these problems, which affect almost all dementia patients, pain in this population is extremely difficult to assess.

There is evidence that pain assessment is currently inadequate and that elderly people with dementia are being undertreated. ${ }^{5,618: 21}$ This undertreatment could lead to various additional problems like cognitive (e.g., concentration problems) and behavioural symptoms (e.g., aggression or depression) at patient level, as well as to greater and heavier demands on caregivers and increased care demands and costs at organization level. The main reason for undertreatment is underdetection. ${ }^{+5}$ Existing evidence of underreported, underdetected and undertreated pain among people with dementia provides the clearest argument for the urgent need to use a pain assessment scale regularly. Assessment to detect pain is thus essential, and is the first crucial step towards adequate treatment of geriatric pain patients with dementia. ${ }^{22}$ There is therefore a need for manageable, valid and reliable pain assessment tools. 
Pain can be assessed by means of self-reports, behavioural or physiological measures. Self-reporting is often considered as the 'gold standard' in pain assessment. A broad range of self-report scales is currently available to assess pain in the elderly, most of which have been developed for and tested in a different setting before being used among elderly people with dementia. ${ }^{23}$ The most frequently assessed component of pain is pain intensity. Commonly used measures of pain intensity include Visual Analogue Scales (VAS), Verbal Rating Scales (VRS), Numeric Rating Scales (NRS) and Facial Pain Scales (FPS). ${ }^{23,24}$ It is generally worth noting that elderly people find it more difficult to use self-report scales correctly than younger adults, ${ }^{22}$ and no single self-report scale seems appropriate for all elderly people. Self-report scales require the capacity to understand the task and to communicate about the pain experienced. Increasing age has been associated with difficulties in abstract thinking, which makes it more difficult to use scales requiring this cognitive skill. This also implies that self-reported scores might be affected and influenced by context and are not always that solid.

A substantial proportion of elderly people living in institutions are unable to understand and answer even simple yes/no questions, and therefore cannot selfreport pain. ${ }^{6.25}$ In the advanced stages of dementia, when the elderly persons are severely impaired, other methods of assessment, like behavioural pain assessment methods, become more useful and necessary. Developing a tool that can be used to assess their pain may greatly improve the quality of life of the estimated $20-30 \%$ of nursing home residents who cannot adequately communicate their needs. ${ }^{26}$ Non-verbal assessment tools based on behavioural observation methods include observation of changes in behaviour and functioning, involving sleep, appetite, physical activity, mobility and facial/body language. Physiological measures, like heart rate or blood pressure, can also provide important information, especially in the assessment of non-verbal demented elderly people. Therefore, behavioural pain assessment scales often use physiological indicators in combination with other (e.g., social) indicators. Research into physiological measures has been scarce, due to their limited validity and practical limitations. ${ }^{27}$ Physiological responses are often not specific enough to serve as pain indicators, and autonomous physiological responses to pain are difficult to discriminate from other states of distress. ${ }^{2 *}$

In recent years, research in the field of pain among elderly people with severe dementia has increasingly focused on understanding expressions indicating possible pain. ${ }^{+},{ }^{29}$ However, there have been a limited number of studies focusing on the development of scales to measure pain in these people, and to our best knowledge no overview was available of behavioural pain assessment scales developed especially to assess pain in elderly people with dementia. The main research questions in the present study were therefore: (1) which behavioural pain assessment tools are available to assess pain in eldetly people with dementia and (2) what are the psychometric qualities of these tools? 


\section{METHODS}

We reviewed the relevant publications based on an extensive search strategy, involving computer searches of Medline, Psychinfo and Cumulative Index to Nursing and allied Health Literature (CINAHL) to identify the literature. The keywords we used and the search results are listed in Table 1.

Table 1 Search strategy

\begin{tabular}{|c|c|c|c|c|}
\hline Source & Hits $(\mathrm{N}=)$ & & $\begin{array}{l}\text { based on } \\
\text { bstracts }(N=)\end{array}$ & $\begin{array}{l}\text { Final selection based } \\
\text { on publications }(N=)\end{array}$ \\
\hline \multirow[t]{3}{*}{ Databases } & Psychinfo & 191 & 29 & \\
\hline & Medline & 977 & $70^{*}$ & 31 \\
\hline & CINAHL $* * * *$ & 219 & $17^{* *}$ & \\
\hline Abstracts & & 8 & 5 & 5 \\
\hline $\begin{array}{l}\text { Citation/teference } \\
\text { screening }\end{array}$ & & 37 & 17 & 15 \\
\hline $\begin{array}{l}\text { Unpublished } \\
\text { manuscripts }\end{array}$ & & 6 & 3 & 3 \\
\hline Total & & & 141 & 54 \\
\hline
\end{tabular}

Keywords used: (Pain) AND (Scale OR assessment OR measure) AND (Elderly OR residents $O R$ geriatric $O R$ nursing homes $O R$ cognitive impairment $O R$ dementia $O R$ Alzheimer)

* $\quad \mathrm{N}=19 / 70$ overlapping the Psychinfo search

** $\quad \mathrm{N}=15 / 17$ overlapping the Psychinfo and Medline searches

*** Because of the large number of publication found using CINAHL, search in this database was limited by using the keyword 'nursing'

In addition, citations and references in selected journal articles were screened to supplement the search strategy. Unpublished manuscripts were collected by approaching colleagues working in the field of pain among the elderly. Finally, the abstract books of the 7th, 8th, 9th and 10th International Association for the Study of Pain World Congresses were screened for relevant publications.

The review focused on publications that have appeared over the last 17 years, from 1988 to January 2005. The following selection criteria were used to screen relevant publications: 
- Publications had to describe an assessment instrument/scale for elderly patients with dementia or a subgroup of elderly patients with dementia, for example, Alzhcimer patients.

- The assessment scale had to have been used to measure pain by means of self-reports by patients or behavioural measures.

- Publications had to be in English, Dutch, German or French.

- Publications had to be other than case reports or secondary sources/reviews.

Our search yielded a large number of publications (see Table 1). After the abstracts of all publications had been screened, 141 publications remained. Not all of these studies were included in the present review, however, because several were reviews/secondary sources or reported on physiological measures. Our database search finally identified 31 publications, while screening citations and references identified another 15 publications. Five relevant abstracts were found in abstract books and three unpublished manuscripts were included. Eventually, 54 publications were identified as suitable for the review on behavioural assessment and self-report tools. Twenty-nine of these 54 publications referred to 14 behavioural assessment scales, while 29 reported on the use of self-reports. The evaluation of self-report tools will be presented in another article [Zwakhalen et al., in preparation]. Two of the 14 scales were not included in this review. The Discomfort Scale for Patients with Dementia of the Alzheimer Type (DS-DAT) by Hurley et al." was not included because the concept of discomfort measured by the DS-DAT differs from the concept of pain. The Pain Assessment Tool in Confused Older Adults (PATCOA) by Decker \& Perry ${ }^{34}$ was not included because on closer examination, this tool was found to have been designed for use in a confused but cognitively intact sample of elderly people.

Data abstraction criteria used to evaluate behavioural assessment scales (see Table 2) were partly based on Streiner \& Norman's requirements for health measurement scales. ${ }^{32}$ The following data were extracted (if available) to examine the nature and methodological quality of the assessment scales: type of assessment scale (including items of the scale), source of the items (origin), scoring/scaling response, sample size of patients, content validity, information about feasibility (including completion rate of self-report scales and instructions accompanying behavioural scales), homogeneity, reliability and validity. As a quality check, a small part of the data abstraction process $(\mathrm{N}=3$ articles on behavioural pain assessment scales) was conducted by two reviewers (with overall agreement found to be $90 \%$ ). 


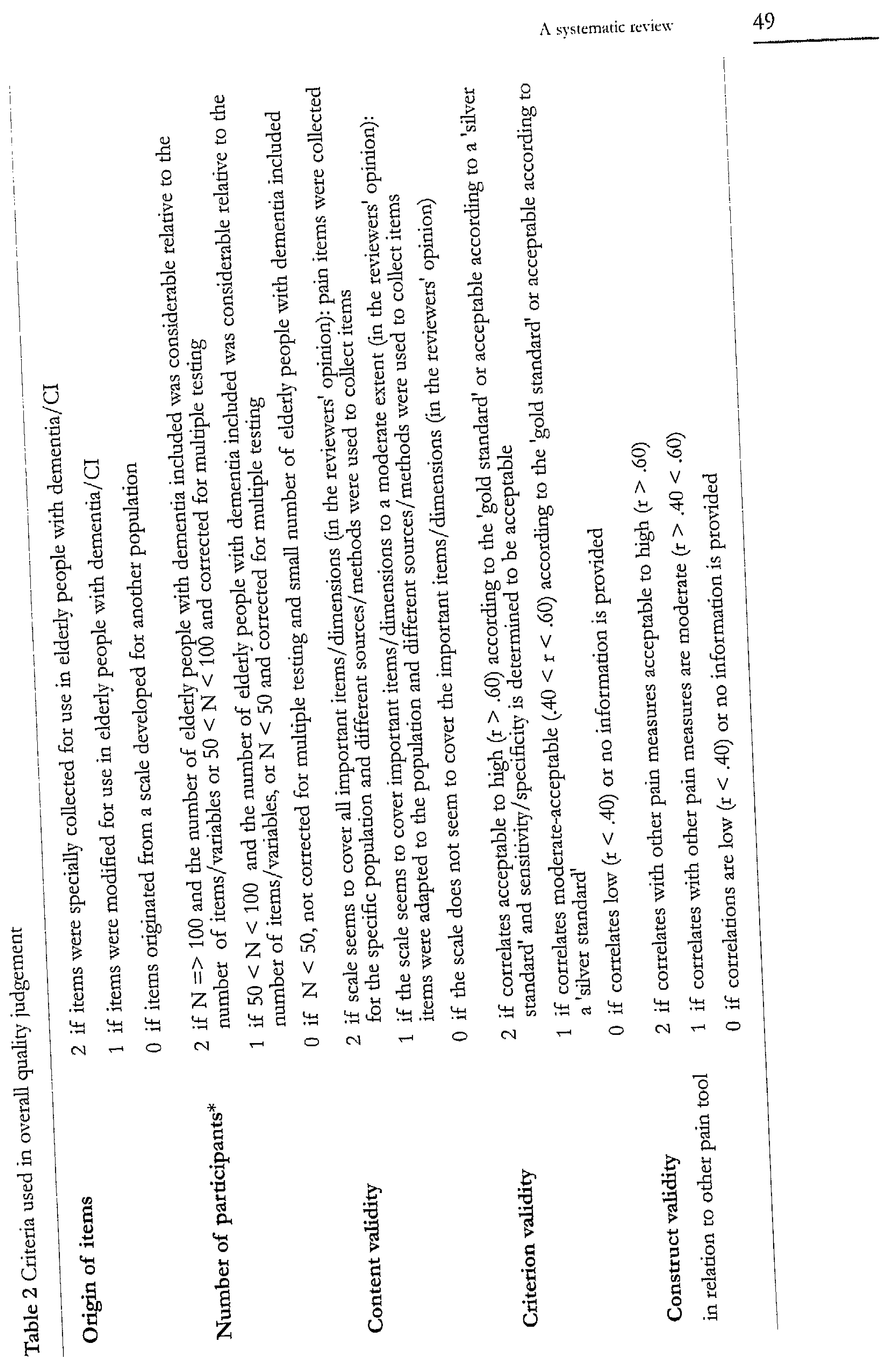




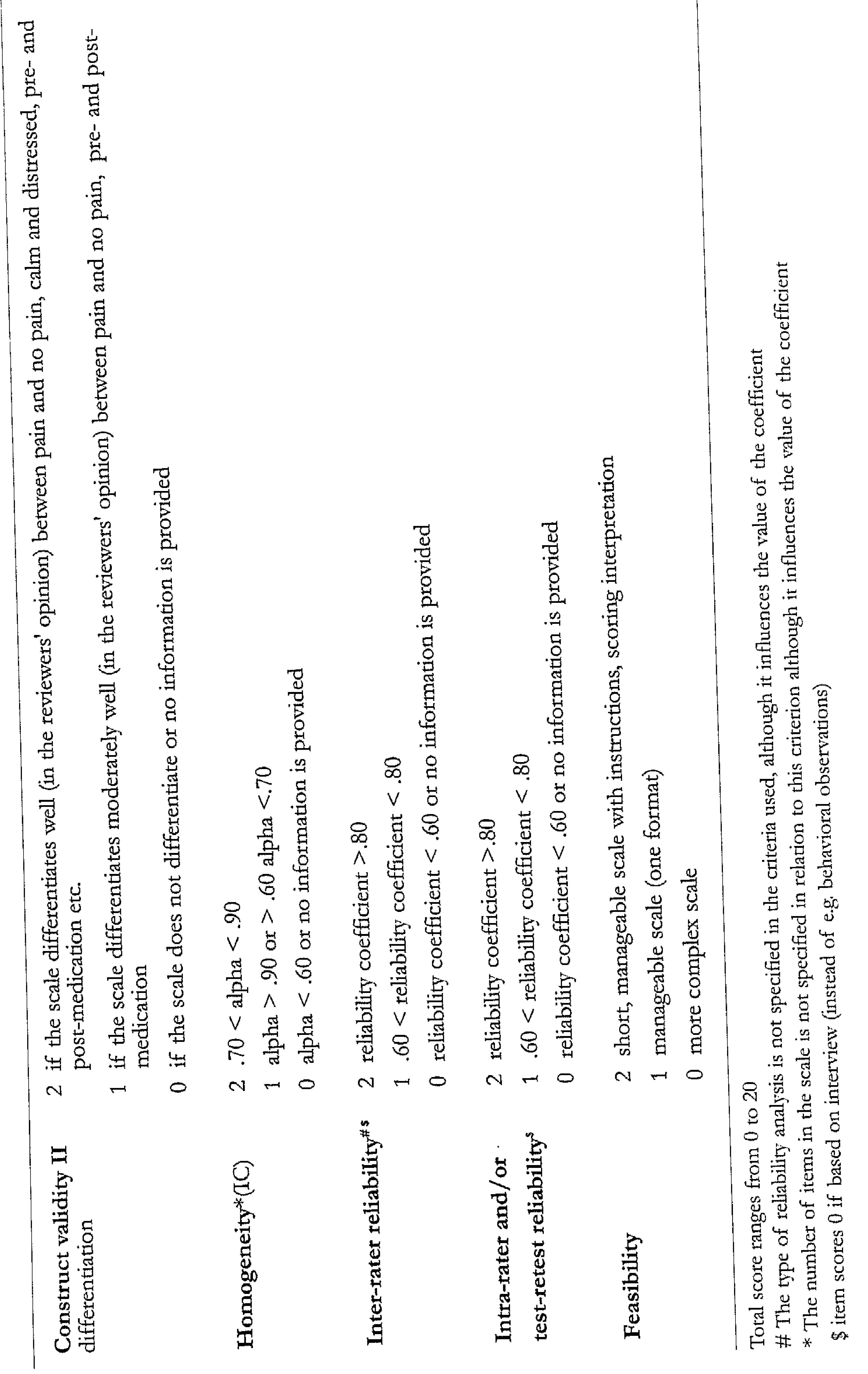




\section{RESULTS}

An extensive literature search traced 12 behavioural pain scales, each of which is described below. Specifically, information is provided about the name of the scale, its origin, the number of items/dimensions, the setting, the scoring method/tange and practical aspects. In addition, Table 3 presents information on psychometric qualities of the behavioural scales (partly based on Streiner and Norman's criteria for health measurement scales ${ }^{32}$ ). The assessment scales are discussed in chronological order.

The DOLOPLUS2 by Wary et al. (1992) is a behavioural scale evaluating pain in elderly people. ${ }^{3.35}$ The DOLOPLUS2 is available in a French and an English version. Its is unclear whether the English version has been psychometrically tested. The scale is based on the Douleur Enfant Gustave Roussy (DEGR) scale ${ }^{3 / 6}$ for young children and has been adapted for use in the elderly. It involves observations of patient behaviour in ten different situations (10 items/3 dimensions) that could potentially involve pain. Items include sleep, verbal reaction and problems of behaviour. Each of the ten items can be described at one of four different levels - rated from zero to three - representing increasing intensity of pain. ${ }^{3+}$ A score greater than or equal to five out of 30 (maximum pain score) confirms pain. The DOLOPLUS2 score does not represent pain experience at a specific moment but reflects on the progression of experienced pain.

Several studies have been conducted in geriatric centres and palliative care units to validate the scale, investigating test-retest reliability, concurrent validity and inter-rater reliability. ${ }^{37,38}$ The proportion of non-vetbal individuals tested was rather small $(1-5 \%$ of the sample). According to the authors, the convergent validity of the DOLOPLUS2 and the VAS-patient was significant $(p<0.001)$ and DOLOPLUS2 demonstrated good sensitivity. There was satisfactory stability on the retest. A t-test analysing the intra-observer differences found no significant differences for the total score or for item scores. An interrater correlation test between two physicians showed no significant difference $(p<0.001)$, and good levels of internal consistency $(\alpha=0.82)$ were found. Closer examination of the scale reveals that little information is provided about several aspects of the tool and tool construction. These limitations include a lack of information on correlation coefficients (inter-rater reliability, test-retest reliability) and of information about the determination of cutoff scores and the impairment level of the participants. In acute settings, its value might be limited because patients must be well known to the nurses who have to complete the DOLOPLUS2, whereas the value of a scale becomes greater if it can be used without in-depth knowledge of the patient." Although the scale is accompanied by a lexicon and instructions for use, and is, according to its authors, easy to use, it is conceivable 
that nursing home staff may have difficulties interpreting items of the DOLOPI.US2, as certain items seem difficult to understand or interpret. In addition, the scale's clinical utility should also be further tested directly at the bedside in larger samples of non-verbal cognitively impaired elderly patients. A final comment concerns the total pain score and its sensitivity. The DOLOPLUS2 score does not represent pain experienced at a particular moment but reflects the progression of experienced pain. The maximum score on the DOLOPLUS2 is 30 , and a score of 5 already represents pain. This raises questions about the scale's specificity.

L' échelle Comportementale pour Personnes Agées (ECPA) by Alix et al. is a behavioural scale for non-communicating elderly people."10, +1 French and German $^{12}$ versions of the ECPA are available, although it is unclear whether the German version has been validated.

This scale was also inspired by the Douleur Enfant Gustave Roussy (DEGR) scale $^{36}$ for young children and was adapted for use in the elderly. The scale consists of 11 items with five response modalities scored from 0 to 4 , representing increasing degrees of pain. The total score ranges from 0 (no pain) to 44 (absolute pain). Factor analysis showed that the ECPA has three dimensions, defined on the basis of principal component factor analysis: precare, post-care and during activities." An example of response modalities comprising the item 'facial expression' is $0=$ relaxed face; $1=$ concerned face; $2=$ face sometimes grimacing; $3=$ frightened, face contorted with pain.

The homogeneity of the items (Cronbach's $\alpha=.70$ ), convergent validity between the VAS and ECPA (Pearson $r=.67, \mathrm{~N}=16$ ) and inter-rater reliability (Intra-class reliability $=.80$ ) have been preliminarily tested in a sample of hospitalised patients in a long-term stay department." Its clinical value needs to be further examined.

The Simplified Behavioural Scale (ECS) was published in 1995 by Baulon and colleagues to detect changes in behaviour in geriatric patients with and without communicative limitations. ${ }^{43}$ ECS was designed by a multidisciplinary team of nurses and medical staff. The scale consists of ten items scored on three, four or five levels, depending on the item. The first six items are assessed after care, while items 7 and 8 are assessed during care, and items 9 and 10 every 24 hours. Examples of items included in the scale are sleep, verbal reaction and interaction with the environment. A lexicon and users' instructions for the ECS are available. The scale has not been tested for validity and reliability.

The Observational Pain Behaviour Tool by Simons \& Malabar (1995) is an assessment tool designed specifically for everyday use with elderly patients in hospital settings. ${ }^{30}$ The tool is based on the pain tool described by Keefe and 
Block. ${ }^{+1}$ The tool consists of a data sheet, a pain assessment chart and a menu of observable pain behaviours $(\mathrm{N}=25)$ that are to be recorded. These behaviours had been found to discriminate between manifestations of pain and depression in tests using alert adults with chronic low back pain. Scoring is based on entering the behaviour on the sheet as being present at a certain moment and does not include information on pain intensity. Examples of the 25 items included in the scale are 'verbal expression' (e.g., 'ouch'), 'not relaxed, drawn-up knees', and 'drowsy'. The tool has been pilot-tested in 105 elderly hospitalised patients by observing pain behaviours, carrying out pain interventions and re-observing later to verify the effectiveness of the intervention." The authors claim that the tool is practical. The fact that carers without in-depth knowledge of the patient were able to use the tool is an important clinical advantage. Based on the result of the evaluation, further investigation of the tool's validity and reliability is necessary.

The Checklist of Nonverbal Pain Indicators (CNPI) by Feldt is a behavioural observation scale for non-verbal residents with severe cognitive impairment. ${ }^{+5}$ The scale is a modification of the University of Alabama Birmingham Pain Behaviour Scale (UAB PBS), which was designed to measure chronic pain, ${ }^{\text {th }}$ from which some items were eliminated and others redefined. Scoring involves patient observation at rest and during movement. Examples of the six more or less clustered items are 'restlessness', 'rubbing' and 'vocal complaints' (verbal). An item is scored as ' 1 ' if the behaviour was observed during activity or rest and as ' 0 ' if the behaviour was not observed (range of total scale 0-6). After adding up the two scores (for movement and rest) the interpretation is as follows: '1-2' mild pain, '3-4' moderate pain, '5-6' severe pain. ${ }^{15}$ The tool was tested in a convenience sample of hospitalised patients aged 65 and older with a hip fracture. The cognitively impaired group $(N=53)$ had MMSE scores below 23 (mean $=12.2$ ). The authors claim good face validity. CNPI and the patients Verbal Descriptive Scale correlate significantly, although in the impaired subgroup, CNPI only correlated significantly with the VDS during movements. A more important finding was that these correlations were low $(r=.372$ at rest; $r=.428$ during movements). Moderate levels of internal consistency ( $\alpha=.54$ at rest, $\alpha=.64$ during movement) and good inter-rater reliability (IR agreement 93\%) were found on the dichotomous checklist (although measured in a relatively small sample, $N=13$ ). Based on reported findings, the CNPI has poor psychometric qualities. Therefore, further development of the scale and psychometric testing (e.g., inter-rater reliability, test-retest reliability) in larger populations seems essential.

The Pain Assessment Checklist for Seniors with Limited Ability to Communicate (PACSLAC) by Fuchs et al. intends to be a clinically useful scale for assessing pain in patients with dementia. ${ }^{47}+8$ PACSLAC, which is still under 
construction, has good content validity, thanks to its extensive item collection. While most items of the scales are based on existing scales appropriate for other populations, the PACSLAC developers collected items that are characteristic of pain in elderly people with dementia. A preliminary checklist of pain behaviours was created based on interviews with professional long-term caregivers of older adults with severe communicative limitations due to dementia. In the second part of the study, nurses were asked to complete the checklist with reference to the pain experienced by a senior under their care. The current version is a long list, consisting of 60 items covering four sub-scales (facial expressions; activity/ body movements; social/ personality/ mood; physiological/ eating/ sleeping/ vocal), which were composed on the basis of item analysis. The underlying factor structure remains to be analysed. Examples of the items included in the scale are 'opening mouth', 'pacing', 'verbal aggression' and 'changes in sleep'. The items are scored if the behaviour is present. No scoring interpretation is currently available.

The third part of the study focused on the preliminary validation of PACSLAC. High levels of internal consistency were found for the total scale $(\alpha=0.82-0.92)$, although Cronbach's $\alpha$ values for the subscales were lower (.55-.73). The PACSLAC total score seemed to discriminate between painful, calm and distressing events. Correlations calculated between global intensity ratings and PACSLAC scores were moderate $(r=.39-.54)$. Inter-correlations between the subscales suggest that although the checklist measures a unified construct, the subscales are sufficiently discriminatory. ${ }^{\text {th }}$

Additional refinement and psychometric testing (test-retest, intra-rater reliability and factor analyses) of the PACSLAC is essential. This should include an assessment of its value in clinical situations and in latger samples. The checklist is long and covers a broad range of possible pain cues, included specifically for elderly people with limited communication abilities due to dementia. A major disadvantage is the fact that no patients participated directly in the studies undertaken to construct the scale. Instead, participating caregivers reported from memory on patients they had cared for. ${ }^{+8}$ It is questionable whether it is realistic to ask people to score a list of 60 items from memory. A final comment concerns the sample size involved in the study by Fuchs-Lacelle \& Hadjistavropoulos that was used to construct the scale. Given the fact that the checklist contains many items, a sample size of 40 (recalled) patients seems inadequate.

The Pain Assessment IN Advanced Dementia Scale (PAINAD) by Warden et al (2003) was developed to assess pain in individuals with advanced dementia.4, in The scale can be described as a modification of the DS-DAT and was based on a review of the literature, available pain assessment tools (FLACC by Merkel et al., $1997^{51}$ and DS-DAT by Hurley et al., 1992 $2^{31}$ ) and consultation with expert clinicians. Testing was done in a residential setting (dementia care ward) 
involving 19 severely impaired patients. The current version consists of five items with three tesponse modalities scored from 0 to 2 (with a range for the total scale of 0 to 10). Increasing levels reflect increasing degrees of pain. Examples of response modalities included in the 'facial expression' item are $0=$ smiling; $1=$ sad, frightened, frowning; $3=$ facial grimacing, ${ }^{+1,51}$ Internal consistency was moderate and lower than desired $(\alpha<, 70)$. Given the fact that the scale contains only a limited number of items $(\mathrm{N}=5)$, the IC score is remarkably low. High levels of inter-rater reliability were found (Pearson $r=.82-.97$ ). The scale showed evidence of construct validity. The tool correlated well with the DSDAT, VAS for discomfort and a VAS for pain. Pain scores were found to be lower during pleasant than during aversive activities and scores differed before and after pain modification. Factor analysis showed that there was one underlying construct, and item-total correlations were also investigated." ," s" However, sample sizes used in developing PAINAD were small $(\mathrm{N}=19)$, which limits its findings. Furthermore, pain scores were often clustered around 0 , reflecting absence of pain. Since this might be a worrying aspect, further research should test the scales in more standardized pain situations in order to develop an adequate pain scale. Notwithstanding its good preliminary psychometric quality, PAINAD needs to be further tested (including test-retest reliability) in a larger sample. A training session is needed before the PAINAD scale can be used, and a manual is provided. Before applying the scale, a 5minute observation period is required. The authors claim the scale to be userfriendly.

The Pain Assessment for the Dementing Elderly (PADE) by Villanueva et al. (2003) was developed to measure pain in individuals with advanced dementia. ${ }^{52}$ The scale was developed after a literature review, interviews with nursing staff and observations. Testing was conducted in a residential setting (long-term care facilities) involving a sample of elderly people $(\mathrm{N}=65)$ with mostly severe dementia. The PADE consists of 24 items covering three individual parts, the first assessing facial expressions, the second activities of daily living and the third the overall caregiver's judgement of pain. Examples of the items included in the scale are 'restless', 'frowning' and 'time spent out of bed'. The items are tated using several different scoring methods. While some items are rated on a four-point Likert scale, others are multiple choice and some items are scored on a VAS. While some items are scored retrospectively, others are not. Scoring interpretation is absent and the scale seems complex because it includes different scoring methods, which might be confusing or difficult to interpret. Therefore its clinical utility needs to be determined at the bedside. Because the scale includes different scoring methods, it seems problematic to calculate cut-off scores for pain and determine sensitivity and specificity. Considering the comprehensiveness of the tool, the number of participants was small. Several psychometric aspects have been investigated in a two-part study. 
Inter-rater reliability was found to be adequate (intra-class reliability .54-.96) while test-retest reliability was acceptable for most parts but low (intra-class reliability .34) for part 2 of the scale. Scores for the homogeneity of the scale were good for most parts of the scale, except for part 3 . Results show that the second part of the scale is the most problematic part in terms of reliability. When correlated with a scale to measure agitation, the scale demonstrated a relation as hypothesized. The scale also provided evidence of construct validity by differentiating between pain and no-pain groups, but the construct validity of the scale needs to be further investigated. Although it seems a long list, authors stated that, with practice, PADE requires 5-10 minutes to complete. ${ }^{52}$ Given the scoring complexity, however, this is probably an underestimation.

Rating Pain in Dementia (RaPID) by Sign and Orrell (2003) was developed to rate pain in elderly people with dementia. It was developed from expert advice $\left(N=38\right.$ experts) and reviewed research literature. ${ }^{53}$ It consists of 18 items covering four dimensions (behavioural, emotional, autonomic and postural). No specific information is provided about the origin of the items. The items are clustered and sometimes broadly defined. Examples of the items include 'tense body language', 'tearfulness', 'sweating' and 'general increase in muscle tone'. Items can be scored on a four-point scale ( 0 absent to 3 severe). The total score of the scale ranges from 0 to 54. Testing was done in a hospital setting (psychiatric and medical care units) involving 48 demented patients.

Observers score each item based on complaints, symptoms and signs occurring during one week, prior to using clinical judgements from a range of information such as clinical notes and interviews with staff, patient, and carer. To establish concurrent validity, RaPID scores were compared with the McGill Pain Questionnaire and a VAS. Findings showed that the instruments correlated highly with each other. In addition, good internal consistency of the total scale $(\alpha=.79)$ and good inter-rater reliability were found (mean .97). Similar high scores were found for test-retest reliability (ranging from .84 to .98)..$^{53}$ Closer examination of the data collection process on which this scale was based also yielded many pain scores clustered around 0 . Investigation of the psychometric quality has so far been superficial, so this quality needs to be further investigated in larger samples. Based on these preliminary findings, further development of this scale seems warranted.

The Abbey Pain Scale by Abbey et al. (2004) is a brief assessment scale for people with end-stage dementia. ${ }^{5+}$ The scale is based on the pain scales described by Hurley et al. ${ }^{311}$ and Simons \& Malabar. ${ }^{37}$ and modified by geriatric and pain experts by means of a Delphi study. The scale consists of 6 items (e.g., physiological changes, physical changes) with four response modalities scored from 0 (absent) to 3 (severe), with a range for the total scale of $0-18$. The scale was tested in residential care facilities. After completing the observations and 
adding up the scores, the interpretation is as follows: ' $>3$ ' mild pain, ' $8-13$ ' moderate pain, ' $>14$ ' severe pain. These cut-off scores are based on crosstabulation of the Abbey pain scores against the holistic pain impression of the participating nurses (named holistic measure). To establish construct validity, scores were compared with nurses' overall pain impression. Findings showed that these scores correlated moderately (.59) with each other. Furthermore, pain scores were found to be lower after the intervention. Adequate levels of internal consistency were found for the total scale $(\alpha=0.74-0.81)$, but low inter-tater reliability scores (scoring $\mathrm{N}=18$ patients) were found and test-retest reliability was not reported. Although several psychometric aspects have thus been tested, the current version of the pain instrument still lacks reliability and validity.

The Non-Communicative Patient's Pain Assessment Instrument (NOPPAIN) by Snow et al. (2004) consists of four sections and combines information about pain behaviour (words, noises, facial expression, bracing and restlessness), care conditions and a Likert scale of pain intensity. ${ }^{55}$ Information about the origin of the items has not been clearly provided. After an initial feasibility study, the preliminary version of the NOPPAIN was tested in a small sample of 21 nursing assistants (NA). The researchers used a video gold standard method to portray a patient's painful situation during care. The recently published study ${ }^{55}$ focuses on the validity of NA pain intensity scores compared to the video gold standard. The authors reported excellent agreement (kappa .87), providing preliminary evidence of construct validity. The scale might present a useful contribution but has not been extensively tested for validity or reliability. According to the authors, the scale is easy to administer (requiring very little training) and brief, and combines text and pictures to make it easier to understand. By focusing on nursing assistants, the developers underline the importance of pain assessment during daily care by key figures in nursing home care. However, it is questionable whether nursing assistants are capable of assessing a complex problem like pain during daily care situations. Evidence of validity and generalizability might be limited because developers created an artificial situation using a video approach (acting out a painful situation).

Davies et al. (2004a; 2004b) recently developed the pain assessment scale for use with cognitively impaired adults. ${ }^{56,57}$ The scale was developed based on literature analysis and expert focus group discussions. While most assessment strategies have focused on one aspect of pain (e.g., pain intensity), these researchers tried to incorporate several pain aspects into one multidimensional tool which focuses on the assessment of existing painful conditions, physiological measures of pain, self-report, facial expression, usual pain behaviour and changes from usual behaviour. As a result, the current version, covering 11 sections, is very comprehensive. The sections/items are rated using different scoring methods. The clinical utility of the scale has been pilot-tested 
in a small sample $(N=27$ cognitively impaired elderly patients of a dementia care unit and a psycho-geriatric unit) by implementing the scale in practice over a three-month period. The tool was often not fully completed by respondents and was reported to be complex and time-consuming. There was a strong tendency to skip the section that relates to physiological assessment strategies, like blood pressure. ${ }^{50}$ Before further determining the utility of the scale, it needs to be refined and tested for validity and reliability.

Table 3 presents the scores for individual criteria, as well as overall quality judgements, which reveal that the quality of the scales we have reviewed is generally moderate. Only four of the scales scored 11 points on our quality judgement which has a scoring range from 0 to 20, viz. DOLOPLUS2, ECPA, PAINAD, PACSLAC. It must be taken into account, however, that most of the scales are still under construction, especially with regard to criterion and construct validity. Future publications will probably highlight more research and psychometric findings.

\section{DISCUSSION AND CONCLUSION}

The purpose of the present study was to review behavioural pain assessment tools available to assess pain in elderly people with severe dementia, and to evaluate the psychometric quality of these tools.

This systematic review revealed that at least 12 behavioural pain assessment tools currently exist. We conclude from the results of our review that at present, none of these assessment scales is convincingly the most appropriate, and therefore preferable, scale for assessing pain in elderly people with dementia. Our findings (based on quality judgement criteria relating to validity, reliability and homogeneity) demonstrate that PAINAD, PACSLAC, DOLOPLUS2 and ECPA show the best psychometric qualities. It should be stressed, however, that none of these tools scored more than 12 points out of a maximum quality score of 20 , so their overall psychometric quality can be regarded as moderate. The tools therefore still await confirmation of various aspects of their psychometric properties.

Our review of the studies on behavioural assessment scales identified several general issues and weaknesses that need to be addressed, including methodological issues and practical limitations. First, to achieve the required validity, most instruments were correlated with a VAS or alternative intensity scale filled in by a proxy (mostly nurses). In the absence of self-reports, the interpretation of pain by a significant other has been frequently discussed, and the legitimacy of this approach (using a self-report scale by proxy as a gold standard or acceptable silver standard) is questionable. The assumption that caregivers' pain impression can be quantified by tools like VAS could only be legitimated if nurses' perceptions are comparable to patients' own perception of pain. 
A ststematic review

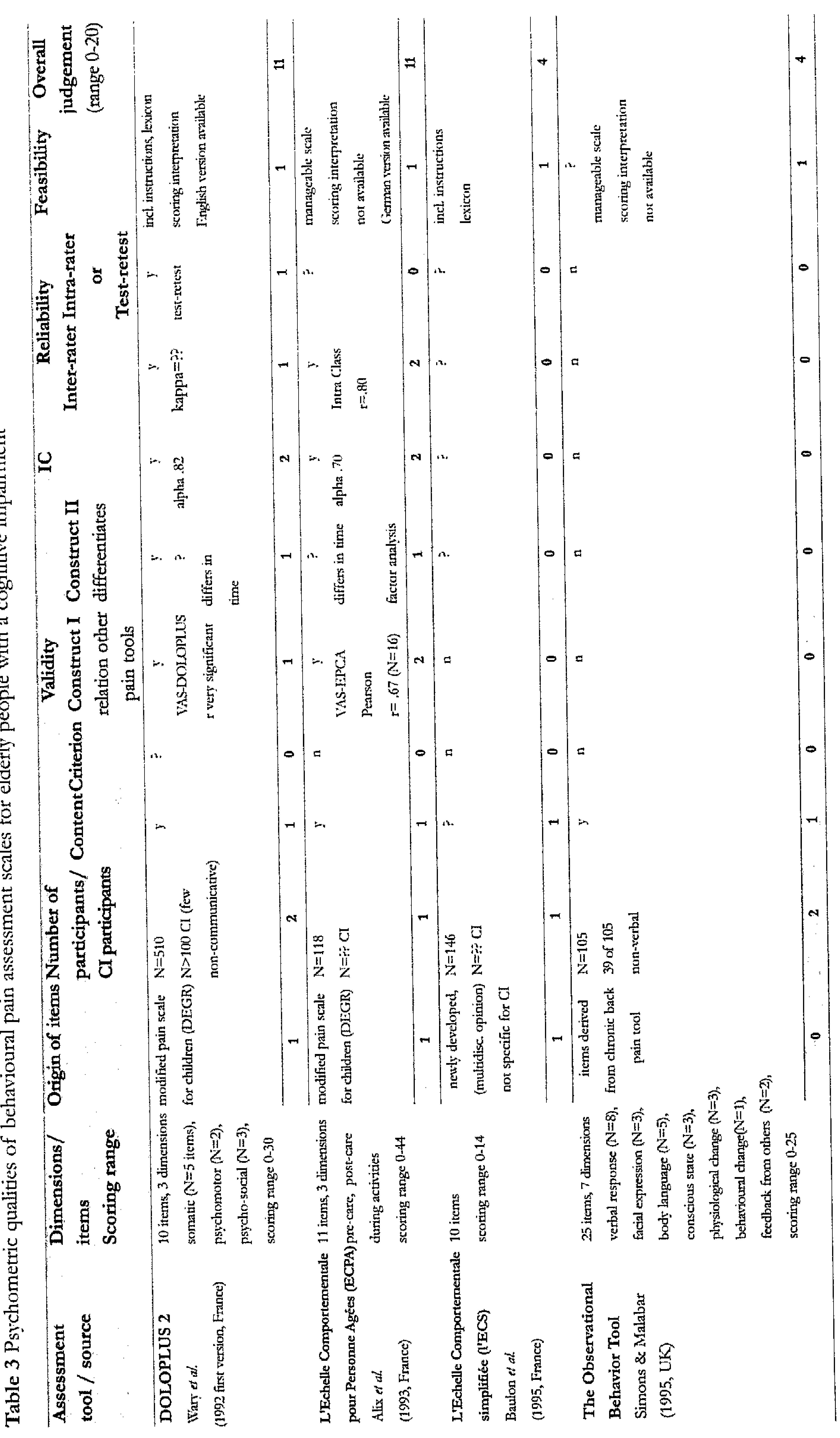




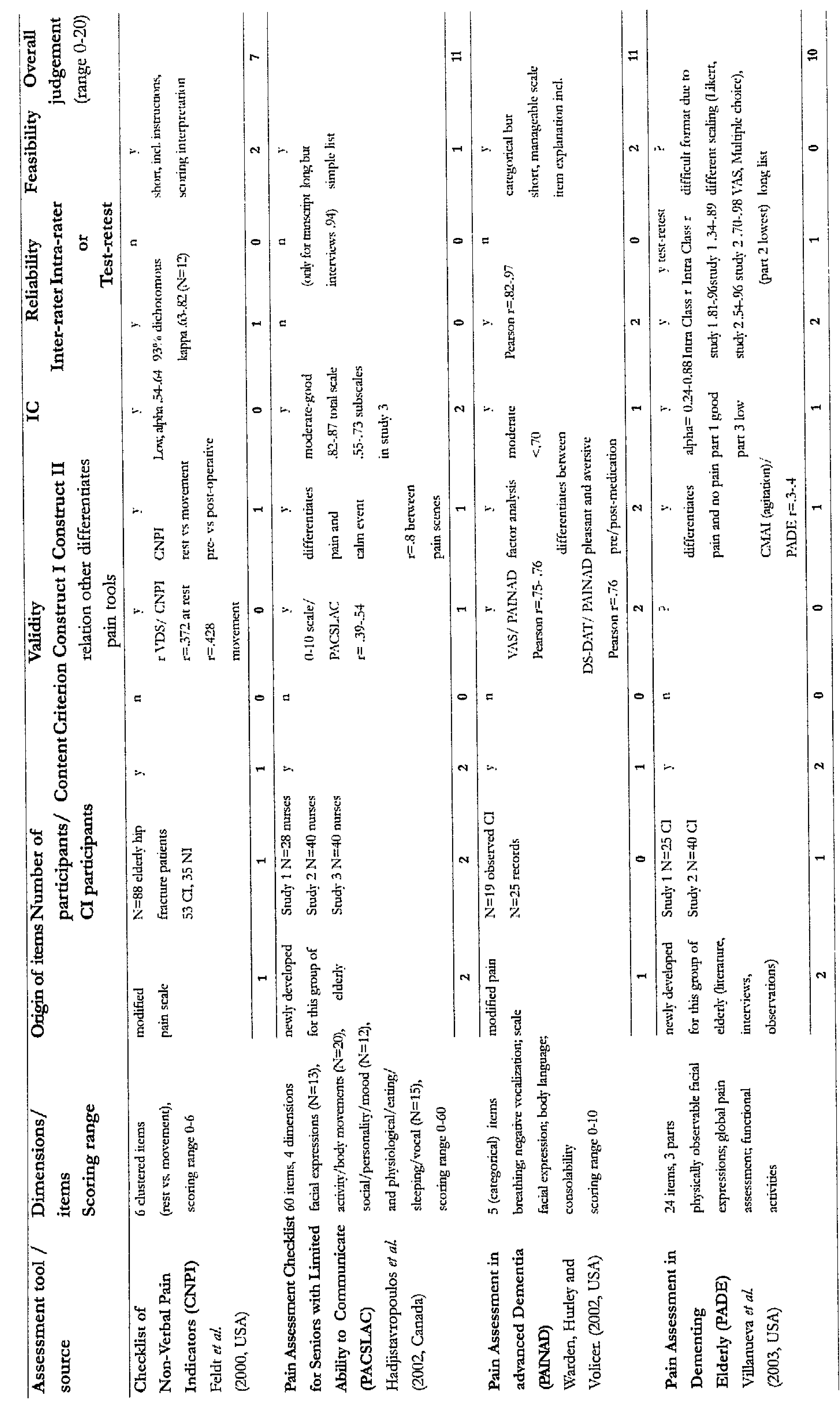




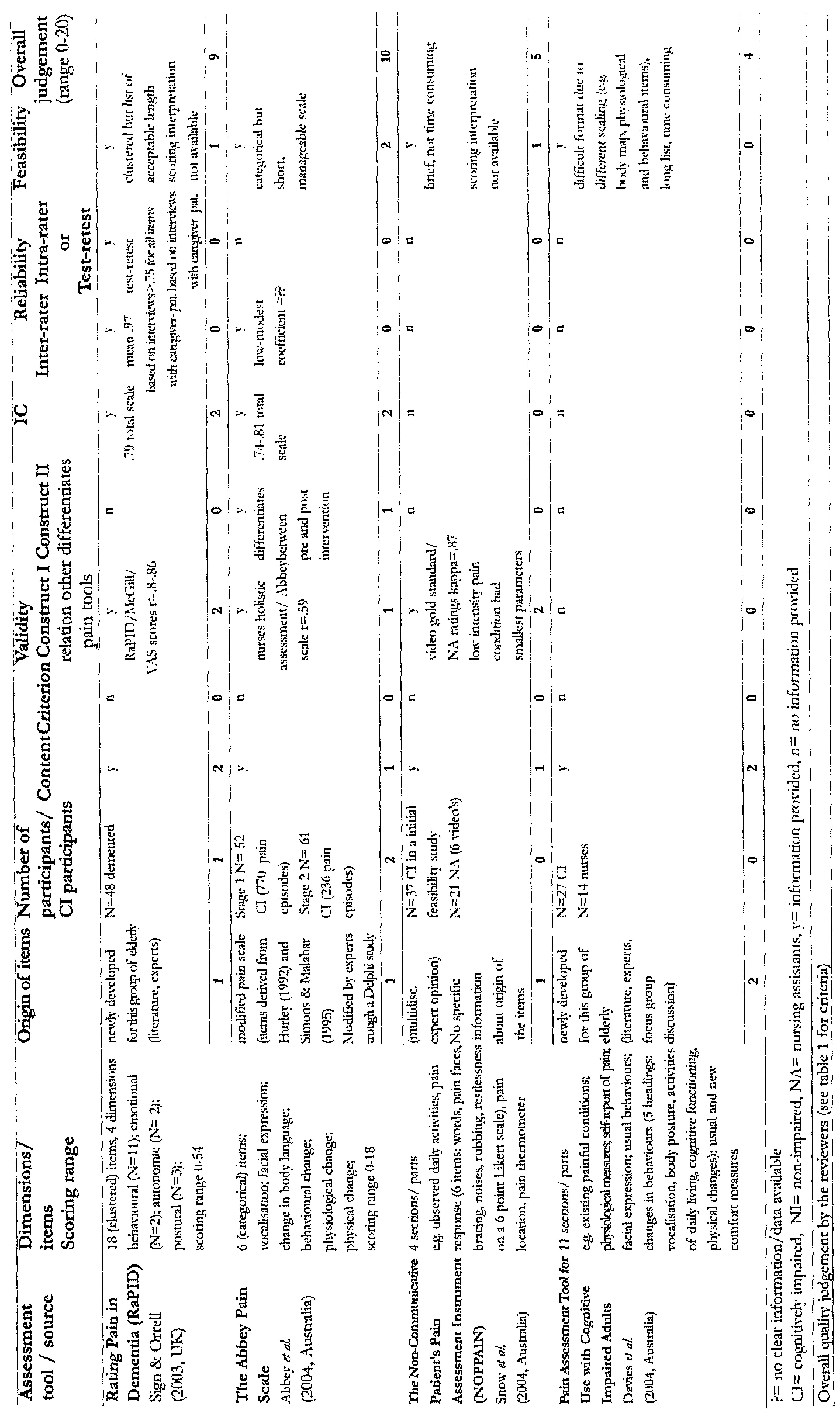


Differences in pain rating between nurses and patients have been identified as an issue affecting pain measurement and management in elderly people. ${ }^{5 \times}$ If nurses' pain impression was a valid and reliable measure, a more complex behavioural scale to assess pain would become redundant. Instead of using a proxy report approach, an option could be to use a selected group of elderly people with opportunities to self-report their pain as an alternative strategy to further validate behavioural scales. Nonetheless, the scoring of observational tools also depends largely on pain perception by proxies. Although it remains a methodological pitfall, proxy reporting is often a valuable option in this population.

There are also some methodological concerns about sample sizes and the indicators collected to construct pain scales. We must be aware of the fact that the pain indicators collected for this purpose may be influenced by the type of pain focused on in collecting the items and the setting in which indicators are collected. Given the fact that some scales contain a large number of items, many of the studies used small samples of participants or a limited number of pain situations. In addition, articles do not always provide information about the frequency of endorsement of certain items in the population examined. Not providing information about the importance of items at rest and during a painful situation can affect results. Furthermore the current scales are heterogeneous in terms of items used to assess pain. The overlapping items of the scales might be the most common and important ones, while unusual items might be more characteristic of the target group but less useful for a general pain scale for elderly people with dementia. In other words, item responsiveness to pain adds to further item reduction and refinement of a scale.

In view of the limited qualities of the scales, including PAINAD, PACSLAC, DOLOPLUS2 and ECPA, further research is essential for additional refinement and development. It may therefore be questioned if recommendations can at this stage be made for the implementation of one of these tools in clinical practice. In answering this question, two further criteria could be added.

The first criterion concerns the ability of items in the scale to detect subtle changes in behaviour. These specific items add important information and help nurses to create a certain pain image of the non-verbal patient. Therefore, we would expect that indicators which focus on subtle behaviours should be adequately covered by the items in the pain scale. While PAINAD, DOLOPLUS2 and ECPA tend to focus on main indicators like facial expression, PACSLAC is the only scale that primarily focuses on these subtle changes in behaviour. Notably, PACSLAC is one of the few instruments in which the item collection is based on pain items specifically geared towards elderly persons with dementia, instead of items adjusted from existing scales developed for use in different patient groups (like paediatrics). In view of the special needs of the heterogeneous group of elderly people with dementia, this is a more suitable 
procedure to use in creating an item bank specifically for the target group. The second criterion relates to the clinical utility of the scales. Ramelet et al." stated that clinical utility and feasibility are of paramount importance for the acceptability of a measure in clinical practice. Authors often claim good clinical utility even though these aspects have not been properly evaluated. Scoring method, number of items and scoring interpretation are factors that must be considered in valuing an instrument's utility. Available evidence of clinical utility is scarce and criteria for scoring and interpreting scores are often not available. Furthermore, most studies lack information on sensitivity and specificity, and without this information, a scale is useless for clinical practice. This major limitation must receive more attention, which means that further testing in clinical practice is needed. Having an instrument tested in nursing home practice by nurses adds to the body of knowledge about its real utility value. It must be concluded that none of the behavioural pain assessment scales have been extensively tested in a variety of care settings under different pain conditions by various caregivers, which means that so far they cannot be said to have good clinical utility. None of the scales has thus proved practicable enough to be used in clinical situations like nursing practice on a daily basis. Of the four highest scoring scales, DOLOPLUS2 has been most comprehensively tested.

After adding these criteria to the psychometric properties, we conclude that PACSLAC and DOLOPLUS2 are the most appropriate scales currently available.

\section{Limitations of the study}

Before recommendations for further research can be formulated, there are some limitations of the present systematic review that need to be addressed. To begin with, it must be noted that the studies reviewed above show considerable heterogeneity in terms of design (retrospective vs. prospective), method (pain in vivo vs. observational methods), research population (different types of dementia, different levels of impairment, different settings) and conceptualisation of pain, making their results hard to compare. Aspects that make the studies difficult to compare include differences in format/structure and scoring method. DOLOPLUS2, PADE and PACSLAC, for example, are extremely different in these respects. Although we used a set of criteria to arrive at an overall judgement to make our review more objective and systematic, quality judgement scores should always be interpreted with caution, because the use of some criteria inevitably involves a subjective element derived from the reviewer's expertise. Each criterion used to evaluate the quality of the scales was given an equal weight of 1 (except for construct validity, which was given a weight of 2 , based on perceived importance). It is important to realize that this weighting approach inevitably has consequences for the quality judgement scores. 


\section{Recommendations and furtber research}

The findings of this review have important implications for future research and for everyday practice. Pain assessment is recognized as a significant area for future research and for the improvement of nursing care."II Pain assessment fits into a broader perspective of evaluating elderly people's daily functioning and quality of life, which is the core business for nurses. Assessment and reassessment lead to accurate and regular documentation of pain scores, which is extremely important in the evaluation and continuity of daily care.

Although huge progress has been made over the last decade, and studies of pain assessment among cognitively impaired elderly people have yielded promising results, studies have so far been limited. Assessment in the severely demented elderly remains difficult, and diagnosing pain continues to be a daily challenge to nurses. Although using a pain assessment scale is an important resource in detecting pain, it is often an element of a more comprehensive approach that also uses other resources, like physical examination and information from close relatives. These explorations of various resources can add information to solve the pain problem and therefore remain necessary.

In recent years, there has been growing interest in pain among cognitively impaired elderly people, which is illustrated by the fact that more than half of the 12 scales included in this review were published after 2002. Evidently, the number of newly developed scales has grown very rapidly. In view of this proliferation of behavioural tools and the promising quality of some of the scales reviewed here, we recommend improving these scales on the basis of further testing of their validity, reliability and clinical utility. It is the researchers' as well as the funding agencies' and journals' responsibility to prevent excessive growth of newly developed tools. Thus, further psychometric evaluation of existing scales should be given priority over developing new scales for future use. Valid, practical and reliable scales can add to the body of knowledge about pain and help to improve pain treatment in this important and growing population.

Scherder and colleagues ${ }^{21,61,62}$ concluded that the type of dementia seemed to influence pain reports. This might actually imply a validity issue regarding the use of specific behavioural indicators across different stages and types of dementia. Knowing that the type and stage of dementia does matter in relation to pain assessment, further research should determine the utility, validity and reliability of pain assessment using a pain scale that takes the type of dementia into account. Furthermore, the results of the various studies show that there has been little research addressing the effect of cultural background on pain. Since none of the reviewed pain assessment scales seriously considers this variable, this is another aspect that should be included in future research.

A final recommendation concerns the Behavioural and Psychological Symptoms of Dementia (BPSDs) in relation to pain. BPSDs can confound pain assessment. Until now, little is known about the interaction between pain 
symptoms and these behavioural problems. Therefore, the relation between pain and BPSDs needs to be explored. Further research will be needed to determine its sensitivity in relation to these other concepts, as well as the way pain affects these symptoms and how these symptoms affect pain expression.

\section{REFERENCES}

1. Ferrell BA, Ferrell BR, Osterweil D. Pain in the nursing home. Journal of the American Geriatrics Society. 1990;38(4):409-414.

2. Ferrell BA. Pain management in elderly people. Journal of the American Geriatrics Society. 1991;39(1):64-73.

3. Cook AK, Niven CA, Downs MIG. Assessing the pain of people with cognitive impairment. International Journal of Geriatric Psychiatry. 1999;14(6):421-425.

4. Marzinski LR. The tragedy of dementia: clinically assessing pain in the confused nonverbal elderly. Journal of Gerontological Nursing. 1991;17(6):25-28.

5. nursing home residents. Journal of the American Geriatrics Society. 1993;41(5):541-544.

6. Ferrell BA, Ferrell BR, Rivera L. Pain in cognitively impaired nursing home patients. Journal of Pain \& Symptom Management. 1995;10(8):591-598.

7. Wagner AM, Goodwin M, Campbell B, et al. Pain prevalence and pain treatments for residents in Oregon nursing homes. Geriatric Nursing. 1997;18(6):268-272.

8. Proctor WR, Hirdes JP. Pain and cognitive status among nursing home residents in Canada. Pain Research \& Management. 2001;6(3):119-125.

9. Blomqvist $K$, Hallberg IR. Recognising pain in older adults living in sheltered accommodation; the views of nurses and older adults. International Journal of Nursing Studies. 2001;38(3):305-318.

10. CBS bttp://statine.cbs.nl/StatWeb/Table.asp?PA=03766nederD1=a\&D2=0@D $3=$ $5,10,15,2 . .] 2005$.

11. Matthews FE, Dening T. Prevalence of dementia in institutional care. Lancet. 2002;360(9328):225-226.

12. Wancata J, Benda N, Meise U, Windhaber J. Non-cognitive symptoms of dementia in nursing homes: frequency, course and consequences. Social Psychiatry \& Psychiatric Epidemiology. 2003;38(11):637-643.

13. Lange de J, Gijsen R, Poos MJJC. Hoe vaak komt dementie voor en hoeveel mensen sterven eraan? Volksgezondheid Toekomst Verkenning, Nationaal Kompas Volksgezondheid. Bilthoven: RIVM; 2002.

14. Patterson CJ, Gauthier S, Bergman $\mathrm{H}$, et al. The recognition, assessment and management of dementing disorders: conclusions from the Canadian Consensus Conference on Dementia. CMAJ Canadian Medical Association Journal. 1999;160(12 Suppl):S1-15.

15. Folstein MF, Folstein SE, McHugh PR. "Mini-mental state". A practical method for grading the cognitive state of patients for the clinician. Journal of Psychiatric Research. 1975;12(3):189-198.

16. Herr K. Pain assessment in cognitively impaired older adults. American Journal of Nursing. 2002;102(12):65-67.

17. Feldt KS, Ryden MB, Miles $S$. Treatment of pain in cognitively impaired compared with cognitively intact older patients with hip-fracture. Journal of the American Geriatrics Society. 1998;46(9):1079-1085. 
18. Horgas AL, Tsai PF. Analgesic drug prescription and use in cognitively impaired nursing home residents. Nursing Research. 1998;47(4):235-242.

19. Loeb JI. Pain management in long-term care. American Journal of Nursing. $1999 ; 99(2): 48-52$.

20. Morrison RS, Siu AL. A comparison of pain and its treatment in advanced dementia and cognitively intact patients with hip fracture. Journal of Pain \& Symptom Management. 2000;19(4):240-248.

21. Scherder E, Oosterman J, Swaab D, et al. Recent developments in pain in dementia. BMJ. 2005;330(7489):461-464.

22. Gagliese L, Melzack R. Chronic pain in elderly people. Pain. 1997;70(1):3-14.

23. Galiese L. Assessment of pain in elderly people. In: Turk DC, Melzack R, eds. Handbook of Pain Assessment. 2 ed. New York-London: The Guilford Press; 2001:119-133.

24. Herr KA, Garand L. Assessment and measurement of pain in older adults. Clinics in Geriatric Medicine. 2001;17(3):457-478.

25. Parmelce PA, Smith B, Katz IR. Pain complaints and cognitive status among elderly institution residents. Journal of the American Geriatrics Society. 1993;41(5):517-522.

26. Cohen-Mansfield J, Creedon M. Nursing staff members' perceptions of pain indicators in persons with severe dementia. Clinical Journal of Pain. 2002;18(1):64-73.

27. Chambers CT. The application of measurement tool to the assessment of pain in children with cognitive impairments: What has been accomplished and what more is there to do? Paper presented at: Paper presented at the conference on pain with significant neurological impairment., 2000; Toronto.

28. Hadjistavropoulos T, Von Baeyer $\mathrm{C}$, Craig $\mathrm{KD}$. Pain assessment in petsons with limited ability to communicate. In: Turk DC, Melzack R, eds. Handbook of Pain Assessment. 2 ed. New York-London: The Guilford Press; 2001; 2001:134-150.

29. Parke B. Gerontological nurses' ways of knowing. Realizing the presence of pain in cognitively impaired older adults. Journal of Getontological Nursing. 1998;24(6):21-28.

30. Hurley AC, Volicer BJ, Hanrahan PA, Houde S, Volicer L. Assessment of discom fort in advanced Alzheimer patients. Research in Nursing \& Health. 1992;15(5):369-377.

31. Decker SA, Perry AG. The development and testing of the PATCOA to assess pain in confused older adults. Pain Management Nursing. 2003;4(2):77-86.

32. Streiner DI, Norman CR. Health measurement scales. A practical guide to their development and use. Oxford: University Press; 2003.

33. Wary B, Doloplus C. Doloplus-2, une echelle pour evaluer la douleur. Soins. Getontologie. 1999(19):25-27.

34. Lefebre-Chapiro L. Doloplus group: The Doloplus 2 scale-evaluating pain in the elderly. European Journal of Palliative Care. 2001;8(5):191-194.

35. Wary B, Serbouti S, collectif: D. Validation d'une échelle d'évaluation comportemen tale de la douleur chez la personne âgée. Douleurs. 2001;2(1):35-38.

36. Gauvain Piquard A, Pichard Leandri E. La douleur chez l' enfant. Paris: Medsi McGraw Hill; 1989.

37. Michel M, Capriz I; Gentry A, et al. Doloplus 2, une échelle comportementale de la douleur valide chez la personne âgée. La Revue de Gériatrie. 2000;25(3):155-160. 
38. Serbouti S, Rat P, Passadori Y. Validation of DOLOPLUS. A pain assessment tool for non-verbal or cognitively impaired elderly patients [abstract]. IASP congrcss, 2002; San Diego.

39. Simons W, Malabar R. Assessing pain in elderly patients who cannot respond ver bally. Journal of Advanced Nursing. 1995;22(4):663-669.

40. Jean A, Morello R, Alix M. Evaluation de la douleur de sujet très âgé hospitalise en long séjour. La Revue de Gériatrie. 1998;23(3):253-256.

41. Morello R, Jean A, Alix M. LÉCPA: une échelle comportementale de la douleur pour personnes âgées non communicantes. InfoKara. 1998;51(3):22-29.

42. Kunz R. Palliative medizin für ältere menschen. Schweiz Med Forum. 2002;5:100105.

43. Quintrec Le JL, Maga M, Baulon A. L'échelle comportementale simplifiée (E.C.S.). La Revue de Gériatrie. 1995;20(6):363-368.

44. Keefe FJ, Block $\Lambda$ R. Development of an observation method for assessing pain in chronic low back pain patients. Behavioural Therapy. 1982;3:363-375.

45. Feldt KS. The checklist of nonverbal pain indicators (CNPI). Pain Management Nursing. 2000;1(1):13-21.

46. Richards JS, Nepomuceno C, Riles M, Suer Z. Assessing pain behavior: the UAB Pain Behavior Scale. Pain. 1982;14(4):393-398.

47. Fuchs SK, Hadjistavropoulos T, McGrath PJ. Psychometric development of a pain assessment scale for older adults with severe dementia: a report on the first two studies [abstract]. IASP congress, 2002; San Diego.

48. Fuchs-Lacelle S, Hadjistavropoulos T. Development and prcliminary validation of the pain assessment checklist for seniors with limited ability to communicate (PACLAC). Pain Management Nursing. 2004;5(1):37-49.

49. Lane P, Kuntupis M, MacDonald S, et al. A pain assessment tool for people with advanced Alzheimer's and other progressive dementias. Home Healthcare Nurse. 2003;21(1):32-37.

50. Warden V, Hurley AC, Volicer I. Development and psychometric evaluation of the Pain Assessment in Advanced Dementia (PAINAD) scale. Journal of the American Medical Directors Association. 2003;4(1):9-15.

51. Merkel SI, Voepel-Lewis T, Shayevitz JR, Malviya S. The FLACC: a behavioral scale for scoring postoperative pain in young children. Pediatric Nursing. 1997;23(3):293-297.

52. Villanueva MR, Smith TL, Erickson JS, Tee AC, Singer CM. Pain Assessment for the Dementing Elderly (PADE): reliability and validity of a new measure. Journal of the American Medical Directors Association. 2003;4(1):1-8.

53. Sign B, Orrell $M$. The development, validity and relaibility of a new scale for tating pain in dementia (RaPID). 2003.

54. Abbey J, Piller N, De Bellis A, et al. The Abbey pain scale: a 1-minute numerical indicator for people with end-stage dementia. International Journal of Palliative Nursing. 2004;10(1):6-13.

55. Snow AL, Weber JB, O'Malley KJ, et al. NOPPAIN: a nursing assistant-administered pain assessment instrument for use in dementia. Dementia \& Geriatric Cognitive 
Disorders. 2004;17(3):240-246.

56. Davies E, Male M, Reimer V, Turnet M. Pain assessment and cognitive impairment: part 2. Nursing Standard. 2004;19(13):33-40.

57. Davies L, Male M, Reimer V, Turner M, Wỵlie K. Pain assessment and cognitive impairment: part 1. Nursing Standard. 2004;19(12):39-42.

58. Bergh I, Sjostrom B. A comparative study of nurses' and elderly patients' ratings of pain and pain tolerance. Journal of Gerontological Nursing. 1999;25(5):30-36.

59. Ramelet AS, Abu-Saad HH, Rees N, McDonald S. The challenges of pain measurement in critically ill young children: a comprehensive review. Australian Ctitical Care. 2004;17(1):33-45.

60. AGS Panel on Persistent Pain in Older Persons. The management of chronic pain in older persons: AGS Panel on Chronic Pain in Older Persons. American Geriatrics Society. Journal of the American Geriatrics Society. 1998;46(5):635-651.

61. Scherder E, Bouma A, Slaets J, et al. Repeated pain assessment in Alzhcimer's disease. Dementia \& Geriatric Cognitive Disordets. 2001;12(6):400-407.

62. Scherder EJ, Slaets J, Deijen JB, et al. Pain assessment in patients with possible vascular dementia. Psychiatry. 2003;66(2):133-145. 


\section{Chapter 4}

The psychometric quality and clinical usefulness of three pain assessment tools for elderly people with dementia

This chapter was published as:

Zwakhalen SM, Hamers JP, Berger MP. The psychometric quality and clinical usefulness of three pain assessment tools for elderly people with dementia. Pain. 2006;126(1-3):210-220.

(nominated for the Care And Public Health Research Institute 2007 Philipsen Award for best publication 2005/2006) 


\section{ABSTRACT}

T $\mathrm{n}$ view of the need for valid, reliable, and clinically useful scales to assess pain I in elderly people with dementia, this study evaluated the psychometric properties of translated versions of the PAINAD, PACSI.AC, and DOI.OPLUS-2 scales. In an observational study design, two raters simultaneously assessed the nursing home residents $(n=128)$ for pain during influenza vaccination and care situations.

The PACSLAC was valued as the most useful scale by nurses. Cronbach's alpha was high $(>.80)$ for the total scale at $\mathrm{T} 2$ and $\mathrm{T} 3$ and adequate for the 'Facial expression' and 'Social/personality/mood' subscales. IC scores for the 'Activity/body movement' and 'Physiological indicators/eating/sleeping changes/vocal behaviors' subscales were low. It demonstrated good validity and reliability, although the scale should be further refined. This refinement should increase homogeneity. The PAINAD showed good psychometric qualities in terms of reliability, validity and homogeneity ( $\alpha$ ranged .69 to .74 at T2 and T3) (except for the 'Breathing' item). The PAINAD scale had lower scores for clinical usefulness in this sample. The Dutch version of the DOLOPLUS-2 was considered more difficult to use but showed acceptable psychometric qualities in terms of the issues assessed, except for the 'psychosocial reactions' subscale. IC of the DOLOPLUS were adequate for the total scale ( $\alpha$ ranged .74 to .75) and almost all subscales ( $\alpha$ ranged $.58-80$ ). Findings of this study provide evidence of validity and reliability of the three pain assessment scales. Now that a pain scale is available, future studies also need to focus on its implementation in nursing practice. 


\title{
INTRODUCTION
}

\begin{abstract}
A geing is known to be associated with high prevalences (up to $80 \%$ ) of persistent pain among those living in nursing homes. ${ }^{1+4}$ Assessing pain is crucial, as inadequate assessment could mean that pain remains under-detected and under-treated, with negative effects on quality of life. However, measuring pain is often extremely difficult, especially in people with dementia. Several factors might contribute to the complexity of this assessment. First, dementia is a syndrome characterized by progressive decline in cortical functions." This may reduce a person's ability to interpret and report pain. Moreover, behavioral and psychological repertoires of elderly people with dementia can be very heterogeneous. Just as in cognitively impaired children, behavior that is typically associated with pain (like yelling) may well appear in non-painful situations, or behavioral limitations may mask expressions of pain." In addition, increasing age is often associated with increasing somatic and physical problems, limiting people in their ability to express pain.
\end{abstract}

In the last decade, several observational scales have been developed to measure pain in (severely) demented people. A review of the literature identified twelve observational pain scales, whose psychometric qualities have been evaluated.' Findings of this review indicate that most observational scales are still under development and show moderate psychometric qualities. Most scales lack validity, reliability, and clinical usefulness. Nevertheless, the findings demonstrated that PAINAD, PACSLAC, and DOLOPLUS-2 showed promising psychometric qualities, though they required further testing.

Until now, no Dutch pain assessment scale is available to reliably and validly measure pain in nursing home settings. The number of newly developed behaviotal scales has grown rapidly and in view of this growth, it seemed useful to adapt and improve these scales for use in the Netherlands, instead of developing a new tool. Therefore, three scales were translated. A backwardforward method was used in the translation procedure to adapt these scales for use in Dutch nursing home settings. Translated scales were finally adjusted based on the results of pre-testing to investigate nurses' opinion on their clinical usefulness (Zwakhalen et al., in preparation). The final versions of the translated scales were used in the present study.

This study was thus initiated to evaluate the psychometric properties of three translated pain assessment scales (PAINAD, PACSLAC, and DOLOPLUS-2) in nursing home practice, using potentially painful situations.

More specifically, this study addressed the following research questions:

- What items of the translated PAINAD, PACSLAC, and DOLOPLUS 2 scales are most frequently used to assess pain in elderly nursing home 
patients with dementia?

- Are the translated versions of the scales and subscales internally consistent?

- Are the translated versions of the scales reliable (in terms of inter-rater and intra-rater reliability)?

- Do the translated versions of the scales show good construct validity using a known-groups technique?

- Do the translated versions of the scales show good congruent-validity?

- How do nurses rate the clinical usefulness of the scales?

\section{METHODS}

Design

An observational study design was used to answer the research questions. Observations were carried out with patients at rest and during potentially painful situations / interventions. All patients were observed while receiving their influenza vaccination and a selection of patients were also observed at a patientspecific pain moment (like care, washing or mobilization). In prior pain research, ${ }^{k .9}$ injections have been successfully used as potentially painful stimuli.

\section{Participants}

The study involved 144 nursing home patients, including 128 demented patients of 12 psycho-geriatric (PG) wards and 16 somatically ill nursing home patients of one ward receiving their annual planned influenza vaccination. This group of somatically ill patients was included to serve as a control group for pain intensity scores (using a VAS only) during the influenza injection.

To be included, elderly residents with dementia had to have been living in the nursing home for at least 4 weeks prior to the influenza vaccination. Patients were at least 60 years old and had not undergone major environmental changes in the last month. Excluded were patients with acute medical illness or a purely psychiatric disorder and patients with Korsakov's syndrome. The type of dementia syndrome as well as the severity of the impairment varied.

Twelve nurses of three nursing homes in the Netherlands participated in this study.

\section{Measures}

A data sheet was used to collect demographic and additional information about medication use (analgesics and psycho-tropics), environmental changes during the last month, and type of dementia diagnoses. Information was obtained from patients' medical and nursing records. 
The patients' cognitive status was evaluated using the Minimum Data Set (MDS) Cognitive Performance Scale (CPS)."' The CPS combines fives MDS items relating to cognitive functioning, eventually yielding seven categories of cognitive impairment." The MDS-CPS has been validated against the MiniMental State Examination (MMSE)' ${ }^{12}$ and showed substantial agreement. ${ }^{11}$

The present study used Dutch versions of three selected pain assessment scales (DOLOPLUS-2, PAINAD, and PACSLAC).

The DOLOPLUS-2 scale by Wary et al. ${ }^{13,14}$ consists of 10 items covering the somatic, psychomotor, and psychosocial impacts of pain. Each of the ten items can be described at one of four different levels - rated from 0 to 3 - representing increasing intensity of pain. ${ }^{15}$ A score of at least 5 out of 30 (the maximum pain score) is considered to indicate pain. Several studies have been conducted in geriatric centers and palliative care units to validate the scale, investigating testretest reliability, concurrent validity, and inter-rater reliability. ${ }^{16,17}$ According to the authors, the findings showed convergent validity of the DOLOPLUS-2 with a VAS and that DOLOPLUS-2 demonstrated good sensitivity. There was satisfactory stability on the retest. An inter-rater correlation test between two physicians showed no significant difference $(p<0.001)$ and high levels of internal consistency $(\alpha=0.82)$ were found. However, the publications about the DOLOPLUS-2 provide almost no concrete information about correlation coefficients (inter-rater reliability, test-retest reliability) and about the determination of cut-off-scores and the impairment level of the participants. ${ }^{7}$

The Pain Assessment Checklist for Seniors with Limited Ability to Communicate (PACSLAC) by Fuchs et al..$^{18,19}$ consists of 60 items covering four sub-scales. PACSLAC, which is still under construction, has good content validity. The PACSLAC developers collected items specifically indicating pain in elderly people with dementia.7 PACSLAC has been the subject of a partial, preliminary validation study. High levels of internal consistency were found for the total scale ( $\alpha=0.82-0.92)$, although Cronbach's $\alpha$ values for the subscales were lower (.55-.73). Therefore, the developers of the PACSLAC scale recommended use of the total score only. "The PACSLAC total score seemed to discriminate between painful, calm, and distressing events. Correlations calculated between global intensity ratings and PACSLAC scores were moderate $(r=.39-.54)$. Correlations among the subscales suggest that although the checklist measures a unified construct, the subscales are sufficiently discriminatory."

The Pain Assessment IN Advanced Dementia Scale (PAINAD) by Warden et al." can be described as a modification of the Discomfort Scale for Patients with Dementia of the Alzheimer Type (DS-DAT). ${ }^{21}$ The current version consists of five items with three response options scored from 0 to 2 . The instrument has been tested in a residential setting (dementia care ward) involving 19 severely 
impaired patients. Although Warden et al. reported high levels of inter-rater reliability (Pearson $r=.82-.97$ ), internal consistency was below $\alpha<.70$. The scale showed evidence of construct validity. The tool correlated well with the DSDAT $(r=.76)$, a VAS for discomfort $(r=.81)$, and a VAS for pain $(r=.75)$. Pain scores were found to be lower during pleasant than during aversive activities and scores differed before and after pain modification..$^{20,22}$

In our study, a Visual Analogue Scale (VAS) was used by nurses and an independent rater (rater 1) to estimate the pain intensity. A VAS is a $100 \mathrm{~mm}$ line on which pain can be marked with anchors at either end. The left hand anchor was labeled 'no pain at all' and the right hand anchor was labeled 'pain as bad as it could possibly be'.2.3 VAS is frequently used in pain studies as a self-report scale or for proxy reports of pain.

We used two self-report scales to assess pain in our elderly patients with dementia, namely a Verbal Rating Scale (VRS) ${ }^{23}$ and the Color Analogue Scale (CAS) developed by McGrath et al. ${ }^{2+}$ The CAS is a colored variant of the VAS developed as a pain intensity scale for children. The VRS consists of a list of adjectives describing various levels of pain intensity ${ }^{23}$ using a 4-point scale ranging from 0 (no pain) to 3 (severe pain), and was also used as a self-report scale. CAS and VRS have demonstrated their usefulness and showed adequate to high completion rates in previous research on pain assessment in elderly people with various types of dementia. ${ }^{25,26}$

Information on pain was also gathered using the Residents Assessment Instrument (RAI) Minimum Data Set (MDS), of which we applied the items on pain frequency (J2a), pain intensity (J2b), and location of pain (J3). ${ }^{10}$

To assess the usefulness of the three scales (DOLOPLUS, PACSLAC, and PAINAD), nurses were asked which scale they considered most useful and which scale they preferred. A 10-point scale was used for scoring the clinical usefulness. Finally, nurses had the opportunity to comment on the scales (on aspects like confusing items, overlapping information and scoring difficulties).

\section{Procedure}

Two raters (rater 1 and rater 2) simultaneously assessed the patients' pain at rest (T1) and during vaccination (T2). A selected group of patients was also assessed during a specific moment (T3). Observations of the first two moments lasted for approximately 2 minutes and were conducted on the same day. To avoid differences in scores due to developments over time, the time interval between $\mathrm{T} 2$ and T3 was minimized, and was mostly shorter than 3 weeks.

Demographic information was gathered by the nurse when residents were at rest (T1). At T1, T2, and T3, the VAS and pain assessment scales (PACSLAC and 
PAINAD) were scored in random order immediately after the patient had been observed. Because DOLOPLUS-2 does not represent pain experience at a specific moment but reflects the progression of pain experienced, the DOLOPLUS-2 scale was scored last, at a separate time after the observations. Because the DOLOPLUS-2 cannot be used without in-depth knowledge of the patient, the DOLOPI.US-2 was the only scale that was not scored simultaneously (in the absence of rater 1 scores). Patients were questioned about their current pain intensity immediately after all moments, using CAS and VRS at random. At T3, participants underwent a variety of specific potentially painful interventions (like care activities, washing or mobilization). Patients who, in the opinion of the nurses involved, were not expected to be in pain at specific moments were not assessed a third time.

Clinical usefulness was assessed last, after the nurses had used all scales for all participants at their ward. An overview of the measures used at particular moments by the raters is presented in Table 1.

Table 1 Overview of measures used by the raters at various moments

\begin{tabular}{|c|c|c|c|c|c|c|c|}
\hline & \multicolumn{4}{|c|}{$\begin{array}{l}\text { Live rating at } \\
\text { the bedside }\end{array}$} & \multicolumn{3}{|r|}{$\begin{array}{l}\text { Retrospective } \\
\text { rating }\end{array}$} \\
\hline & \multicolumn{2}{|c|}{$\begin{array}{l}\text { Moment at } \\
\text { rest (T1) }\end{array}$} & \multicolumn{2}{|c|}{$\begin{array}{c}\text { Moment of } \\
\text { injection (T2) }\end{array}$} & \multicolumn{2}{|c|}{$\begin{array}{c}\text { Specific moment } \\
\text { (T3)* }\end{array}$} & \multirow[t]{2}{*}{$\begin{array}{l}\text { Video recor } \\
\text { ding (T4) }\end{array}$} \\
\hline & Nurse & Rater 1 & Nurse & Rater 1 & Nurse & Rater 1 & \\
\hline \multicolumn{8}{|l|}{ Measures } \\
\hline $\begin{array}{l}\text { Data sheet incl. } \\
\text { MDS-CPS }\end{array}$ & $\mathrm{x}$ & & & & & & \\
\hline VAS pain & $\mathrm{x}$ & $\mathrm{x}$ & $\mathrm{x}$ & $\mathrm{x}$ & $\mathrm{x}$ & $\mathrm{x}$ & $\mathrm{x}$ \\
\hline PAINAD & $\mathrm{x}$ & $\mathrm{x}$ & $\mathrm{x}$ & $\mathrm{x}$ & $\mathrm{x}$ & $\mathrm{x}$ & $\mathrm{x}$ \\
\hline DOLOPLUS & $\mathrm{x}$ & & & & $\mathrm{x}$ & & \\
\hline PACSLAC & $\mathrm{x}$ & $\mathrm{x}$ & $\mathrm{x}$ & $\mathrm{x}$ & $\mathrm{x}$ & $\mathrm{x}$ & $\mathrm{x}$ \\
\hline $\begin{array}{l}\text { Clinical usefulness } \\
\text { evaluation } \$\end{array}$ & & & & & $x$ & & \\
\hline
\end{tabular}

* this observational moment was not included for all patients; selection was based on nurses' estimation of pain potentially occurring at a specific moment

\$ Usefulness was assessed after all scores had been obtained (at T2 or T3) 
Videotaping

Video recordings were obtained by a research assistant for every patient, after approval had been obtained from legal guardians. The observational moments were videotaped, as part of the study, to test the inter-rater reliability. Video recordings were made from an estimated distance of $2.5 \mathrm{~m}$ and were conducted in the patients' customary environment. Videotaping was once intertupted in a situation where the patients showed resistance to taping.

\section{Ethical considerations}

The study was approved by the Medical Ethics Committee of the University Hospital Maastricht and the University of Maastricht. Permission to conduct the study was also obtained from the managing directors of the nursing homes. Approached nurses participated on a voluntary basis.

Before participation, registered legal guardians of the residents provided written informed consent. One of the response options provided on the informed consent form was participating in the study but refusing videotaping (with $26.6 \%$ of the legal guardians refusing videotaping).

\section{Analyses}

Descriptive statistics were generated for the characteristics of the respondents, as well as for examining the clinical usefulness. Frequency of endorsement ratings were also computed using descriptive statistics to examine the frequency with which various items were used.

Internal consistency (IC) analyses were carried out, the IC of the scales and subscales being determined using Cronbach's alpha. Inter- and intra-rater reliability for the pain scores was measured by intra-class correlation coefficients (ICCs). The two-way mixed consistency method was used to examine the intrarater reliability, since these scores focus on results within the study. In order to allow generalization of tesults, the two-way random absolute agreement method was used to examine the inter-rater reliability, which compensates for an extra source of variance due to differences between raters.

Construct validity was examined using the known groups technique." On the assumption that higher pain scores would lead to higher sum scores on the PAINAD and PACSLAC, mean scores were calculated. Pain versus non-pain groups were created (assuming that pain at T2 is higher than at $\mathrm{T} 1$ and based on VAS scores, viz. VAS $=0$ versus VAS $>=30$ ). To examine the construct validity of the DOLOPLUS-2, pain versus non-pain group were created in slightly different manner because DOLOPLUS-2 scores cannot be collected specifically in a context like an observational moment during care. Therefore groups were created based on information about 'no pain' versus 'daily pain' derived from the MDS scale (pain frequency).

Finally, in order to determine congruent validity, Pearson correlations were computed between the measures. Congruent validity was implied by high correlations between PAINAD and PACSLAC, since the instruments both claim to be adequate pain measures. A moderate to high correlation was expected with the VRS and VAS scores produced by the various raters. 


\section{RESULTS}

\section{Participants}

A total of 128 nursing home patients with dementia participated in this study, $21.9 \%(n=28)$ men and $78.1 \%(n=100)$ women. Ages ranged from 60 to 96 years, with a mean age of $82.4(\mathrm{SD}=6.8)$. Sixteen somatically ill patients with an average age of 78.1 years also participated in this study, five men and 11 women.

Nursing staff $(n=12)$, mostly female $(n=10)$, ranged in age from 18 to 51 years (mean=34.3: $\mathrm{SD}=9.6$ ). The mean number of years of experience in nursing was $10.2(\mathrm{SD}=5.2)$. Table 2 presents further information on the participants' characteristics.

Analyses focused firstly on detailed information on the pain situation. Based on descriptive information derived from the MDS item on pain or pain (frequency), 25\% of the psycho-geriatric (PG) residents experienced pain on a daily basis, while $17.2 \%$ of the residents experienced pain less frequently than daily. Perceived pain intensity scores showed that of those residents frequently experiencing pain (42.2\%), 14.1\% had only mild pain, $22.7 \%$ experienced moderate pain, and 5.5\% experienced unbearable pain now and then. MDS findings indicated that the most frequently mentioned pain locations were joints $(23.4 \%)$, other places $(10.9 \%)$, soft tissues $(7.8 \%)$, back $(3.9 \%)$, bones $(3.1 \%)$, and hips (3.1\%). Further investigation of the MDS item on pain frequency showed that almost $35 \%$ of the people who suffered daily pain received no pain medication at all.

\section{Observed moments}

A total of 128 participants with a dementia syndrome were observed on 290 occasions, including moments of rest $(\mathrm{T} 1, \mathrm{n}=128)$, immediately after the influenza vaccination ( $T 2, n=127)$, and immediately after a patient-specific moment of potential pain $(T 3, n=35)$. Most $T 3$ observational moments were while patients were being washed in the morning $(n=19)$. Other T3 moments included transfer situations during care $(n=3)$, manipulation of the hand $(n=4)$, and wound care $(\mathrm{n}=1)$.

Because most observations and ratings were carried out simultaneously by the nurses and rater 1, a total of 573 (7 missing) scores were gathered. The data were not normally distributed, since scores were frequently clustered around zero, especially at $\mathrm{T} 1$ and $\mathrm{T} 2$.

\section{Frequencies of endorsed itemis and internal consistency}

Item usage was assessed by calculating frequency of endorsement tates for items of the pain assessment scales for participants with a VAS greater than or equal to 30 ( $n=53$ moments). Given the fact that rater 1 was the consistent factor in all patient ratings, these VAS ratings were used.

The most frequently used items of the PACSLAC and PAINAD scales for patients with a VAS scored by rater 1 as $>=30$ are listed in Table 3. 
Table 2 Descriptive information on the nursing home residents and nurses

Characteristics of somatic residents $(n=16)$

Male / Female

$5 / 11$

Age in years (SD)

$78.1(10.6)$

Characteristics of $P G$ residents $(n=128)$

Male / Female

$28 / 100$

Age in years (SD)

$82.4(6.8)$

Severity of the impairment $n=(\%)$

mild, CPS $<=2$

$28(21.9 \%)$

moderate to moderately severe, $C P S=3$ or 4

$36(28.1 \%)$

$61(47.7 \%)$

severe to very severe, $\mathrm{CPS}=5$ or 6

$3(2.3 \%)$

Dementia diagnosis $n=(\%)$

Alzheimer's disease

$41(32.0 \%)$

Vascular dementia

$24(18.8 \%)$

Other (e.g. Parkinson's disease, frontal lobe)

$7(5.5 \%)$

Mixed (Alzheimer's / vascular)

$5(3.9 \%)$

Unknown

$51(39.8 \%)$

Medication (analgesic and psycbotropic) $n=(\%)$

Analgesic

$\begin{array}{ll}\text { none } & 85(66.4 \%) \\ \text { regular } & 32(25.0 \%) \\ \text { when necessary } & 8(6.3 \%) \\ \text { daily and when necessary } & 2(1.6 \%)\end{array}$

Psychotropic

$\begin{array}{ll}\text { none } & 58(45.3 \%) \\ \text { regular } & 65(50.8 \%) \\ \text { when necessary } & 1(0.8 \%) \\ \text { daily and when necessary } & 3(2.3 \%)\end{array}$

Characteristics of nurses ( $n=12)$

Male / Female

Age in years (SD)

$34.3(9.6)$

Years of experience in nutsing (SD

$10.2(5.2)$

Educational level

Nurses (RN) / caregivers 
Table 3 Most frequently used items of PACSLAC and PAINAD (VAS rater $1>=30$ )

\section{M2 M3}

\begin{tabular}{|c|c|c|c|}
\hline Scale & Items & $\%$ scored by rater 1 & $\%$ scored by rater 1 \\
\hline \multirow[t]{19}{*}{ PACSLAC } & tighter face & 96.4 & 100 \\
\hline & change in eyes & $96.4 *$ & 78.3 \\
\hline & pain expression & 82.1 & 69.6 \\
\hline & frowning & 75 & 78.3 \\
\hline & creasing forehead & $75 *$ & 65.2 \\
\hline & $\begin{array}{l}\text { specific sound or } \\
\text { vocalisation for pain }\end{array}$ & 71.4 & 65.2 \\
\hline & grimacing & 46.4 & 69.6 \\
\hline & moaning and groaning & 46.4 & 69.6 \\
\hline & pulling away & 46.4 & 47.8 \\
\hline & opening mouth & $42.9 *$ & 43.5 \\
\hline & mumbling & $32.1 *$ & 17.4 \\
\hline & not wanting to be touched & 28.6 & 43.5 \\
\hline & upset & 28.6 & 21.7 \\
\hline & restless & 25 & 30.4 \\
\hline & flushed / red face & 25 & 21.7 \\
\hline & flinching & 25 & 4.3 \\
\hline & anxious & 21.4 & 39.1 \\
\hline & clenching teeth & 17.9 & 43.5 \\
\hline & stiff/rigid & 14.3 & 30.4 \\
\hline \multirow[t]{3}{*}{ PAINAD } & facial expressions & 92.9 & 95.7 \\
\hline & body language & 89.2 & 95.7 \\
\hline & negative vocalization & 75 & 92.3 \\
\hline
\end{tabular}

* also frequently present (> 15\%) during a non-painful situation (VAS =0) 
In a painful situation (VAS $>=30$ ), 28 of the 60 items of the translated version of the PACSLAC were not used for over $90 \%$ of the study participants, neither by rater 1 nor by the nurses who scored at the bedside. This indicates that these items could be 'less likely' candidates for inclusion in a general pain instrument for the target group of elderly people with dementia. For over $80 \%$ of the study participants, both raters did not use the item 'breathing' in PAINAD in painful situations (VAS $>=30$ ).

For each of the scales (PACSLAC, PAINAD, and DOLOPLUS-2) and the subscales of the PACSLAC, Cronbach's alpha was calculated to examine the homogeneity of the scale items. The resulting values are shown in Table 4.

The lowest internal consistency (IC) scores were found for the 'activity and body movement' subscale (ranging from .40 to .57) and the 'physiological indicators / eating / sleeping changes / vocal behaviors' subscale (ranging from .20 to .43), both of the PACSLAC. Although Cronbach's alpha for the total scale was high, it is positively influenced by the large number of scale items ( $n=60$ items).

Overall analyses showed adequate levels of IC for the PAINAD instrument at T2 and T3, ranging from .69 to .74. Corrected item-total correlations showed that the 'breathing' item scored persistently low at all moments (ranging from -.51 to .12$)$.

IC scores of the DOLOPLUS-2 were adequate for almost all subscales (ranging from .58 to .80) and for the total scale (ranging from .74 to .75). Cronbach's alpha $(.58$ - .63) was moderate for the 'psychosocial reactions' subscale but corrected item-total correlations never scored below 20 .

\section{Reliability of the translated scales}

To examine inter- and intra-rater reliability, ICCs were calculated for the VAS, PAINAD, and PACSLAC. Inter-rater reliability was calculated between rater 1 and the nurses (mean scores) and was found to be high for all measures, including the VAS. Compared to the two behavioral scales, the VAS scored slightly lower. Furthermore, irrespective of the measure used, agreement was less perfect at T1 (moment of rest). Further analyses examined the differences between pairs of raters/observers. These analyses showed some remarkable variability in the inter-rater reliability between individual pairs of raters. Examining T2 specifically, inter-rater agreement between scoring pairs on the VAS ranged from -.32 to .97 , those on the PAINAD from .00 to .95 , and those on the PACSLAC total scale from .39 to .97.

Intra-rater reliability was assessed by comparing the scores allocated by rater 1 at the bedside with those allocated by re-scoring the same moments based on video recordings ( $\mathrm{n}=29$ scenes). Intra-rater reliability scored high for all measures included. Reliability scores are presented in Table 5. 
Psychometric testing pain torls

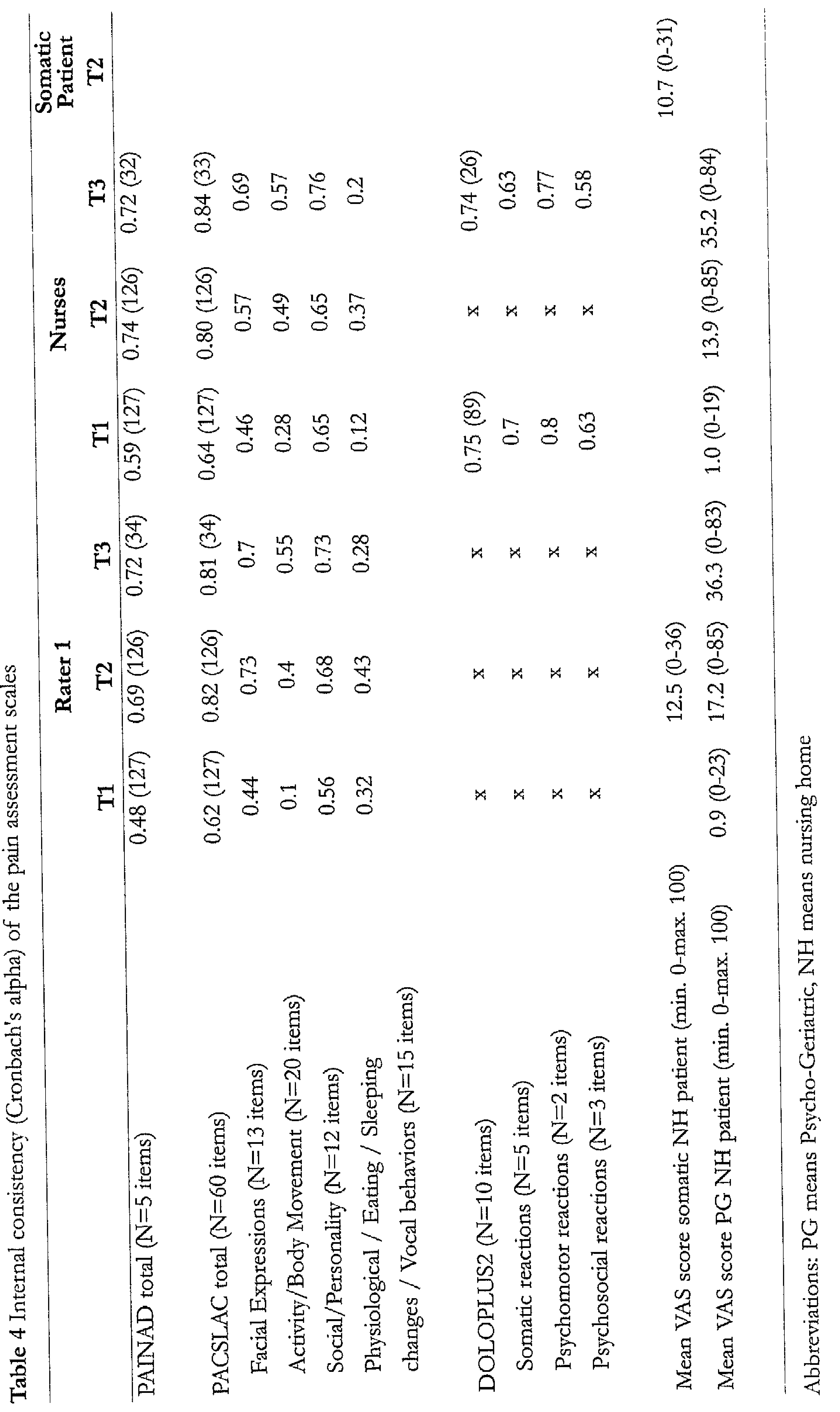


Table 5 Inter- and intra-rater reliability of the PAINAD, PACSL AC and VAS scores

\begin{tabular}{|c|c|c|c|c|}
\hline \multicolumn{4}{|c|}{ inter-rater \# } & \multirow[t]{2}{*}{ inter-rater * } \\
\hline & $\mathrm{T} 1$ & $\mathbf{T} 2$ & T3 & \\
\hline PAINAD total $(\mathrm{N}=5$ items $)$ & 0.75 & 0.85 & 0.81 & 0.89 \\
\hline PACSLAC total $(\mathrm{N}=60$ items) & 0.93 & 0.95 & 0.96 & 0.86 \\
\hline Facial Expressions ( $N=13$ items) & 0.95 & 0.96 & 0.91 & 0.92 \\
\hline Activity/Body Movement ( $N=20$ items) & 0.77 & 0.85 & 0.92 & 0.72 \\
\hline Social/Personality $(\mathrm{N}=12$ items $)$ & 0.91 & 0.94 & 0.95 & 0.89 \\
\hline $\begin{array}{c}\text { Physiological / Eating / Sleeping changes/ } \\
\text { Vocal behaviors ( } N=15 \text { items) }\end{array}$ & 0.90 & 0.91 & 0.83 & 0.89 \\
\hline VAS score & 0.69 & 0.86 & 0.78 & 0.85 \\
\hline
\end{tabular}

\# Two way random absolute agreement intra-class correlation

* Two way mixed consistency intra-class correlation

\section{Validity of the translated scales}

To examine the ability of the translated scales to detect pain, total scores for different pain moments were compared, based on the assumption that more pain would increase the number of observed behaviors and hence the total scores on the PAINAD and PACSLAC scales. Pain versus non-pain groups were created. Higher VAS scores at T2 and T3 confirmed that pain was more prevalent at these moment than at T1 (at rest). In addition, pain versus non-pain groups were also created on the basis of the patients' self-reports, rated by VRS.

Approximately half of the participants were able to use the VRS. The ability of the nursing home residents to complete a VRS differed between T1, T2, and T3. Completion rates were lowest at T1, when 78.6\% $(n=21)$ of the people with a mild cognitive impairment were able to complete the VRS, compared to $61.1 \%$ $(n=22)$ of the moderately impaired and $26.2 \%(n=16)$ of the severely impaired residents. At T2, 82.1\% $(\mathrm{n}=23)$ of mildly impaired, $77.1 \%(\mathrm{n}=27)$ of moderately impaired, and $37.7 \% \quad(n=23)$ of severely impaired residents were able to complete the VRS. At T3, 70\% $(n=7)$ of mildly impaired, $55.6 \% \quad(n=5)$ of moderately impaired, and $12.5 \%(n=2)$ of severely impaired residents were able to complete the VRS to report their pain intensity.

Results presented in Table 6 show a consistent upward trend, confirming the above hypothesis and supporting construct validity. 
Table 6 Mean total score on PAINAD and PACSLAC (rater 1)

\begin{tabular}{lcc} 
& PACSLAC & PAINAD \\
\hline VAS $<30$ & $3.2(0 ; 15)$ & Mean (min.; max.) \\
VAS 30-60 & $11.2(6 ; 22)$ & $0.6(0 ; 4)$ \\
VAS $>60$ & $15.0(10 ; 24)$ & $3.8(1 ; 6)$ \\
& & $5.9(3 ; 8)$ \\
M1 at rest & $2.6(0 ; 11)$ & $0.4(0 ; 4)$ \\
M2 injection & $5.5(0 ; 22)$ & $1.5(0 ; 7)$ \\
M3 specific moment & $9.6(1 ; 24)$ & $3.6(0 ; 8)$ \\
& & $0.3(0 ; 3)$ \\
VRS no pain & $2.1(0 ; 10)$ & $1.6(0 ; 5)$ \\
VRS minor pain & $5.6(1 ; 14)$ & $3.3(1 ; 6)$ \\
VRS moderate & $10.6(6 ; 13)$ & $4.7(2 ; 7)$ \\
VRS severe & $13.4(6 ; 20)$ & \\
\hline
\end{tabular}

Since DOLOPLUS-2 scores cannot be easily gathered after a specific observational moment, we examined the construct validity of the DOLOPLUS2 scale by comparing total DOLOPLUS-2 scores between a 'non-pain group' and a 'pain group'. Groups were created based on information about 'no pain' versus 'daily pain' derived from the MDS scale (pain frequency), with mean total scores in the 'daily pain' group obviously higher (mean 9.8; SD 6.0; tange 2-23) than those for the 'no pain group' (mean 5.1; SD 3.9; range 0-16).

Congruent validity was assessed by comparing the scores of the three translated behavioral pain scales with those from other pain measures (VAS scored by rater 1 , VAS scored by nurse, and VRS). Pearson correlations between PACSLAC, PAINAD, and other pain measures were all significantly positive. The magnitude of the correlations ranged from $r=.29$ to $r=.89$. The correlations were highest between the PAINAD scores and the VAS scores by rater 1 at the bedside. The correlation between PACSLAC and PAINAD scores was .85. As expected, low scores were found for the DOLOPLUS-2 compared to other pain measures. Findings confirm the difference between DOLOPLUS-2 as a pain measure and PAINAD and PACSLAC. Table 7 presents the congruent validity results. 
86

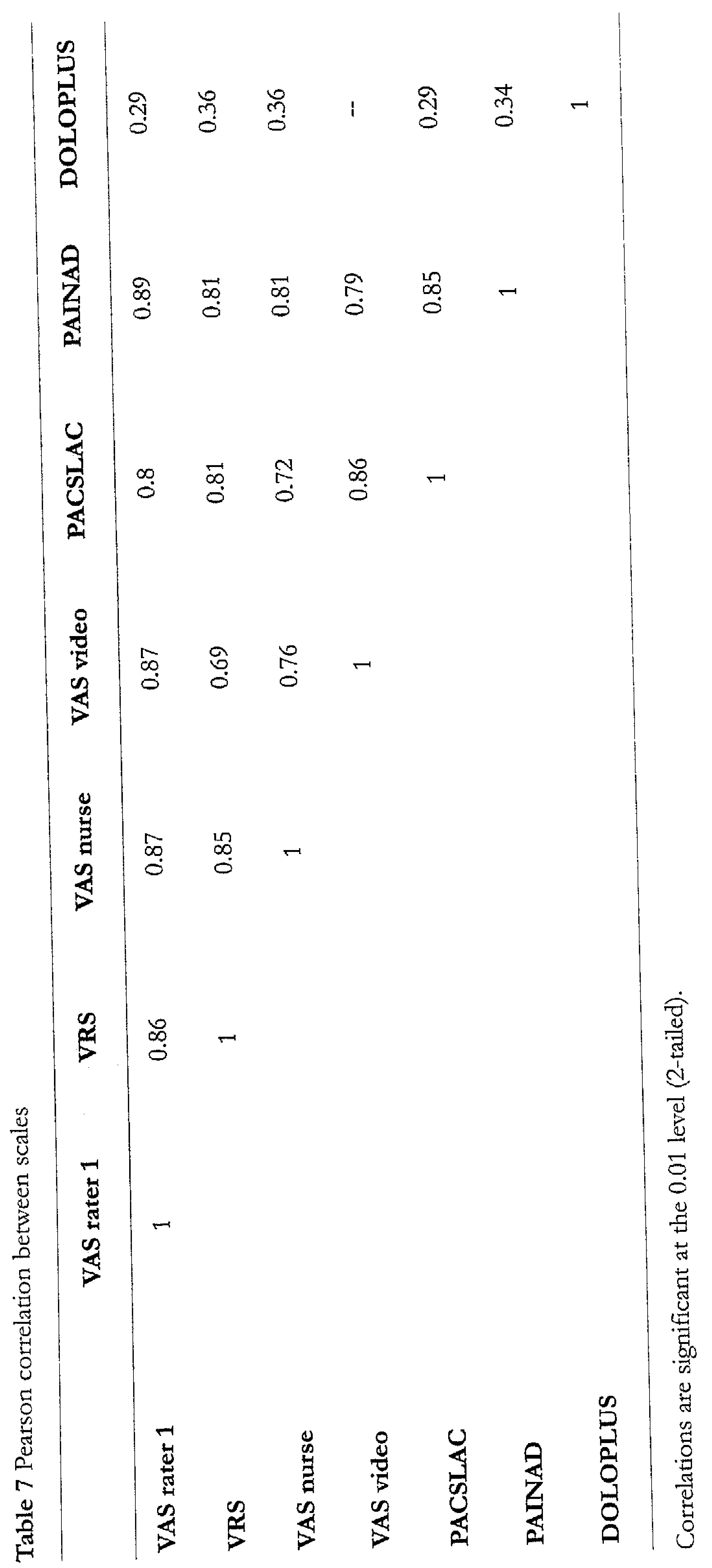




\section{CLINICAL USEFULNESS}

Finally, the nurses' ratings of clinical usefulness (scored on a 10-point scale) showed that $75 \%$ preferred the PACSLAC to measure pain in elderly residents with dementia. Mean scores were highest for the PACSLAC (mean 7.0; SD 0.5), while the PAINAD scored 5.89 (SD 1.7). The lowest usefulness scores were reported for DOLOPLUS-2 (mean 5.6; SD 2.2).

PAINAD and PACSLAC were considered user-friendly and not timeconsuming by the participating nurses. Once they were used to the scale, they could assess patients within a few minutes.

Qualitative information was gathered from the participating nurses who used the scales in this study. The following comments nurses wrote on the clinical usefulness evaluation form reveal some additional important information:

- $\quad$ PACSLAC is comprehensive, significant and specifies behavior. Items guide you towards certain possible pain cues. The current translated version of the PACSLAC contains many items. Several items are superfluous and other items overlap. PACSLAC is feasible for all nurses, no matter what their educational level is".

- "Although PAINAD is brief and well-structured, in order to detect pain, I expect a scale with specific cues. PAINAD is too concise".

- "DOLOPLUS-2 provides a more general view. A clear manual is pro vided. The scale is difficult to score and interpret. Its is questionable whether all items of the DOLOPLUS are relevant to detect pain. The psychosocial items in particular are difficult to interpret as solid specific pain behavior. Other causes, like the dementia itself, could explain a change in psychosocial behavior. This is also a possible problem with a few PACSLAC items".

\section{DISCUSSION}

The findings of this study provide evidence on the validity and reliability of three pain scales (PAINAD, PACSLAC, and DOLOPLUS-2) for nursing home residents with dementia.

Our main conclusions from the findings are as follows:

- The Dutch version of PACSLAC was valued as the most useful scale by care providers. It demonstrated good validity and reliability, although the scale should be further refined. This refinement should increase the homogeneity of the scale and subscales.

- The translated version of the PAINAD instrument showed good psychometric qualities in terms of homogeneity (except for the 'Breathing' item), reliability, and validity. The PAINAD scale had lower scores for clinical usefulness in this sample.

- The Dutch version of the DOLOPLUS-2 was considered more difficult 
to use but showed acceptable psychometric qualities in terms of the issues assessed, except for the 'psychosocial reactions' subscale.

\section{Reliability}

Cronbach's alpha for newly developed scales should be above .70.27 Our findings showed adequate levels of internal consistency for the PAINAD scale. Cronbach's alpha ranged from .69 to .74 at T2 and T3, moments when participants were more likely to be in pain. 'Breathing' was the poorest scoring item of the PAINAD, with a corrected item-total correlation below .2. Using the usual rule of thumb which says that the corrected item-total correlation should have a value of at least $.20,{ }^{28}$ this item could be discarded to increase Cronbach's alpha by approximately .50. Warden et al.," found similar results but decided to not discard this item because of the threat of respiratory diseases and the fact that changes in respiration have been mentioned in reaction to acute pain.

Although Cronbach's alpha was good (>.80) for the total PACSI.AC scale at $\mathrm{T} 2$ and $\mathrm{T} 3$ and adequate for two subscales, IC scores of the 'activity / body movement' and 'physiological indicators /etc.' subscales were low. The fact that many of the PACSLAC items were frequently not used and the item-total correlation was below 20 indicates that the number of items could be reduced. If items of the translated scale were discarded based on the following criteria: I. "(not) used in over $90 \%$ and II. item-total correlation below .20, then a number of 29 items would remain. Item reduction would clearly increase the internal consistency. If this item reduction is indeed implemented, we suggest performing an additional factor analysis. A few items, like 'refusing medication', were probably not observed due to the data collection method used.

Internal consistencies of the DOLOPLUS were adequate for the total scale (ranged $.74-.75$ ) and almost all subscales (ranged .58 -.80). Lowest internal consistencies were found for the 'psychosocial reactions' subscale. Hølen et al." recently translated the DOLOPLUS2 into Norwegian and pilot-tested it in patients with cognitive impairment. Their analyses showed that the psychosocial category in their study was also the weakest component.

The observational methodology used in our study was more adequate for evaluating the psychometric qualities of the PAINAD and the PACSLAC than for the DOLOPLUS. As a result, we were unable to determine the intra- and inter-rater reliability of the DOLOPLUS. Our findings showed good inter- and intra-rater agreement for the PAINAD and PACSLAC. Closer examination revealed that many pain scores still clustered around 0 , which may have influenced the agreement. Inter-rater agreement was mostly lower at T1 than at T2 and T3. This confirms that it is evidently harder to estimate a person's pain at rest or in a clinically normal situation without a specific stimulus.

\section{Validity}

The scales were able to detect differences between patients who were in pain or not in pain. Discriminating between pain and non-pain events is one of the most 
essential aspects of a useful tool. Our analysis of congruent validity found moderate to high correlations (.72-.89) between the VAS scores by the various raters and the behavioral scales. These high correlation rates between VAS and PAINAD are consistent with the result of a study by Warden et al." In a validation study on pain measures (recalling pain), Leong et al." found high correlations (Kendall's tau $=.842$ ) between PAINAD and nurses' pain reports. By contrast, other studies found lower correlations between self-report and behavioral scales. Hadjistavropoulos et al. ${ }^{31}$ found that their self-report measure was not related to the non-verbal scales and expressed the opinion that both measures assessed different parameters of pain experience. The high correlations found in our study could be due to the fact that the scales were tested in a controlled situation with an acute stimulus. Nurses were not blinded to the intervention (influenza injection). Another aspect may also be that we used the Pearson correlation coefficient, a liberal measure ${ }^{2 x}$ which might partially explain the high correlations.

A significant number of patients, were able to report pain by means of a VRS. Higher VRS scores were consistent with higher total scores on the observational scales PAINAD and PACSLAC. Given the high correlations between patients' VRS and proxies' VAS scores, the results of our study suggest that proxies adequately estimated the pain intensity of persons in a controlled situation. This does not, however, resolve some of the doubts often voiced about self-reports, which mostly relate to construct validity and reliability. Jensen concluded that the major validity question concerning self-report pain scales involves the extent to which self-report measures actually reflect pain experience. ${ }^{32}$ Craig et al $^{33}$ noted that the tendency to trust non-verbal information more than self-report is widespread; "Non-verbal expressions will be more spontaneous and less subject to purposeful manipulation than selfreport". Scherder et al. ${ }^{3+}$ also supports the use of behavioral assessment scales, because these scales also assess affective aspects of pain.

\section{Clinical usefulness}

Jensen ${ }^{32}$ stated that "no measure should be used without evidence for both its reliability and its validity". Although we agree, we want to emphasize that besides reliability and validity, usefulness is at least of equal importance. Therefore, from the start of this project, we highly valued nurses' opinions about the usefulness of the scales, as they are, after all, the main intended users. Analyses of clinical usefulness revealed that the nurses found PACSLAC to be the most useful and the preferred scale in this setting.

\section{Limitations}

Some limitations need to be acknowledged. Firstly, we are aware that the methodology used in this study may have influenced findings. Elderly nursing home residents were observed in controlled situations with mostly a standardized acute pain stimulus. Raters were not blinded to the intervention, 
which may affected the findings and their generalizability. Vaccinations were chosen as the standardized pain stimulus, as it is not easy to choose a pain stimulus which provides an opportunity to observe a considerable number of patients with a reasonable level of pain. We hypothesized that there would not be many extremely high pain scores in reaction to the injection. Our analyses confirmed that the injection caused low to moderate levels of pain in the majority of participants. However, we used additional pain moments at T3 to enhance the reliability of our results. Patients who were not expected to be in pain at any specific moment, according to the nurses, were not assessed a third time. Hence, nurses who observed these patients were well aware of the fact that pain might be present. Another concern could relate to the fact that an acute pain moment was picked for this data collection. It is imaginable that more chronic pain moments would involve more frequent use of other items.

A second issue is our assumption that pain would less prevalent at rest (T1) than at $\mathrm{T} 2$ and $\mathrm{T} 3$. Since elderly nursing home patients often suffer chronic pain, this assumption could be challenged.

\section{Recommendations}

The design of future studies should take account of knowledge we posses. Scherder et al. ${ }^{3+}$ showed that the type of dementia probably plays an important role in pain experience. In the present study, the type of the dementia was often unknown as we depended on medical records for this information. Since we now know that the type of dementia do matter, this aspect should play a more prominent part in future studies.

The inability to diagnose pain adequately in nursing home residents with dementia is a significant problem for health care professionals. It is therefore an important step forward to have a clinically useful and psychometrically sound pain assessment scale available for this setting. The next step involves its implementation in nursing practice, which would allow further examination of psychometrics, like responsiveness or sensitivity to change. Future studies also need to focus on examining the prevalence of pain by using an observational pain scale.

This study took place in a highly controlled situation, in which elderly persons were observed in a standardized situation. In daily practice, the assessment of pain in elderly people with dementia is often influenced by many uncontrollable aspects, which add to the level of uncertainty. The challenge will be to examine the adequacy of scales in clinical practice and their effects on pain management.

\section{Acknowledgements}

This research was funded by the Research Council for Medical and Health Research of the Netherlands Organization for Scientific Research. The authors would like to thank all the staff of the participating Dutch nursing homes 
(Hambos Kliniek in Kerkrade, Lückerheide Kliniek in Kerkrade, Grubbeveld in Maastricht and VKH in Heerlen) for their co-operation in this study.

\section{REFERENCE LIST}

1. Ferrell BA. Pain evaluation and management in the nursing home. Annals of Internal Medicine. 1995;123(9):681-687.

2. Weissman DF, Matson S. Pain assessment and management in the longterm care setting. Theoretical Medicine \& Bioethics. 1999;20(1):31-43.

3. Lansbury G. Chronic pain management: a qualitative study of elderly people's preferred coping strategies and barriers to management. Disability \& Rehabilitation. 2000;22(1-2):2-14.

4. Helme RD, Gibson SJ. The epidemiology of pain in elderly people. Clin Geriatr Med. Aug 2001;17(3):417-431.

5. Farrell MJ, Katz, B, Helme RD. The impact of dementia on the pain experience. Pain. 1996;67(1):7-15.

6. McGrath PJ, Rosmus C, Canfield C, Campbell MA, Hennigar A. Behaviours caregivers use to determine pain in non-verbal, cognitively impaired individuals. Developmental Medicine \& Child Neurology 1998;40(5):340-343

7. Zwakhalen SM, Hamers JP, Abu-Saad HH, Berger MP. Pain in elderly people with severe dementia: a systematic review of behavioural pain assessment tools. BMC Getiatrics. 2006;6:3.

8. Oberlander TF, Gilbert CA, Chambers CT, O'Donnell ME, Craig KD Biobehavioral responses to acute pain in adolescents with a significant neurologic impairment. Clinical Journal of Pain. 1999;15(3):201-209.

9. Breau LM, McGrath PJ, Craig KD, Santor D, Cassidy KL, Reid GJ. Facial expression of children receiving immunizations: a principal components analysis of the child facial coding system. Clinical Journal of Pain. 2001;17(2):178-186.

10. Morris JN, Fries BE, Mehr DR, et al. MDS Cognitive Performance Scale. Journal of Gerontology. 1994;49(4):M174-182.

11. Hartmaier SL, Sloane PD, Guess HA, Koch GG, Mitchell CM, Phillips $\mathrm{CD}$. Validation of the Minimum Data Set Cognitive Performance Scale: agreement with the Mini-Mental State Examination. J Gerontol A Biol Sci Med Sci. Mar 1995;50(2):M128-133.

12. Folstein MF, Folstein SE, McHugh PR. "Mini-mental state". A practical method for grading the cognitive state of patients for the clinician. Journal of Psychiatric Research. 1975;12(3):189-198.

13. Wary B, Doloplus C. Doloplus-2, une echelle pour evaluer la doulcur. Soins. Gerontologie. 1999;(19):25-27.

14. Wary B, Serbouti S, Doloplus C. Validation d'une échelle d'évaluation comportementale de la douleur chez la personne âgéc. Douleurs. 2001;2(1):35-38.

15. Lefebre-Chapiro $\mathrm{S}$. The Doloplus 2 scale-evaluating pain in the elderly. European journal of palliative care. 2001;8(5):191-194.

16. Michel M, Capriz F, Gentry A, et al. Doloplus 2, une échelle comportementale de la douleur valide chez la personne âgée. La Revue de Gériatrie. 2000;25(3):155-160. 
17. Serbouti S, Rat P, Passadori Y. Validation of DOI.OPLUS. A pain assessment tool for non-verbal or cognitively impaired elderly patients. (Abstract) IASP, 2002; San Diego.

18. Fuchs-Lacelle S, Hadjistavropoulos T, McGrath P. Psychometric development of a pain assessment scale for older adults with severe dementia: a report on the firts two studies. (Abstract) IASP conference, 2002; San Diego.

19. Fuchs-Lacelle $\mathrm{S}$, Hadjistavropoulos T. Development and preliminary validation of the pain assessment checklist for seniors with limited ability to communicate (PACSLAC). Pain Management Nursing. 2004;5(1):37-49.

20. Warden V, Hurley AC, Volicer L. Development and psychometric evaluation of the Pain Assessment in Advanced Dementia (PAINAD) scale. Journal of the American Medical Directors Association. 2003;4(1):9-15.

21. Hurley AC, Volicer BJ, Hanrahan PA, Houde S, Volicer L. Assessment of discomfort in advanced Alzheimer patients. Research in Nursing \& Health. 1992;15(5):369-377.

22. Lane P, Kuntupis M, MacDonald S, et al. $\Lambda$ pain assessment tool for people with advanced Alzheimer's and other progressive dementias. Home Healthcare Nurse. 2003;21(1):32-37.

23. Jensen MP, Karoly P. Self-report scales and procedures for assessing pain in adults. In: Turk D, Melzack R, eds. Handbook of pain assessment. 2 ed. New York-London: The Guildford Press; 2001:14-34.

24. McGrath PA, Seifert CE, Speechley KN, Booth JC, Stitt L, Gibson MC. $\Lambda$ new analogue scale for assessing children's pain: an initial validation study. Pain. 1996;64(3):435-443.

25. Scherder EJ, Slaets J, Deijen JB, et al. Pain assessment in patients with possible vascular dementia. Psychiatry. 2003;66(2):133-145.

26. Closs SJ, Barr B, Briggs M, Cash K, Seers K. A comparison of five pain assessment scales for nursing home residents with varying degrees of cognitive impairment. Journal of Pain \& Symptom Management. 2004;27(3):196-205.

27. Nunnally JJC. Psychometric theory. 2 ed. New York: McGraw-Hill; 1978.

28. Streiner DI, Norman CR. Health measurement scales. A practical guide to their development and use. Oxford: University Press; 2003.

29. Holen JC, Saltvedt I, Fayers PM, et al. The Norwegian Doloplus-2, a tool for behavioural pain assessment: translation and pilot-validation in nursing home patients with cognitive impairment. Palliative Medicine. 2005;19(5):411-417.

30. Leong IY, Chong MS, Gibson SJ. The use of a self-reported pain measure, a nurse-reported pain measure and the PAINAD in nursing home residents with moderate and severe dementia: a validation study. Age \& Ageing. 2006;35(3):252-256.

31. Hadjistavropoulos T, LaChapelle DL, MacLeod FK, Snider B, Craig KD. Measuring movement-exacerbated pain in cognitively impaired frail elders. Clinical Journal of Pain. 2000;16(1):54-63. 
32. Jensen MIP. Validity of self-report and observational measures. Paper presented at: 8th World congress on pain, 1997; Seattle.

33. Graig KD, Prkachin KM, Grunau RE. The facial expression of pain. In: Turk D, Melzack R, eds. Handbook of pain assessment. 2 ed. New York-London: The Guildford Press; 2001:153-169.

34. Scherder E, Oosterman J, Swaab D, et al. Recent developments in pain in dementia. BMJ. 2005;330(7489):461-464. 


\section{Chapter 5}

Improving the clinical usefulness of a behavioural pain scale for older people with dementia

This chapter was published as:

Zwakhalen SMG, Hamers JPH, Berger MPF. Improving the clinical usefulness of a behavioural pain scale for older people with dementia. Journal of Advanced Nursing Jun 2007;58(5):493-502. 
7 his describes the process of item reduction as part of the construction of the PACSLAC-D scale to assess pain in Dutch older nursing home residents with dementia. $\Lambda$ valid and reliable clinically useful tool is important for assessing pain in people with dementia. The PACSLAC has demonstrated good inter- and intra-rater reliability and evidence of construct validity. However, nurses found the scale too long for clinical use. In an observational study in year 2005 , nursing home patients $(n=128)$ were observed while receiving an influenza injection, and a selection of patients were also assessed at a patient-specific pain moment. Internal consistency and Ptincipal Component Analysis were used to refine the scale, to examine the psychometric quality and underlying factor structure of the scale. A brief and manageable version of the PACSLAC-D was developed, with a three-component solution including 24 items. This version had high levels of internal consistency for the complete scale (Cronbach's alpha range .82-.86) and for all subscales (alpha range .72-.82). Social-emotional items played a significant role in detecting pain. It is important to have a valid, reliable, brief and manageable pain scale available for the nursing home setting. Further research is needed to examine the adequacy and effectiveness of the scale in daily clinical practice. 
INTRODUCTION

Dain assessment in older patients has been recognized as a subject of major importance', and adequate assessment is the first crucial step towards adequate treatment. Under-treated pain can cause numerous additional health and behavioural problems, such as agitation, sleep disturbance, weight loss and depression. ${ }^{2}$ However, assessing pain accurately remains an extremely difficult daily challenge for nurses. Limited ability or inability to communicate orally is one of the difficulties in assessing pain in nursing home patients with severe dementia. Furthermore, there is no such thing as a typical patient with dementia: dementia is a syndrome characterized by progressive decline in cortical functions ${ }^{3}$ with great variability in pain responses and behavioural repertoires due to, for example, different causes and different degrees of severity of the syndrome. In addition, the process of ageing and the dementia itself are associated with increasing somatic and psychological problems, limiting the ability of older patients to express their pain. These aspects may also add to the complexity of pain and its assessment.

All constructors of pain scales aim to develop a scale which is psychometrically sound and clinically useful. While collecting the items is the easy part, it is much more difficult to establish a valid, reliable scale that is sensitive to changes and specific, but not too specific to assess pain. Nthough interest in pain assessment in older persons with dementia has grown considerably in the last decade, two recent reviews on pain assessment tools show that the pain scales currently available for this population are still in the early stages of construction, development and testing, and show moderate psychometric qualities. ${ }^{4.5}$ Also, even if excellent psychometric qualities have been established, a scale is of no use if it is not easy to use in clinical practice. This implies that a scale has to be brief, easy to administer and not too timeconsuming.

The Pain Assessment Checklist for Seniors with Limited Ability to Communicate (PACSLAC), developed by Fuchs \& Hadjistavropoulos", is one of the best-performing scales currently available for assessing pain in nursing home residents. The PACSLAC is a dichotomously-scored checklist which includes 60 items, originally covering four sub-scales: Facial expression (13 items); Activity / Body movements (20 items); Social / Personality / Mood (12 items) and Physiological / Eating / Sleeping / Vocal (15 items). The authors of the scale have reported good internal consistency for the total scale $(\alpha=0.82-0.92)$, although the Cronbach's $\alpha$ values for the subscales were lower (.55-.73). The PACSLAC seems to discriminate between painful, calm and distressing events. ${ }^{6}$

Since the scale has not been extensively tested beyond the initial study setting and population, we have conducted a study to compare the psychometric qualities of three pain assessment scales for older people with dementia.' Findings of this recent study showed that the Dutch version of the PACSIAC 
has good inter-rater (range .77-.96) and intra-rater reliability (tange .72-.92) and shows evidence of construct validity (discriminating between pain and no-pain events). Cronbach's alpha for the total scale was high ( $>.80)$, and was adequate for the 'Facial Expression' (range .57-.73) and 'Social / Personality / Mood' (range .65-.76) subscales. Cronbach's alpha was lower than the desired 7 for two subscales, viz. 'Activity / Body movement' $(\alpha=.40-.57)$ and 'Physiological indicators / Eating / Sleeping changes / Vocal behaviours' ( $\alpha=.20-.43)$. Several items showed no variance at all. Information we gathered on clinical usefulness showed that nurses preferred the potentially clinically-relevant PACSLAC for pain assessment in this population, although they found that the Dutch version of the scale had too many items. Qualitative information gathered from the participating nurses showed that several items seemed superfluous and other items overlapped.' The question in the present study was therefore whether the number of items in the Dutch version of the PACSLAC scale (PACSLAC-D) could be reduced, while retaining good psychometric qualities.

\section{THE STUDY}

Aims

The aim of the study was to carry out item reduction as part of the construction of a translated version of the PACSLAC scale to assess pain in Dutch older nursing home residents with dementia. More specifically, the following research questions were addressed:

What PACSLAC items represent the pain cues most frequently used when assessing pain in nursing home residents with dementia?

What is the scale structure of the reduced version of the PACSLAC (PACSLAC-D), established by principal component factor analysis?

Are the reduced version of the PACSLAC (PACSLAC-D) and its subscales internally consistent?

\section{Design}

Data were collected in an observational study design in year 2005. All patients were observed while receiving an influenza vaccination, and a selection of patients were also observed at a patient-specific pain moment (e.g., care activities, washing or mobilisation).

\section{Participants}

One hundred and twenty-eight nursing home patients on 12 dementia care wards receiving their annual planned influenza vaccination were included in this study. To be included, older residents with dementia had to have been living in the nursing home for at least 4 weeks prior to the influenza vaccination. All residents were at least 60 years old and had not undergone major environmental 
changes in the last month. The type of dementia syndrome and severity of the impairment varied. Those with psychiatric disease or with Korsakov's syndrome were excluded because these people generally differ from other residents with dementia (e.g., are younger and have better mobility) and live in special Korsakor or psychiatric wards in the nursing homes.

\section{DATA COLLECTION}

\section{Measures}

The data used to refine the translated version of the PACSLAC were gathered as part of a larger study testing the psychometric qualities of three pain assessment scales and their clinical utility.

Demographic information (age, sex, dementia diagnosis and severity of cognitive impairment) was gathered from all participants and recorded on a data sheet. The Minimum Data Set (MDS) Cognitive Performance Scale (CPS) was also used to evaluate the cognitive status (severity of cognitive impairment) of the residents. The CPS combines $5 \mathrm{MDS}$ items relating to cognitive functioning, eventually yielding 7 categories of cognitive impairment." The MDS-CPS has been validated against the Mini-Mental State Examination (MMSE)" and showed substantial agreement."

Information about environmental changes during the last month and the type of dementia diagnosed was obtained from patient records.

Pain was assessed using the translated (Dutch) version of the PACSLAC, originally developed by Fuchs \& Hadjistavropoulos (2004). The scale had been translated during an earlier stage using a backward-forward method, and had been pre-tested before its psychometric qualities were assessed.? Furthermore, a Visual Analogue Scale-observer (VAS) was used to estimate pain intensity. A VAS is a $100 \mathrm{~mm}$ line, with anchors at either end, on which pain can be marked. The left hand anchor was labeled 'no pain at all' and the right hand anchor was labeled 'pain as bad as it could possibly be'." VAS pain ratings $>=30$ were considered to represent pain. This cut-off score is frequently used in pain

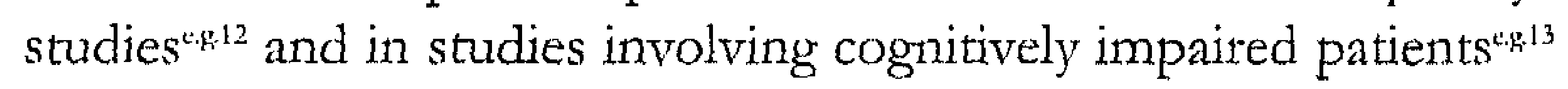

\section{Procedure}

The influenza vaccination was planned simultaneously for all patients in one ward and scheduled to take place on the same day. After baseline measurement and demographic information gathering, patients' pain response was observed for approximately 2 minutes during vaccination (T2). The observer had no prior in-depth knowledge of the nursing home residents. A selected group was also assessed during a specific moment/situation (T3). At T3, patients underwent a variety of specific potentially painful interventions (such as care activities, washing or mobilisation). Those who, in the opinion of the nurses involved, 
were not expected to be in pain at specific moments were not assessed a third time. After the T3 observational moment, the VAS and PACSLAC were scored again by the same observer.

At baseline, T2 and T3, the VAS-observer and the PACSLAC were scored in random order immediately after the patient had been observed. To avoid differences in scores due to developments over time, the time interval between $\mathrm{T} 2$ and $\mathrm{T} 3$ was minimized and was mostly shorter than 3 weeks.

\section{Etbical considerations}

The study was approved by the Medical Ethics Committee of the University Hospital Maastricht and the University of Maastricht. Permission to conduct the study was also obtained from the managing directors of the nursing homes. Before participation, registered legal guardians of the residents gave written informed consent.

\section{Data analysis}

All data were analyzed using SPSS. Descriptive statistics were generated for the characteristics of respondents. Frequency of endorsement ratings were computed using descriptive statistics to examine the frequency of items used.

The item reduction process started with internal consistency (IC) analyses for the total scale. Items were discarded if they were used in over $90 \%$ of recordings or not used in over $90 \%$ recordings at T2 and T3 or if the item-total correlation was lower than .20 . Because of the exploratory character of the study, the factor structure was assessed after the IC analyses, using principal component analysis (PCA). Because T2 yielded the most data, PCA analyses were carried out for T2. An Oblimin rotation was used, allowing components to correlate. Kaiser-Meyer-Olkin (KMO) was used to check if the PCA technique was allowed. Eigenvalues and a scree plot were used to determine the number of components to extract. Items were removed if the measure of sampling adequacy (MSA, KMO for individual items) was below .5. After an item had been deleted, the data were re-examined, computing a new anti-image matrix. Items were also deleted if communalities were low $(<.5)$ or had no substantial factor loading (below 4 given the number of respondents). Finally, the ICs of the final scale and subscales were re-examined using Cronbach's alpha.

\section{RESULTS}

\section{Participants}

A total of 128 nursing home residents with dementia participated in this study, including $78.1 \%$ women $(n=100)$ and $21.9 \%$ men $(n=28)$. Ages ranged from 60 to 96 years, with a mean of $82.4(\mathrm{SD}=6.8)$. All participants were residents on dementia care wards. Almost half of the participants $(n=61,47.7 \%)$ were severely impaired (MDS-CPS $=5$ or 6$), 28.1 \%(n=36)$ were moderately impaired 
and a minority was mildly impaired $(n=28,21.9 \%)$. The dementia diagnosis was Alzheimer's disease in $32 \%$, vascular dementia in $18.8 \%$, other in $9.4 \%$ and unknown in $39.8 \%$.

Most frequently used pain cues

Table 1 presents the item usage, assessed by calculating the frequency with which the rater endorsed PACSLAC items when assessing participants (using the VASobserver $>=30$ ) at $\mathrm{T} 2$ and $\mathrm{T} 3$.

Table 1 Most frequently used items of PACSLAC (VAS > =30)

\begin{tabular}{|c|c|c|}
\hline Items & $\begin{array}{c}\text { T2 }(n=127)^{* *} \\
\% \text { scored by rater } 1\end{array}$ & $\begin{array}{c}\mathrm{T} 3(\mathrm{n}=35) \\
\% \text { scored by rater } 1\end{array}$ \\
\hline Tighter face & 96.4 & 100 \\
\hline Change in eyes * & 96.4 & 78.3 \\
\hline Pain expression & 82.1 & 69.6 \\
\hline Frowning & 75 & 78.3 \\
\hline Creasing forehead * & 75 & 65.2 \\
\hline Specific sound or vocalisation for pain & 71.4 & 65.2 \\
\hline Grimacing & 46.4 & 69.6 \\
\hline Moaning and groaning & 46.4 & 69.6 \\
\hline Pulling away & 46.4 & 47.8 \\
\hline Opening mouth $*$ & 42.9 & 43.5 \\
\hline Mumbling * & 32.1 & 17.4 \\
\hline Not wanting to be touched & 28.6 & 43.5 \\
\hline Upset & 28.6 & 21.7 \\
\hline Restless & 25 & 30.4 \\
\hline Flushed /red face & 25 & 21.7 \\
\hline Flinching & 25 & 4.3 \\
\hline Anxious & 21.4 & 39.1 \\
\hline Clenching teeth & 17.9 & 43.5 \\
\hline Mean VAS scores (tater 1) min. 0- max. 10 & $17.1(0-85)$ & $36.3(0-83)$ \\
\hline
\end{tabular}




\section{Item reduction}

Based on the $90 \%$ criteria or low IC scores, 31 items were discarded. Before running the final analyses, exploratory analyses were used to screen the data and explore KMO values and MSA values. The KMO value for the 29 items scale was .66. Four items (clenching teeth, stiff/rigid, angry/mad, clenched fist) were discarded based on the fact that the MSA values were too low (i.e. below .50). Removing these 4 items clearly increased the $K M O$ value, to .74. A value close to 1 indicates that patterns of correlations are relatively compact and so factor analyses should yield distinct and reliable factors. ${ }^{14}$ Field (2005) reported that Kaiser recommends a bare minimum of .5. Communalities of all remaining 25 items were greater than .5. The eigenvalues and scree plot were then examined to determine the number of components. Using Kaiser's criterion, as referred to by Field (2005), only factors with an eigenvalue greater than 1 should be extracted. Based on the eigenvalues, we should have extracted 8 components. However, this criterion is not accurate for the data in this study, since the sample size was small relative to the number of variables. Plotting the eigenvalues allowed us to detect where the decrease in eigenvalues appeared. According to the scree plot, 3 components retain, all with an eigenvalue above 2 . Finally, the 'opening mouth' item was removed because it had a factor loading below .4, which had been set as the minimum. Table 2 presents an overview of the items discarded in this reduction process.

\section{Factor structure and $I C$ of the refined scale}

Final analyses showed that 3 components explained $45.7 \%$ of the variance. The first component explained $27.3 \%$, the second component $9.3 \%$ and the thitd component $9.1 \%$ of the variance. Table 3 shows the refined version of the PACSLAC, with loadings of the 24 items on the 3 factors extracted.

Re-examination of the IC scores showed that the alpha for the total scale with 24 items was .86 at T2 and .82 at 'T3. The Cronbach's alpha values for the 3 subscales were high, ranging from .72 to .82 (See Table 3). Finally, the reduced version of the scale was correlated with the long 60 -item version of the scale, resulting in a Pearson's correlation coefficient of .945 . This confirmed that the refinement of the scale did not devaluate the findings. 
Table 2 Overview of item reduction

\begin{tabular}{|c|c|c|c|}
\hline Discarded items & $\begin{array}{c}\text { Step } 1^{*} \\
\text { reduction of } \\
n=31 \text { items }\end{array}$ & $\begin{array}{l}\text { Step } 2 * * \\
\text { reduction of } \\
n=4 \text { items }\end{array}$ & $\begin{array}{l}\text { Step } 3 * * * \\
\text { reduction of } \\
n=1 \text { item }\end{array}$ \\
\hline Tighter face & $\mathrm{x}$ & & \\
\hline Dirty look & $\mathrm{x}$ & & \\
\hline Wincing & $\mathrm{x}$ & & \\
\hline Screwing up nose & $\mathrm{x}$ & & \\
\hline Fidgeting & $\mathrm{x}$ & & \\
\hline Pacing & $\mathrm{x}$ & & \\
\hline Wandering & $\mathrm{x}$ & & \\
\hline Trying to leave & $\mathrm{x}$ & & \\
\hline Refusing to move & $\mathrm{x}$ & & \\
\hline 'Thrashing & $\mathrm{x}$ & & \\
\hline Decreased activity & $\mathrm{x}$ & & \\
\hline Refusing medication & $\mathrm{x}$ & & \\
\hline Moving slow & $\mathrm{x}$ & & \\
\hline Impulsive behaviour & $\mathrm{x}$ & & \\
\hline Limping & $\mathrm{x}$ & & \\
\hline Going into foetal position & $\mathrm{x}$ & & \\
\hline Throwing things & $\mathrm{x}$ & & \\
\hline Increased confusion & $\mathrm{x}$ & & \\
\hline Anxious & $\mathrm{x}$ & & \\
\hline Frustrated & $\mathrm{x}$ & & \\
\hline Pale face & $\mathrm{x}$ & & \\
\hline Teary eyed & $\mathrm{x}$ & & \\
\hline Sweating & $x$ & & \\
\hline Shaking/ trembling & $\mathrm{x}$ & & \\
\hline Cold \& clammy & $\mathrm{x}$ & & \\
\hline Change in sleep & $x$ & & \\
\hline Change in appetite & $\mathrm{x}$ & & \\
\hline Calling out & $\mathrm{x}$ & & \\
\hline Crying & $\mathrm{x}$ & & \\
\hline Mumbling & $\mathrm{x}$ & & \\
\hline Grunting & $\mathrm{x}$ & & \\
\hline Clenching teeth & & $x$ & \\
\hline Stiff/rigid & & $\mathrm{x}$ & \\
\hline Angry / mad & & $\mathrm{x}$ & \\
\hline Clenched fist & & $\mathrm{x}$ & \\
\hline Opening mouth & & & $\mathrm{x}$ \\
\hline
\end{tabular}


Table 3 Results of the Principal Components Analysis (PCA) and final Internal Consistency scores of the subscales determined by the PCA

\begin{tabular}{|c|c|c|c|}
\hline \multirow[t]{2}{*}{ Variables } & \multicolumn{3}{|c|}{ Component 1 Component 2 Component 3} \\
\hline & $\mathrm{n}=10$ items & $\mathrm{n}=6$ items & $\mathrm{n}=\mathbf{8}$ items \\
\hline Pain expression & 0.77 & & \\
\hline Specific sound or vocalisation for pain & 0.73 & & \\
\hline Frowning & 0.68 & & \\
\hline Grimacing & 0.63 & & \\
\hline Creasing forehead & 0.60 & & \\
\hline Moaning and groaning & 0.60 & -0.32 & \\
\hline Change in eyes & 0.52 & & \\
\hline Touching/ holding sore area & 0.46 & & \\
\hline Guarding sore area & 0.45 & & \\
\hline Pulling away * & 0.39 & -0.31 & \\
\hline Verbal aggression & 0.53 & -0.41 & \\
\hline Agitated & & -0.68 & 0.60 \\
\hline Physical aggression & & -0.68 & \\
\hline Flinching & & -0.61 & \\
\hline Not wanting to be touched & & -0.59 & 0.39 \\
\hline Uncooperative/ resistant to care & & -0.56 & 0.56 \\
\hline Cranky/ irtitable & & & 0.63 \\
\hline Screaming/ yelling & & & 0.60 \\
\hline Grim face & & & 0.59 \\
\hline Not allowing people near & & & 0.56 \\
\hline Upset & 0.33 & & 0.54 \\
\hline Flushed/ red face & & & 0.50 \\
\hline Restless & & & 0.49 \\
\hline Sad look & & & 0.45 \\
\hline Cronbach's alpha & 0.82 & 0.78 & 0.72 \\
\hline
\end{tabular}

Rotation Method: Oblimin with Kaiser Normalization. All loadings less than .30 are suppressed

* This item is included although the factor loading was marginally below .40

Items loading one more than one component are also shown, using a contrasting colour PACSLAC = Pain Assessment Checklist for Seniors with Limited Ability to Communicate 


\section{DISCUSSION}

A brief and manageable version of the PACSLAC-D was developed, with a three-component solution including 24 items. Our findings demonstrate that the scale has high levels of internal consistency for the complete scale (Cronbach's alpha range .82-.86) and for all subscales (alpha range .72-.82). These findings meet the criteria that Cronbach's alpha for newly-developed scales should be above $.70 .{ }^{15}$ Fuchs \& Hadjistavropoulos (2004) reported similar IC scores for the original total 60-item scale, while IC scores for subscales ranged from .55 to .73 .

Herr et al. (2006) concluded in their review that PACSLAC is potentially useful and appears to be simple to use. However, they recommended that the tool should be prospectively evaluated with a larger sample, including factor analysis, in order to establish reliability and validity. In the present study we addressed both of these aspects. The results of the PCA show that the three factors explaining the underlying factor structure related to facial and vocal expressions, resistance/defence and social-emotional aspects/mood. A closer look at the remaining 24 items (see Appendix A for the final refined version of the PACSLAC-D) shows that many items refer to social-emotional aspects. Behavioural symptoms referring to, for example, mood, aggression and agitation obviously play an important role in detecting pain. While facial expressions seem to be more universal pain cues, occurring in all pain scales for various target groups, these social-emotional cues seem more specific and important for older people with dementia. It is very importance for nurses and other healthcare workers to link these social-emotional behavioural cues to possible painful conditions. Since the refined version of the scale contains so many socialemotional behaviour items, another future challenge is the problem of 'behavioural and psychological symptoms of dementia' (BPSDs) in relation to pain. Since little is so far known about the interaction between pain symptoms and these behavioural problems, the relationship between pain and BPSDs needs to be explored.

Since almost all frequently-used items were retained in the final scale, these are the most probable and solid pain cues in determining pain, especially procedural pain, in older people with dementia. Two of the most frequentlyused items that were not included in the final scale were 'opening mouth' and 'mumbling'. These are the two items that were also frequently reported at rest and in non-painful situations.

Although an Oblimin rotation was justified, we also used a Varimax rotation to check the cluster solution. Varimax rotation resulted in a comparable solution, with overall lower factor loadings.

\section{Study limitations}

Our study, which had a mainly methodological focus, was subject to certain limitations. Given the number of items in the PACSLAC-D and using the rule 
of thumb of 5-10 participants for each item, the sample size of 128 participants was small, particularly given the fact that a minority had moderate or severe pain. Another methodological limitation relates to the data collected to reduce the scale. It must be kept in mind that the items collected for this purpose may be influenced by the type of pain focused on in collecting the items. Items were deleted if they were not present or always present (in over $90 \%$, i.e. showing almost no variance) at the $\mathrm{M} 2$ and M3 observational moments. Whereas acute injection pain was measured at M2, a broader variety of procedural pain during morning care was measured at M3. However, it is possible that if other moments of pain had been used, other items might have been more frequently used. This limitation should be seen in relation to ongoing developments and should also be viewed as a suggestion for future research. It will be of great interest for future studies to determine the validity and reliability of the PACSLAC-D in other types of more chronic pain and to see whether the use of the longer 60item PACSLAC set reveals other pain behaviours to be frequently used.

Furthermore, the criteria used to reduce the number of items may also have influenced our findings. To examine and remediate this possible problem, additional analyses were performed using a different approach to reduce the number of items. Instead of using the $90 \%$ criterion and item-total correlations, items were deleted until the alpha stopped increasing. This approach resulted in mostly the same items being retained. Differences related to items which were not frequently used, such as 'grunting' (used by $0 \%$ of respondents at T2 to $4.3 \%$ at T3) and 'crying' (used by $3.6 \%$ of respondents at T2 to $0 \%$ at T3).

Another concern might be the fact that only one rater made the observations (VAS and PACSLAC) and allocated the scores that were used to perform the PCA and reduce the number of scale items. This observer was the consistent factor in the rating of all patients. It might be questioned whether this has biased the results. As mentioned above, the data for this study were gathered as part of a larger study testing the psychometric qualities of three pain assessment scales and their clinical utility. ${ }^{7}$ This larger study used different raters to score the PACSLAC, and used a VRS self-report to rate the pain if possible. Based on the high levels of intertater reliability $(r=.77-.96)$ and the high correlation with the VRS ( $r=86$ ) at the selected pain moments (T2 and T3 VAS $>=30$ ), we conclude that this approach is reliable.

It is important to have a valid, reliable, brief and manageable pain scale available for nursing home settings. Our future plans include examination of the adequacy and effectiveness of the scale in daily clinical practice.

\section{CONCLUSION}

The availability of a clinically-useful tool has major implications for nursing practice and direct patient care. Objective assessment provides information about possible pain experienced by patients and therefore decreases the risk of 
undertreatment. It also gives opportunities to generate new data to add to the body of knowledge. For example, due to the absence of adequate measurement scales, estimated pain prevalence rates have varied between 40 and $80 \%$, and we do not know exactly how many older people with severe dementia experience pain on a claily basis. The availability of validated behavioural pain scales gives us with the opportunity to assess prevalence rates more precisely.

Finally, standardised pain scoring should be introduced in nursing care protocols and nurses should see it as part of their task to assess pain, record it and apply interventions if necessary. This will undoubtedly lead to better pain assessment and treatment, which is in the best interests of older patients with dementia.

\section{REFERENCES}

1. The management of chronic pain in older persons: AGS Panel on Chronic Pain in Older Persons. American Geriatrics Society. J Am Geriatr Soc. May 1998;46(5):635651.

2. Warden V, Hutley AC, Volicer L. Development and psychometric evaluation of the Pain Assessment in Advanced Dementia (PAINAD) scale. J Am Med Dir Assoc. Jan-Feb 2003;4(1):9-15.

3. Farrell MJ, Katz B, Helme RD. The impact of dementia on the pain experience. Pain. 1996;67(1):7-15.

4. Herr K, Bjoro K, Decker S. Tools for assessment of pain in nonverbal older adults with dementia: a state-of-the-science review. Journal of Pain \& Symptom Management. 2006;31(2):170-192.

5. Zwakhalen SM, Hamers JP, Abu-Saad HH, Berger MP. Pain in elderly people with severe dementia: a systematic review of behavioural pain assessment tools. BMC Geriatrics. 2006;6:3.

6. Fuchs-Lacelle S, Hadjistavropoulos T. Development and preliminary validation of the pain assessment checklist for seniors with limited ability to communicate (PACSLAC). Pain Management Nursing. 2004;5(1):37-49.

7. Zwakhalen SM, Hamers JP, Berger MP. The psychometric quality and clinical usefulness of three pain assessment tools for elderly people with dementia. Pain. Dec 15 2006;126(1-3):210-220.

8. Morris JN, Fries BE, Mehr DR, ct al. MDS Cognitive Performance Scale. Journal of Gerontology. 1994;49(4):M174-182.

9. Hartmaier SL, Sloane PD, Guess HA, Koch GG, Mitchell CM, Phillips CD, Validation of the Minimum Data Set Cognitive Performance Scale: agreement with the Mini-Mental State Examination. Journals of Gerontology Series A-Biological Sciences \& Medical Sciences. 1995;50(2):M128-133.

10. Folstein MF, Folstein SE;, McHugh PR. "Mini-mental state". A practical method for grading the cognitive state of patients for the clinician. Journal of Psychiatric Research. 1975;12(3):189-198.

11. Jensen MP, Karoly P. Self-report scales and procedures for assessing older pain in adults. In: Melzack DCTR, ed. Handbook Pain Assessment. 2nd ed. New York, London: The Guilford Press; 2001. 


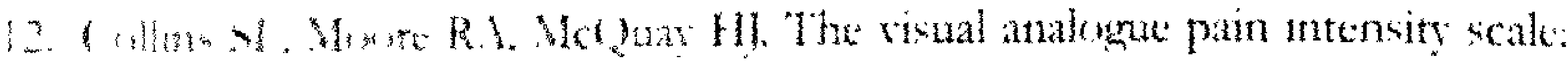

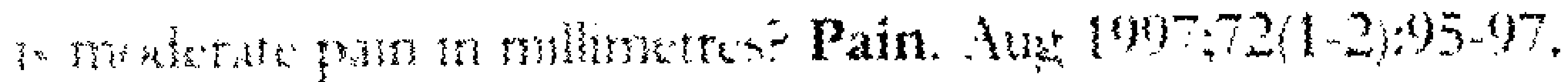

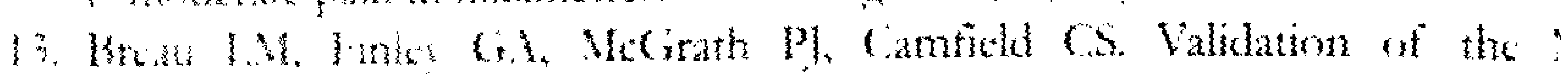

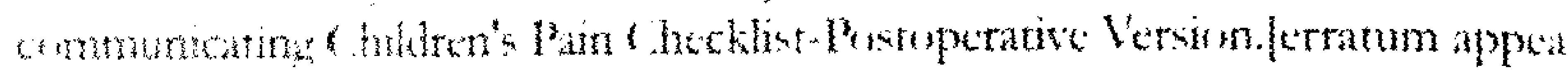

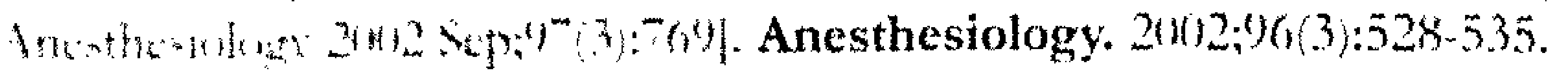

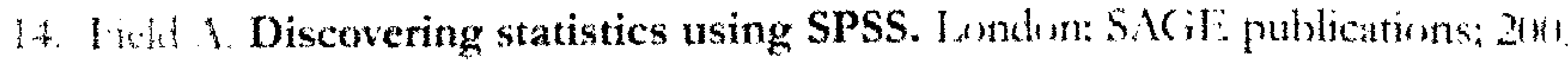

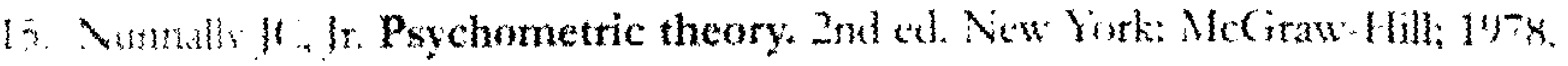


Appendix A. PACSLAC-D, refined shortened version

Date: Time assessed:

Name of patient/ resident:

Purpose:

This checklist is used to assess pain in patients/residents who have dementia and limited ability to communicate

Instructions:

Indicate with a checkmark, which of the items on the PACSLAC occurred during the period of interest. Scoring the Sub-scales is derived by counting the checkmarks in each column

To generate a total pain score sum all sub-scale totals

Comments:

Facial and vocal expressions

Present

Pain expression

A specific sound or vocalization for pain 'ow', 'ouch'

Frowning

Grimacing

Creasing forehead

Moaning and groaning

Change in eyes (squinting, dull, bright, increased movement)

Touching/ holding sore area

Guarding sore area

Pulling away

Resistance / defense

Present

Verbal aggression

Agitated

Physical aggression (e.g. pushing people and/or objects, scratching others, hitting others, striking, kicking)

Flinching

Not wanting to be touched

Uncooperative/ resistant to care

Social-emotional aspects / mood

Cranky/ irritable

Screaming/ yelling

Grim face

Not allowing people near

Upset

Flushed, red face

Restless

Sad look

\section{Sub scale scores}

Facial and vocal expressions

Resistence/defense

Social-economical aspects/mood

\section{Total checklist score:}

The Pacslac and any substation portion of its items are copyrighted by Fuchs-Lacelle and Hadjistavropoulos and may not be reproduced without permission. 


\section{Chapter 6}

The prevalence of pain in nursing home residents with dementia measured using an observational pain scale

This chapter was submitted as:

Zwakhalen SMG, Koopmans TCM, Geels PJEM, Berger MPF, Hamers JPH. The prevalence of pain in nursing home residents with dementia measured using an observational pain scale. 


\section{ABSTRACT}

The body of knowledge about pain and pain prevalence in older people with

1 dementia is limited as compared to cognitively intact older people. Pain prevalence rates in older people with dementia vary and are estimated between $28 \%$ and $83 \%$. This study aimed to explore the prevalence of pain in nursing home residents with dementia as measured by an observational scale, the PACSLAC-D, and to identify the association between several (dementia) demographic parameters such as cognitive status, gender, analgesic use and comorbidity and the prevalence of pain. In an observational study design, 117 residents were observed and assessed for pain during personal morning care. Prevalence data were calculated and regression analyses were applied. Findings of this study showed that almost half of the participants (47\%) experienced pain to some extent. However overall pain intensity scores were relatively mild. Among the independent variables, co-morbidities, analgesic use and the adjusted interaction term 'co-morbidities * analgesic use' were shown to be valid significant predictors having the strongest associations with pain. By using a relatively new approach, measuring pain using a observational scale, this study confirms what we expected from other studies in populations with less impaired older residents, namely, that pain prevalence in older residents with dementia living in Dutch nursing homes is high. 


\section{INTRODUCTION}

Dain represents a major problem with serious consequences for the patient's quality of life.' Pain prevalence rates in older people with dementia vary enormously between $28 \%$ and $83 \%$. ${ }^{\circ}, 27$ These varying rates reflects the use of less reliable an valid approaches which include:

(1) the use of clinical or medical record diagnosis to gather data in order to estimate the pain prevalence ${ }^{\mathrm{x}, 9}$

(2) the use of the Residents Assessment Instrument (RAI), Minimum Data Set (MDS) items on pain. ${ }^{0.7 .710 .11}$

(3) the use of self-report of pain which is often viewed as the gold standard. Although this might be the most accurate way of measuring the prevalence of pain in residents with mild dementia, it implies that a subset of older residents with moderate to severe dementia is not reliably assessed or is excluded when using this method.

Thus, the estimated reported pain prevalence rates should be interpreted with care because of the difference in method used and differences in study populations.

It is evident that there is a need for a valid and reliable tool to measure the prevalence of pain in nursing home residents with severe dementia. The Pain Assessment Checklist for Seniors with Limited Ability to Communicate (PACSLAC-D) ${ }^{12,13}$, based on the PACSLAC ${ }^{14}$, is a reliable, valid and useful observational scale to assess pain in residents with dementia. PACSI_AC was evaluated as one of the best scales currently available. ${ }^{15}$ However, prevalence rates have not been determined yet by using these observational scales.

The same holds true for the associations between pain and the type of (dementia) demographic parameters such as cognitive status, gender, analgesic use and co-morbidity. Residents who received multiple medications, were subsequently associated with greater degrees of pain." Several studies demonstrate that pain prevalence was found to be higher among women as compared to men.", "11 Proctor and Hirdes (2001) demonstrated that the pain prevalence was lower among residents with higher levels of cognitive impairment. ${ }^{16}$ On the other hand, other studies ${ }^{17,18}$ have concluded that cognitive status does not affect pain prevalence. Gruber-Baldini et al., (2005) and Smalbrugge et al. (2007) recently found associations between depression and pain. ${ }^{1120}$ Furthermore, there is evidence that pain tolerance is different in people with Alzheimer's disease. ${ }^{21,22}$ However, more evidence is needed.

The aim of this study is to explore the prevalence of pain in nursing home residents with dementia as measured by the PACSLAC-D, and to identify the association of such pain with residents characteristics. 


\section{METHODS}

Design

An observational study design was used to answer the research questions.

Sample

All residents of the dementia care units of three nursing homes in the Netherlands, one located in Nijmegen (two units), one located in Maastricht (four units) and one located in Landgraaf (four units) were invited to enter the study. Residents were included if (1) they met DSM-IV criteria ${ }^{23}$ for dementia; (2) they were institutionalized for at least four weeks prior to the data collection; (3) they were at least 60 years old; (4) they had not undergone major changes in environment in the last month, and (5) their legal guardians had given written informed consent.

\section{Measurement and residents characteristics}

Pain was assessed using the Dutch version of the Pain Assessment Checklist for Seniors with Limited Ability to Communicate (PACSLAC-D). PACSLAC, developed by Fuchs-Lacelle \& Hadjistavropoulos (2004), is a dichotomously 60item observational scale developed to assess pain in older residents with dementia. The PACSLAC-D is a brief, refined version with 24 items covering three subscales: facial and vocal expressions, resistance/defence and socialemotional aspects/mood. The factor structure of the refined scale was established using Principal Component Analysis. The PACSLAC-D demonstrated high validity ${ }^{12}$ and internal consistency for both the complete scale (alpha .82-.86) and for all subscales (alpha .72-.82). ${ }^{13}$ A score of at least 4 out of 24 (the maximum pain score) is considered to indicate the presence of pain. With a cut-off score $>=4$ the sensitivity of the PACSIAAC-D is .96 and the specificity .90. A step wise approach was conducted to determine these cut-off scores. At first, global cut-off scores were determined by a comparison of a linear transformation using other observational scales for non verbal populations with known cut-off scores for pain (e.g., DOLOPLUS, KIDPAINS). This linear transformation was therefore used as an external criteria. Subsequently, an empirical approach was used to verify the cut of point determined in the fist phase. Therefore, this cut-off point was certified using the data from a previous study. ${ }^{12}$ Based on this study, sensitivity and specificity wete established.

To re-examine the inter-rater reliability of the PACSLAC-D in the present study, fifteen residents were assessed by two raters at the same time during morning care. In order to allow generalization of results, the two-way random absolute agreement method was used to examine the inter-rater reliability, which compensates for an extra source of variance due to differences between raters. 
Intra Class Correlation (ICC) was found to be high for the total scale .89; adequate for the subscales of facial and vocal expressions $(\mathrm{ICC}=.89)$ and resistance/defence (ICC=.76); and moderate for the subscale social-emotional aspects/mood $(\mathrm{ICC}=.56)$.

Demographic information (age, gender) was gathered from all the participants and recorded on a data sheet. Information about the type of dementia was obtained from patients' medical records. Co-morbidities were recorded from the residents medical file and classified according to the classification of diseases in nursing home patients $(\mathrm{CvZ}-\mathrm{V})^{2+}$ derived from the International Classification of Diseases, version 10 (ICD-10). ${ }^{25}$ Also, 'depressive symptoms' were inventoried if these were mentioned as being present in the resident's medical record. Prescribed medication use (analgesics and psychotropics) were registered and classified according to the Anatomical Therapeutic Chemical (ATC) classification system. ${ }^{20}$ Cognitive status of all residents was evaluated using the standardized Mini-Mental State Examination (MMSE). ${ }^{27}$ This test (ranges: 0-30 points) is widely used and designed to briefly screen for cognitive impairment in older adults.

\section{Pain ratings}

Two weeks prior to the data collection, the ten raters of the three participating nursing homes received a short instruction of approximately thirty minutes on how to use the PACSLAC-D. The raters, mostly female $(n=6)$, ranged in age from 23 to 48 years (mean=36.2: $\mathrm{SD}=7.2$ ). The mean number of years of experience was $15.4(\mathrm{SD}=8.1)$. The majority $(70 \%, \mathrm{n}=7)$ were certified caregivers and two $(20 \%)$ were registered nurses (RNs).

Residents were observed once for five randomly selected minutes during personal morning care (e.g., washing, showering). Morning care was chosen as the observational moment because it is supposed to be a possible provocative moment for pain. After observation, the PACSLAC-D was scored immediately. Additional comments of the PACSLAC-D checklist could be made on the first page (such as 'pain medication was distributed prior to observational moment'). Demographics and information on medication use and co-morbidity were gathered by a research assistant after residents were observed during morning care in order to ensure that nurses were unaware of this information and, therefore, that this information would not be able to influence scoring procedures. Almost all observers (except for two RNs) had no prior in-depth knowledge of the nursing home residents because they were observing residents of a ward that they were not familiar with.

\section{Ethical considerations}

Ethical approval was obtained by the Medical Ethics Committee (in the Arnhem-Nijmegen region in the Netherlands; \#2006/068). Permission to 
conduct the study was also obtained from the managing directors of the nursing homes. Before participation, tegistered legal guardians of the residents provided written informed consent.

\section{Data anabyses}

Descriptive statistics were computed for the characteristics of the respondents and in relation to pain. Differences between groups were determined using t-test. Prevalence data were calculated.

At first a multiple linear regression model was tested with pain as the outcome variable, and the predictors of gender, number of co-morbidities, use of analgesics (dichotomized), use of psychotropics (dichotomized), depressive symptoms (dichotomized), type of dementia (vascular dementia versus Alzheimer's) and total MMSE score as independent variables. The starting model was included with the interaction term 'analgesics * co-morbidities', which was tested and found to be significant. In this multiple regression model the explained variance $\left(R^{2}\right)$ was described. Because data were positively skewed, data were transformed using a log transformation.

In addition, a logistic regression model was tested by dichotomizing the outcome pain/no pain on the PACSLAC-D (cut-off score pain >=4). Statistical analyses were performed using SPSS software for all analyses. Results were considered statistically significant if $p$-values were less than 0.05 .

\section{RESULTS}

Sample

Of the 179 nursing home residents that were invited to participate, 117 residents gave permission and met the inclusion criteria; $20 \%$ were men $(n=23)$ and $80 \%$ women ( $\mathrm{n}=94)$. Ages ranged from 60 to 97 years, with a mean age of 82.8 $(\mathrm{SD}=6.1)$. The type of dementia syndrome, as well as the severity of the impairment, varied. The mean MMSE score of the participants was 5.7 $(\mathrm{SD}=6.8)$, indicating that the majority of the residents were severely cognitively impaired. Participants had on average $4.2(\mathrm{SD}=1.9)$ co-morbid conditions. Table 1 presents further information on the residents' characteristics.

\section{Prevalence of pain and characteristics of the residents in pain}

Of the 117 residents, 47\% ( $n=55)$ had a PACST_AC-D score greater than or equal to 4 , indicating pain. Pain prevalence rates differed slightly between the three participating nursing homes: $41 \%, 48 \%$ and $52 \%$.

The mean pain score of those 55 residents who experienced pain was 6.31 $(S D=2.8$; range 4-13) with a median of 5 . Further investigation of the data showed that $40 \%$ of the residents who experienced pain, as measured by the PACSLAC, received no pain medication. The overall mean pain score for the 
Table 1 Descriptive information of the nursing home residents included in the study

Characteristics of PG residents $(n=117)$

Male/ Female

$23 / 94$

Age in years (SD)

$82.8(6.1)$

Severity of the impairment based on the MMSE $n=(\%)$

MMSE $>=24$

$1(0.9 \%)$

mild-moderate. MMSE $>=8<24$

$39(33.3 \%)$

severe. MMSE <=7

$68(58.1 \%)$

not applicable. missing

Dementia diagnosis $n=(\%)$

Alzheimer's disease

$41(35.1 \%)$

Vascular dementia

$31(26.5 \%)$

Other (e.g. parkinson's disease. frontal lobe)

$10(8.4 \%)$

Mixed (Alzheimer's/ vascular)

$15(12.9 \%)$

Unknown

$20(17.1 \%)$

Medication (analgesic and psychotropic) $n=(\%)$

Analgesic

$\begin{array}{lc}\text { none } & 63(53.8 \%) \\ \text { regular } & 37(31.6 \%)^{*} \\ \text { when necessary } & 8(6.8 \%) \\ \text { daily and when necessary } 9(7.7 \%)\end{array}$

Psychotropic

$\begin{array}{ll}\text { none } & 34(29.1 \%) \\ \text { regular } & 52(44.4 \%) \\ \text { when necessary } & 6(5.1 \%) \\ \text { daily and when necessary } & 25(21.4 \%)\end{array}$

Total amount of different psychotropics per patient per day

$41(49.4 \%)$

$29(34.9 \%)$

$9(10.8 \%)$

$4(4.2 \%)$

Depressive symptoms

yes

$95(81.2 \%)$

no

* the use of acetylsalicylic acid is not included in the total use of analgesic otherwise total regular use would become $47 \%$ instead of $31.6 \%$, this medication is frequently used in long term low doses to prevent cardio vascular diseases. 
total group measured by the PACSLAC-D was $3.6(\mathrm{SD}=3.2$; range 0-13).

Of these 55 residents with pain score (PACSLAC> $>4$ ), all tended to be more severely cognitively impaired. $67 \%$ of the residents $(\mathrm{n}=37$ ) had an MMSE score below 7 , indicating severe cognitive impairment as compared to $50 \%(\mathrm{n}=$ 31) of the non-pain residents.

Residents with pain did not have significantly more additional diagnoses (mean number of co-morbidities=4.4) as compared to those with no pain (mean number of co-morbidities $=4.1$ ).

There seems to be a difference in PACSLAC-D scores between Alzheimer's residents $(n=41)$ and residents with vascular $(n=31)$ dementia. Although not significant, $(\mathrm{p}=.2)$ that slightly higher PACSLAC-D scores (mean score $=4.2$; $\mathrm{SD}=3.5$ ) were determined for the Alzheimer's group as compared to the residents with vascular dementia (mean score $=3.3 ; \mathrm{SD}=2.7$ ).

\section{Predictors associated with pain}

The multiple linear regression analyses showed that gender $(p=0.03)$, comorbidities $(p<0.001)$, use of analgesics $(p<0.01)$ and the interaction term 'comorbidities * analgesics' $(p<0.001)$ were significantly related to pain as measured on the PACSLAC-D. See Table 2 for the final linear regression model.

Table 2 Summary of results of linear regression model: characteristics associated with pain

\begin{tabular}{|c|c|c|c|c|c|c|}
\hline Predictor & B & Std. error & Sign. & Std. B & $95 \%$ & C.I. \\
\hline \multicolumn{7}{|l|}{ Final linear model $R^{2}=.150$} \\
\hline gender (women $=0$, men $=1$ ) & -0.16 & 0.07 & 0.03 & -0.19 & -0.30 & -0.01 \\
\hline co-morbidities & 0.09 & 0.02 & $<0.001$ & 0.54 & 0.04 & 0.14 \\
\hline use of analgesics & 0.40 & 0.14 & $<0.01$ & 0.60 & 0.13 & 0.67 \\
\hline co-morbidities* analgesics & -0.10 & 0.03 & $<0.001$ & -0.86 & -0.17 & -0.04 \\
\hline
\end{tabular}

Note: $95 \%$ C.I. $=95 \%$ confidence interval

The regression analyses demonstrated that women were at higher risk for suffering from pain than were men $(p=0.03)$. Residents with more health problems or residents who received analgesics on a regular basis had a higher chance of being in pain. The variables (use of psychotropics, total MMSE score) did not contribute to explaining variance significantly. The overall $\mathrm{R}$ square $=$ .150 indicates that predictors account for $15 \%$ of the variation in pain.

In addition, to confirm our findings, we used logistic regression by dichotomizing the outcome pain/no-pain on the PACSLAC-D (cut-off score pain $>=4$ ). The results of this logistic regression were similar to the results of the linear regression with the exception of the variable gender, which was not found 
to be significantly associated with pain in the logistic regression. The association remained significant for the variables, co-morbidities ( $\mathrm{p}<0.01$; OR $1.74 ; 95 \% \mathrm{CI}$ $1.15-2.62)$ and the interaction term $(p<0.01$; OR $0.48,95 \%$ CI $0.29-0.79)$. In particular, the logistic regression demonstrated that those residents who used analgesics were more likely to have pain (OR 14.94; 95\% CI 1.88-119.06).

Since no objective assessment tool was used to measure depressive symptoms and since data were more explorative on this variable, 'depressive symptoms' was not included as a variable in the primary regression analyses. If we additionally perform a linear regression analysis including this variable (depressive symptoms yes/no), 'depressive symptoms' proved to be a weak association for the presence of pain $(p=.05)$. The logistic regression showed that this variable 'depressive symptoms' was not found to be significant.

The demographic information in Table 1 shows that the type of dementia was unknown for $17 \%$ of the residents; this is because we depended on medical records for this information. Furthermore, a considerable number $(21 \%)$ of residents displayed a wide variety of dementia types (e.g., Parkinson's dementia, mixed type, frontal lobe). Due to these missing data and heterogeneity, type of dementia was not included in the primary regression analyses. However, subsequently, in an additional linear and logistic regression analysis, this variable (type of dementia: vascular/Alzheimer's) was also added. Analysis showed that 'type of dementia' did not contribute significantly to explaining variance $(p>$.2).

\section{DISCUSSION}

This study confirms what we expected from other studies in populations with less impaired older residents, namely, that pain prevalence in older tesidents with dementia living in Dutch nursing homes is high. Almost one out of two residents is possibly in pain, as assessed with a PACSLAC-D score greater than or equal to 4 . However, it must be noted that the overall scores of residents who experienced pain during morning care were 'mild' to 'moderate' (median=5). Furthermore, this study shows number of co-morbidities, the use of analgesics and the interaction term 'co-morbidities * use of analgesics' as most strongly associated with pain prevalence.

Although there are some studies ${ }^{0.4 .4} .7$ that determine the pain prevalence in a sample of older residents with dementia by using the MDS or patient's selfreport, to the best of our knowledge there is only one other study that has used an observational tool specially developed for this target population. The recently published study by Leong \& Nuo (2007) used the PAINAD with a sample of 36 severely impaired residents to determine pain prevalence rates. The PAINAD, a five-item observational tool, was scored retrospectively by asking the nurses if they had noticed any of the behaviours the previous week. In that study, pain was present in approximately $44 \%$ of the residents. Because of the retrospective 
character of this study, rates are only comparable to some degree with the rates found in our study. In accordance with our findings they also found high proportions of residents with mild pain $(33 \%)$.

Predictors of pain in our study were gender, number of co-morbidities, and analgesic use. The linear regression showed that women were more at risk for pain than were men. These findings are consistent with other international studies. ${ }^{2 * 31}$ However, it should be mentioned that gender in our study was not found to be statistically significant and had only a weak association $(p=.03)$ in the linear regression and was not a significant predictor in the logistic regression.

The OR related to analgesic use was found to be high (OR 14.94). Patients who received analgesics were almost 15 times more likely to have pain. These findings confirm that even treated residents obviously do not receive adequate treatment, since analgesic use was found to be the strongest predictor for the presence of pain. Pain management by complete pain relief is obviously very difficult. The use of a pain scale provides the opportunity to register and reevaluate the scores after an intervention such as analgesic use. On the other hand this result (high OR related to analgesic use) could also be interpreted as a validity support of the PACSLAC-D, since the scale seems to be well aware of detecting especially those who are at high risk for experiencing pain.

Our findings showed that the level of cognition, as measured by the MMSE, seems to be a significant predictor of pain. Fisher et al. found similar results although they excluded severely impaired older residents. ${ }^{17}$ Leong \& Nuo (2007) also found that pain prevalence did not differ among residents with normal, mildly impaired or severely impaired cognition. In contrast, other studies did find a significant association between cognition and pain. ${ }^{\text {e... }}$.

In previous studies depression was shown to relate to pain in cognitively impaired and non-impaired populations. ${ }^{10,}{ }^{18-211,31,32}$ In our study, depression was not optimally assessed mainly because it was not one of the main outcome measures. When 'depressive symptoms' was added as an independent variable, this variable proved to be of barely predictive value for the presence of pain.

The literature suggests that residents with Alzheimer's dementia experience a decrease in pain. ${ }^{21,33}$ Contradictory, descriptive statistics generated from the data in this study demonstrated that the PACSLAC scores of residents with Alzheimer's dementia (mean score $=4.2 ; \mathrm{SD}=3.5$ ) were slightly higher (nonsignificant) as compared to residents with vascular dementia (mean score $=3.3$; $\mathrm{SD}=2.7$ ). However, results of the regression analysis showed that 'type of dementia' did not contribute significantly to explaining variance. This analysis should be interpreted with care because of the limited sample size $(n=71)$.

These results should be interpreted in the context of some limitations, including a relatively small sample size. However, there is no reason to doubt that the results are representative since, with respect to most variables (with the exception of the use of psychotropics and analgesics), subjects did not differ 
between nursing homes. Yet, in order to allow for generalizibility and to avoid over- or underestimation of pain, performance of a larger study on pain prevalence is clearly warranted in the near future. In this future study we would recommend using another staging instrument in addition to the MMSE in order to classify the stage of dementia, for example, the Global Deterioration Scale (GDS). ${ }^{3+}$ The MMSE used in the present study is a relatively cruder instrument, initially developed as a screening instrument.

In previous studies ${ }^{12,35,36}$, residents (mostly mild and moderately impaired) were successfully asked to score a self-report scale (e.g., VRS). In this study no patient's self-report was included, a factor which might have strengthened the methodology. This could also be true for the fact that we used a 'one-point' measurement approach. Methodologically speaking, it would have been ideal to measure the prevalence of pain over a number of days in a row. But this was not possible because of practical limitations, and so a one-time measurement approach was chosen with the same rater per ward.

In the present study the inter-rater reliability of the PACSLAC-D was reexamined by assessing fifteen residents by two raters at the same time. Although, the Intra Class Correlation (ICC) was found to be high for the total scale .89 and adequate for almost all the subscales in this study, the fact that only two of the raters assessed the inter-rater reliability should be seen as a limitation of this study. However, in an earlier research study the inter-rater reliability of the PACSLAC between all scoring pairs $(n=12)$ was addressed and ranged from .39 to $.97 .^{12}$

Furthermore, residents were assessed during five randomly selected minutes of morning care. This approach was chosen because of the large variability of time spent on personal morning care such as washing and bathing. By randomly selecting five-minute intervals, observational procedures were standardized for all participants. However, the time factor may have fluctuated as far as content was concerned due to the fact of this standardization. Data were gathered during morning care, a possible provocative moment for pain. However, it should be kept in mind that this approach has its limitations and might have influenced findings to some extent. Selection of moments could lead to underdiagnosing of pain.

\section{CONCLUSION}

Overall pain intensity scores were relatively mild, but almost half of the participants experienced pain to some extent. Among the independent variables, co-morbidities, analgesic use and the adjusted interaction term 'co-morbidities * analgesic use' were shown to be valid significant predictors having the strongest associations with pain. 
A widespread implementation of observational pain scales such as the PACSI.AC-D should help health care workers to recognize and evaluate pain cues in a more reliable, valid and easy way. Although, the use of a proper pain scale in a non-verbally communicating population is just one aspect of the complete package deal for adequate pain assessment and management, it could definitely increase nurses' awareness and stimulate them to take the process of pain management one step further towards a pain-free nursing home.

\section{ACKNOWLEDGEMENTS}

The authors would like to thank all the staff of the participating nursing homes for their collaboration.

\section{REFERENCES}

1. Herr KA, Mobily PR. Complexities of pain assessment in the elderly. Clinical considerations. Journal of Gerontological Nursing. 1991;17(4):12-19.

2. Wagner AM, Goodwin M, Campbell B, et al. Pain prevalence and pain treatments for residents in Oregon nursing homes. Geriatric Nursing. 1997;18(6):268-272.

3. Weiner D, Peterson B, Ladd K, McConnell E, Keefe F. Pain in nursing home residents: an explotation of prevalence, staff perspectives, and practical aspects of measurement. Clinical Journal of Pain. 1999;15(2):92-101.

4. Ferrell BA, Ferrell BR, Rivera L. Pain in cognitively impaired nursing home patients. Journal of Pain \& Symptom Management. 1995;10(8):591-598.

5. Parmelee PA, Smith B, Katz IR. Pain complaints and cognitive status among elderly institution residents. J Am Geriatr Soc. May 1993;41(5):517-522.

6. McClean WJ, Higginbotham NH. Prevalence of pain among nursing home residents in rural New South Wales. Medical Journal of Australia. 2002;177(1):17-20.

7. Lin WC, Lum TY, Mehr DR, Kane RL. Measuring pain presence and intensity in nursing home residents. Journal of the American Medical

Directors Association. 2006;7(3):147-153.

8. Jones $\mathrm{KR}$, Fink $\mathrm{R}$, Hutt $\mathrm{E}$, et al. Measuring pain intensity in nursing home residents. Journal of Pain \& Symptom Management. 2005;30(6):519527.

9. Sengstaken EA, King SA. The problems of pain and its detection among geriatric nursing home residents. Journal of the American Geriatrics Society. 1993;41(5):541-544.

10. Sawyer P, Lillis JP, Bodner EV, Allman RM. Substantial daily pain among nursing home residents. Journal of the American Medical Directors Association. 2007;8(3):158-165.

11. Zyczkowska J, Szczerbinska K, Jantzi MR, Hirdes JP. Pain among the oldest old in community and institutional settings. Pain. May 2007;129(1-2):167-176. 
12. Zwakhalen SM, Hamers JP, Berger MP. The psychometric quality and clinical usefulness of three pain assessment tools for eldetly people with dementia. Pain. 2006;126(1-3):210-220.

13. Zwakhalen SM, Hamers JP, Berger MP. Improving the clinical usefulness of a behavioural pain scale for older people with dementia. Journal of Advanced Nursing. 2007;58(3):1-9.

14. Fuchs-I acelle $S$, Hadjistavropoulos T. Development and preliminary validation of the pain assessment checklist for seniors with limited ability to communicate (PACSLAC). Pain Management Nursing. 2004;5(1):37-49.

15. Zwakhalen SM, Hamers JP, $\Lambda$ bu-Saad HH, Berger MP. Pain in elderly people with severe dementia: a systematic teview of behavioural pain assessment tools. BMC Geriatrics. 2006;6:3.

16. Proctor WR, Hirdes JP. Pain and cognitive status among nursing home residents in Canada. Pain Res Manag. Fall 2001;6(3):119-125.

17. Fisher SE, Burgio LD, Thorn BLi, et al. Pain assessment and management in cognitively impaired nursing home residents: association of certified nursing assistant pain report, Minimum Data Set pain report, and analgesic medication use. Journal of the American Geriatrics Society. 2002;50(1):152-156.

18. Leong IY, Nuo TH. Prevalence of pain in nursing home residents with different cognitive and communicative abilities. Clinical Journal of Pain. 2007;23(2):119-127.

19. Gruber-Baldini AL, Zimmerman S, Boustani M, Watson LC, Williams CS, Reed PS. Characteristics associated with depression in long-term care residents with dementia. Gerontologist. 2005;45 Spec No 1(1):50-55.

20. Smalbrugge M, Jongenelis LK, Pot AM, Beekman AT, Eefsting JA. Pain among nursing home patients in the Netherlands: prevalence, course, clinical correlates, recognition and analgesic treatment--an observational cohort study. BMC Geriatrics. 2007;7:3.

21. Benedetti F, Vighetti S, Ricco C, et al. Pain threshold and tolerance in Alzheimer's disease. Pain. 1999;80(1-2):377-382.

22. Scherder $E$, Bouma A, Borkent $M$, Rahman O. Alzheimer patients report less pain intensity and pain affect than non-demented elderly. Psychiatry. 1999;62(3):265-272.

23. American Psychiatric Association. Diagnostic and statistical manual of mental disorder. 4 ed. Washington DC: American Psychiatric Association; 1994.

24. Sig Zorginformatie en de Nederlandse Vereniging van Verpleeghuisartsen (NVVA). Classificatie van ziekten voor de verpleeghuisgeneeskunde, standaard. Utrecht 1995.

25. http://www.who.int/classifications/icd/en/.

26. Wold Health Organisation Collaborating Centre for Drugs Statistics Methodology. Anatomical Therapeutical Chemical (ATC) classification index including defined daily doses (DDD's) for plain substances. Olso 1997.

27. Folstein MF, Folstein SE, McHugh PR. "Mini-mental state". A practical method for grading the cognitive state of patients for the clinician. Journal of Psychiatric Research. 1975;12(3):189-198.

28. Brattberg G, Parker MG, Thorslund $M$. The prevalence of pain among the oldest old in Sweden. Pain. 1996;67(1):29-34.

29. Crook J, Rideout E, Browne $G$. The prevalence of pain complaints in a general population. Pain. 1984;18(3):299-314. 
30. Elliott AM, Smith BH, Penny KI, Smith WC, Chambers WA. The epidemiology of chronic pain in the community. Lancet. 1999;354(9186):1248-1252.

31. Magni G, Marchetti M, Moreschi C, Merskey H, Luchini SR. Chronic musculoskeletal pain and depressive symptoms in the National Health and Nutrition Examination. I. Epidemiologic follow-up study. Pain. 1993;53(2):163-168.

32. Landi F, Onder $G$, Cesari $M$, et al. Pain and its relation to depressive simptoms in frail older people living in the community: an observational study. Journal of Pain \& Symptom Management. 2005;29(3):255-262.

33. Scherder E, Bouma A, Slacts J, et al. Repeated pain assessment in Alzheimer's disease. Dementia \& Geriatric Cognitive Disorders. 2001;12(6):400-407.

34. Reisberg B, Ferris SH, de Leon MJ, Crook T. Global Deterioration Scale (GDS). Psychopharmacology Bulletin. 1988;24(4):661-663.

35. Cohen-Mansfield J, Lipson $S$. The utility of pain assessment for analgesic use in persons with dementia. Pain. 2007; In press.

36. Pautex S, Herrmann F, Le Lous P, Fabjan M, Michel JP, Gold G. Feasibility and reliability of four pain self-assessment scales and corrclation with an obscrvational rating scale in hospitalized elderly demented patients. Journals of Gerontology Series A-Biological Sciences \& Medical Sciences. 2005;60(4):524-529. 
Chapter 7

General discussion 


\section{GENERAL DISCUSSION}

\section{Introduction}

7 his thesis investigates pain assessment in elderly nursing home residents 1 with dementia. This chapter begins with an overview of the main findings. After discussing some methodological strengths and limitations of the study, this chapter will end with the clinical and research implications of this study:

\section{MAIN FINDINGS}

\section{Nursing bome staff bave deficits in knowledge related to pain}

Evidence of knowledge deficits regarding pain treatment and medication in elderly nursing home residents was found. These findings agree with the results from other studies on pain knowledge and attitude. ${ }^{2}$ Knowledge gaps or negative beliefs about pain in elderly people with dementia constituted a possible contributing factor to inadequate assessment and treatment. Furthermore, the staffs educational level seemed to influence their beliefs and knowledge about pain in elderly nursing home residents. This finding is of importance considering the fact that nursing home care is provided by a large number of caregivers and nursing assistants, who have a limited educational background.

\section{Of the twelve observational scales available, most sbow moderate psychometric qualities}

Most of the twelve observational scales identified by a systematic review are in the process of development and show moderate psychometric qualities. Many studies lack information on sensitivity and specificity, which is of extreme importance for the clinical implications of such tools. Based on the psychometric qualities and on criteria regarding sensitivity and clinical utility, we have concluded that PACSLAC, PAINAD and DOLOPLUS2 are the most appropriate measurement scales currently available. Further research should focus on improving these scales by further testing their validity, reliability and clinical utility.

\section{PACSLAC-D, a valid, reliable, but above all useful pain scale}

The findings of the psychometric testing presented in Chapter 4 provided evidence for the validity and reliability of three pain scales (PAINAD, PACSLAC and DOLOPLUS-2) for nursing home residents with dementia. With regard to clinical usefulness it was concluded that the PACSI_AC was rated as the most useful scale by care providers, although this scale needed to be refined.

Reduction in the number of items increased the homogeneity of the (sub)scale and further improved its usefulness for daily clinical practice. The findings in Chapter 5 showed how a brief and manageable version of the PACSLAC-D was finally developed, with a three-component solution including 
24 tath. Thi wertion hat high levels of internal consistency for the complete

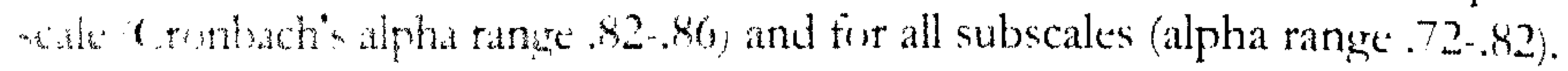

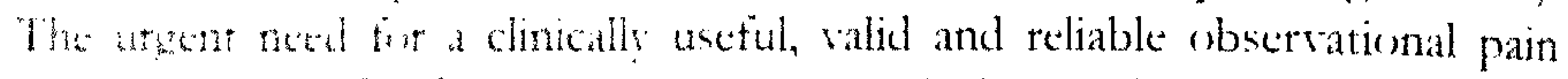
inewentment scale for daily use in measuring pain in Dutch nursing homes was therehs satintidel.

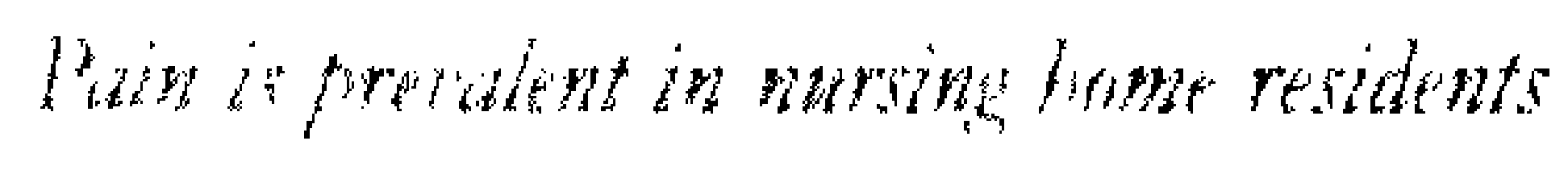

It can be conciuded trom the results of the last study presented in Chapter o that pain in presdent in nursing home residents with dementia. ()erall pain intensity "forten were relatively mild, but almost half of the participants $(47 \%$ \%) experienced pain to wome extent. Among the independent variables used, co. merlondities, andigesic use, gender and the adjusted interaction term (co)merbidities and analyesic use) were shown to be valid significant predictors.

\section{MITHODOLOCICAL CONSIDERATIONS}

Tro answer the research questions, the different studies in this thesis emploved different designs. More specifically, methodologically speaking the project consisted of a systematic review; a cross-sectional survey and two clinical studies with an observational study design. In this section some of the methodological strengths and limitations will be discussed.

\section{Strenuths}

Our teriew of the literature was based on extended quality criteria and provided an optimal starting point for comparing the psychometric qualities of the existing obsetvational pain scales. This was of great advantage when comparing scales, and their reliability and validity, in a systematic way. In addition, this information was used to select the best scoring scales for our subsequent study. Because of our focus on the existing pain scales, we definitely benefited from the lessons of others who already were in the process of scale development. This could be seen as one strength of the study because this focus provided us wirh the opportunity not only to learn from other scale developmental procedures, but also to take the research of pain assessment in this target pepulation one step further by improving a pain scale and its clinical usefulness.

The sistematic review was downloaded nearly 12,000 times during the first vear of its appearance in the online journal BMC geriatrics. This confirms the fact that pain assessment in nursing home residents with dementia is a matter of importance, and that there is a clear and urgent need for a sustematic review that craluates and presents the current observational pain scales available. Within a sherr perien of time, two other reviews were published that showed similar results. "This confirmed the findings of our systematic review:

I indinge from the psychometric testing of the selected scales provide eridence and contirmation for the validlity and teliability of the selected pain 
assessment scales. To the best of our knowledge this was the first time that three different pain scales, were extensively tested beyond the initial study setting and population. This testing of three scales in one cross-sectional study enhanced the comparability of the findings, which is a great advantage of this study.

The PACSLAC originally contained 60 items. Results of the psychometric testing of the scale demonstrated that this 60-item version was valid and reliable. Although Cronbach's $\alpha$ was good $(>.80)$ for the total PACSI.AC scale and two subscales, internal consistency scores of the 'activity/body movement' and 'physiological indicators/etc.' subscales were low $(\alpha<.55)$. The fact that many of the PACSLAC items were frequently not used and that the item-total correlation was below 20 , indicates that the number of items could be reduced. Therefore, the PACSLAC scale was refined and named PACSLAC-D. This final scale encompasses a total of 24 items without losing significant information. Results have shown that the reduced version of the scale correlates highly with the long 60-item version of the scale, resulting in a Pearson's correlation coefficient of 945. Item reduction, which resulted in increased homogeneity of the PACSLAC and improved clinical usefulness, has some minor disadvantages, which should be acknowledged, however. The original 60-item version of the PACSLAC measured all six of the non-verbal pain behaviour domains that were suggested as important by the American Geriatric Pain Society guidelines on pain. ${ }^{5}$ After item reduction, the PACSLAC-D only measures four of the six domains and PACSLAC-D is consequently less comprehensive. Comprehensive scales would potentially have a higher sensitivity than less comprehensive ones if all categories of behaviour have similar sensitivity in the diagnosis of pain. However, its lack of specificity may be an indication of a high number of false positive scores. ${ }^{6}$ PACSLAC items were deleted through strict use of the criteria's set and, since PACSLAC-D did not seem to have lost any important information due to the reduction process, this shortened scale should be given priority over a more comprehensive scale. Thus, we succeeded in developing an observational scale, which is reliable, valid and clinically useful in determining pain in elderly residents with dementia. The end product of this thesis, PACSLAC-D, will contribute to evidence-based practice.

We clearly stressed the importance of clinical usefulness. This has resulted in a scale that is usable without needing in-depth knowledge of the resident's behaviour. This is a great advantage in daily practice, not only for nursing staff who will probably be the most frequent users, but especially for other health care providers who have less frequent contact with the resident.

\section{Limitations}

The total sample size depended on the number of informed consents obtained from legal guardians. A total of 128 residents participated in the study to investigate the psychometric qualities. Given the large amount of items $(n=60)$ 
in the PACSLAC-D and using the rule of thumb of five to ten participants for each item, the sample size in this study $(\mathrm{n}=128)$ was relatively small, particularly given the fact that a majority of residents had mild or moderate pain.

With regard to external validity, one might question to what extent these results are generalizable to all pain settings. To be more precise, data were gathered during vaccinations. However, we did use additional (patient-specific) pain moments to enhance the reliability of our results. Nevertheless, it should be kept in mind that the items collected for this purpose might be influenced by the type of pain focused on when collecting the items. Most of the PACSI_AC-D indicators are more likely to be associated with acute pain or pain during procedures (e.g. care, transfer). In future research, more attention should be paid to considering the differences between acute and chronic pain. Thus, although a variability of pain moments was sclected, it is still imaginable that more chronic pain moments might involve a more frequent use of other items.

In the developmental procedure of a pain scale, ideally one would prefer a normal distribution of pain scores ranging from mild to severe pain, with only a limited number of pain scores clustered around zero. In this study, raters assessed the residents' pain at rest and during vaccination. The data gathered during the influenza injection in our psychometric study were not normally distributed, since scores were frequently clustered around zero. Not only may this positively skewed distribution of pain scores have influenced the agreement (high intra- and inter-rater) but higher pain might also yield other pain cues. Therefore, in addition, a selected group of residents was also assessed during one specific pain moment. This patient-specific pain moment (such as care, washing or mobilization) yielded higher pain scores and this moment definitely made an important contribution to the scale development of the PACSLAC-D.

Another methodological limitation is the fact that residents and raters were not blinded to the intervention, and data were gathered in a controlled situation that was considered to be painful (injection or pain-specific moment). To overcome this problem, in the last study on pain prevalence we asked nurses to rate the residents from another ward during morning care (washing, bathing, etc.).

In retrospect, one might question the comprehensiveness of the data collected in this study. What other variables should have been measured and what information might have been missing? In this study the emphasis was primarily on extensively comparing and testing existing pain scales. A comparison was made between a patient's self-report and the selected scale, and between the scales tested. Less attention was paid to other constructs like distress and depression. As a result, the distinction between pain and other constructs like distress was not determined sufficiently in this study. It would have strengthened our methodology if this had been highlighted more and 
therefore this needs to be further investigated.

As in every study, it can be questioned whether we used the proper statistical analyses. An affirmative answer should be given in response to this question, although other approaches and choices may have yielded different results and therefore different items in the final scale. Scale construction is evident in the choices made during the process of item development and data analyses. Furthermore, it is still to be recommended that other statistical approaches be explored so as to further develop and strengthen the scale when new data are gathered. Up until now the psychometric quality of the PACSLAC-D has been investigated with the classical test theory (CTT). CTT has dominated the area of psychometric testing and is based on the assumption that the observed score of a test-taker is usually seen as an estimate of the true scores of that test-taker plus/minus some unobservable measurement error.' Scores depend on the content of the test. This approach can be criticized because it was assumed in the prior testing that pain was somehow a linear function of the resident's pain. Furthermore, a general pain scale contains only a main set of the most important pain items. Some residents may respond differently, individually, towards pain. One may well wonder whether these general scales measured pain adequately enough for those residents who react to pain in a highly individual way and whether it would not be more informative if these individual differences could also be captured by an individual pain approach that could be used in addition to the general pain scale. A new approach to the assessment of pain, based on the item response theory (IRT), could investigate this in order to resolve some of the above-mentioned problems.

\section{IMPLICATIONS}

The findings from this study may have implications for the different parties involved in the process of pain management, namely, the nursing home residents, policy makers, health care professionals and researchers.

\section{CLINICAL IMPLICATIONS}

\section{Implications for the nursing bome residents}

This project on pain assessment in nursing home residents with dementia provides insight into the importance of two important aspects, namely, pain assessment, and nurses' belief and knowledge about pain. Both aspects could contribute to optimal treatment and improve the care of the demented elderly living in nursing homes.

There is no better moment for a patient in pain than the moment the pain disappears! Therefore, a pain-free condition should be the major aim and greatest challenge in pain treatment. However, this aim will often not be fulfilled, especially for elderly nursing home residents who are non-verbal and dependent 
on others. Research has demonstrated that increased cognitive impairment, together with being over 85 years old, male and of non-white ethnicity, are predictors of poor analgesic administration; these conditions put people at risk for inadequate pain treatment. ${ }^{8}$ The use of an observational pain scale can make a significant contribution to the process of adequate treatment and improve the residents' overall quality of life. Kamel and colleagues ${ }^{9}$ demonstrated that using pain assessment scales increased the overall frequency of diagnosing pain among nursing home residents and thereby proved that pain assessment does matter evidentially.

\section{Implications for policy makers in nursing bomes}

Policy makers should stimulate the effective management of pain, starting with adequate assessment, for several reasons. Adequate assessment is important in providing optimal care and treatment, which is the main goal of nursing home care. But, furthermore, persistent pain is associated with increased health care costs. ${ }^{5}$ Although the direct and indirect costs caused by pain are often difficult to measure, the costs of pain for health care insurance and society are enormous. Only with respect to medication consumption in the Netherlands alone, elderly over 65 years old use 2.9 times as many registered medicines. Due to the ageing population, pharmaceutical costs yearly increase by $0.6 \%{ }^{1 "} \mathrm{~A}$ better pain policy, starting with the use of an adequate pain assessment scale, could be viewed as cost-responsible behaviour with the main goal of providing optimal care.

Another issue that needs to be discussed by policymakers is the deficit in nurses' knowledge and their beliefs about pain. One of the studies revealed that nurses lacked knowledge in particular about pain treatment (e.g., about the uses of medications and the risks of addiction). Educational level was found to influence nursing staff beliefs and knowledge. More highly educated nurses had better knowledge (i.e., were in better agreement with the current literature) and seemed more aware of several issues related to pain. This result is consistent with findings by Brunier, Carson et al." Therefore, there is a need not only for continuing education for nurses already working in nursing homes, but also for more highly educated nurses to be brought in to work in nursing home care.

\section{Implications for bealth care professionals}

The findings from this study have probably the most clear and practical implications for the key users of the PACSLAC-D, namely nursing home staff themselves. The development of the PACSLAC-D might contribute to more evidence-based care guidelines when considering pain assessment and its treatment. A major question for nurses is: how should the PACSLAC-D be used? The use of the PACSIAAC-D should be embedded in a common framework and clinical guidelines should be known. Comprehensive clinical practice guidelines for the assessment of pain in elderly people with and without cognitive 
impairment already exist and were formulated by the AGS in 2002.5 To summarize, these guideline recommendations included:

1. On initial admission of any older person to a health care service, a health care professional should assess the patient for evidence of existing pain.

2. Any persistent pain that has an impact on physical function, psychosocial function or other aspect of quality of life should be recognized as a significant problem.

3. All patients with persistent pain that may affect physical function, psychosocial function or other aspect of quality of life should undergo a comprehensive pain assessment, with the goal of identifying all potentially remediable factors.

4. For the older adult with moderate to severe dementia or who is non-verbal, the practitioner should attempt to assess pain via direct observation or history from caregivers. For the assessment of pain they should refer to an algorithm developed by Snow et.al..$^{12}$; see Figure 1 .

5. The risk and benefits of various assessment and treatment options should be discussed with patients and family.

6. Patients with persistent pain should be reassessed regularly for improvement, deterioration or complications.

In our opinion the use of the PACSLAC fits clearly within those guidelines.

Furthermore, it is important to note that one of the essential findings of our study is that behavioural symptoms referring to, for example, mood, aggression and agitation play a statistically significant important role in detecting pain. Also, Leong and $\mathrm{Nuo}^{\prime}$ concluded that there is an overlap between pain-related behaviour and affect-related behaviour. These behavioural cues have to be considered as important alarm signals for possible pain. However, given the nonpain-specific character of these behavioural pain cues, it is quite imaginable that nurses will fail to interpret or will misinterpret these signs. No single pain cue is an exclusive marker for pain and, therefore, the combination of cues as is specified in a reliable and valid observational scale such as the PACSLAC-D should be used. Scoring provides nurses not only with the opportunity to determine a resident's behavioural pain pattern, but also to record and (re-)evaluate the score after a therapeutic intervention.

The PACSLAC not only provides an objective tool for assessing pain for nurses, but also for other health care professionals who often contact the nursing home resident. In-depth knowledge of the resident is not essential to rate the patient's pain and this is one of the strengths of the PACSLAC-D. Therefore, information gathered by physiotherapists about the resident's pain may be very valuable in creating a complete pain picture. These health care professionals may provoke situations that do not occur during usual nursing care and, therefore, may add important information through a multidisciplinary approach. 
Restarbl intliciations

Although some research implications have been noted in the previous sections and chapters in this thesis, some recommendations for further rescarch should be highlighted in this section. Iirst off all, PACSLAC-D is an adequate pain assessment scale, but it could be improved still further by additional testing of its construct validity and responsireness. One question that remains open for further research relates to whether it is possible to reduce the number of items still further so as to gain a set of key pain items without losing sensitivity: Secondly, in the previous study a cut-off score of 4 was determined. It would seem worthwhile to develop a scoring procedure for PACSLAC-D in order to measure moderate and severe pain as well.

One of our main priorities for the near future will be the widespread implementation of the PACSLAC-D in clinical practice. There are two major reasons for this, namely: (1) to make sure that the PACSLAC-D becomes available to measure pain for nursing home staff who are confronted daily with this problem in nursing home care, and (2) to further research the effectiveness of implementing the PASCLAC-D.

In order to make the scale available, PACSLAC-D needs to be implemented by means of a clear set of instructions and, in addition, a pain protocol needs to be developed. Pharmacological and non-pharmacological treatment options deserve attention, and in addition so does nurses' awareness as to whether pain is present and, therefore, should be part of such a protocol.

A study on the effectiveness of implementing a pain assessment scale would be another point of focus. Measuring the effectiveness of a pain assessment scale in an implementation study should contain multi-faceted implementation strategies needed to address individual, team and organizational factors. ${ }^{.3}$

A future effectiveness study could benefit from the results of this project by using the psychometrically sound PACSLAC-D to measure pain, the primary outcome variable. Given the importance of nurses' knowledge and beliefs, it would be of great importance to measure the effectiveness of implementing the PACSLAC-D on two levels, namely at residents' and nursing-staff levels. With regard to the nursing home residents' level, it should be further noted that behavioural aspects are extremely important in assessing pain. Thercfore, behaviour should play a more prominent role as an outcome measure when measuring the effectiveness of implementing the PACSLAC.

Finally, as it was suggested in the previous section on methodological issues, other approaches to pain assessment such as the Item Response Theory models should be investigated because these may add to the boxdy of knowledge. 
Figure 1 Pain assessment model developed by Snow et al., 2004

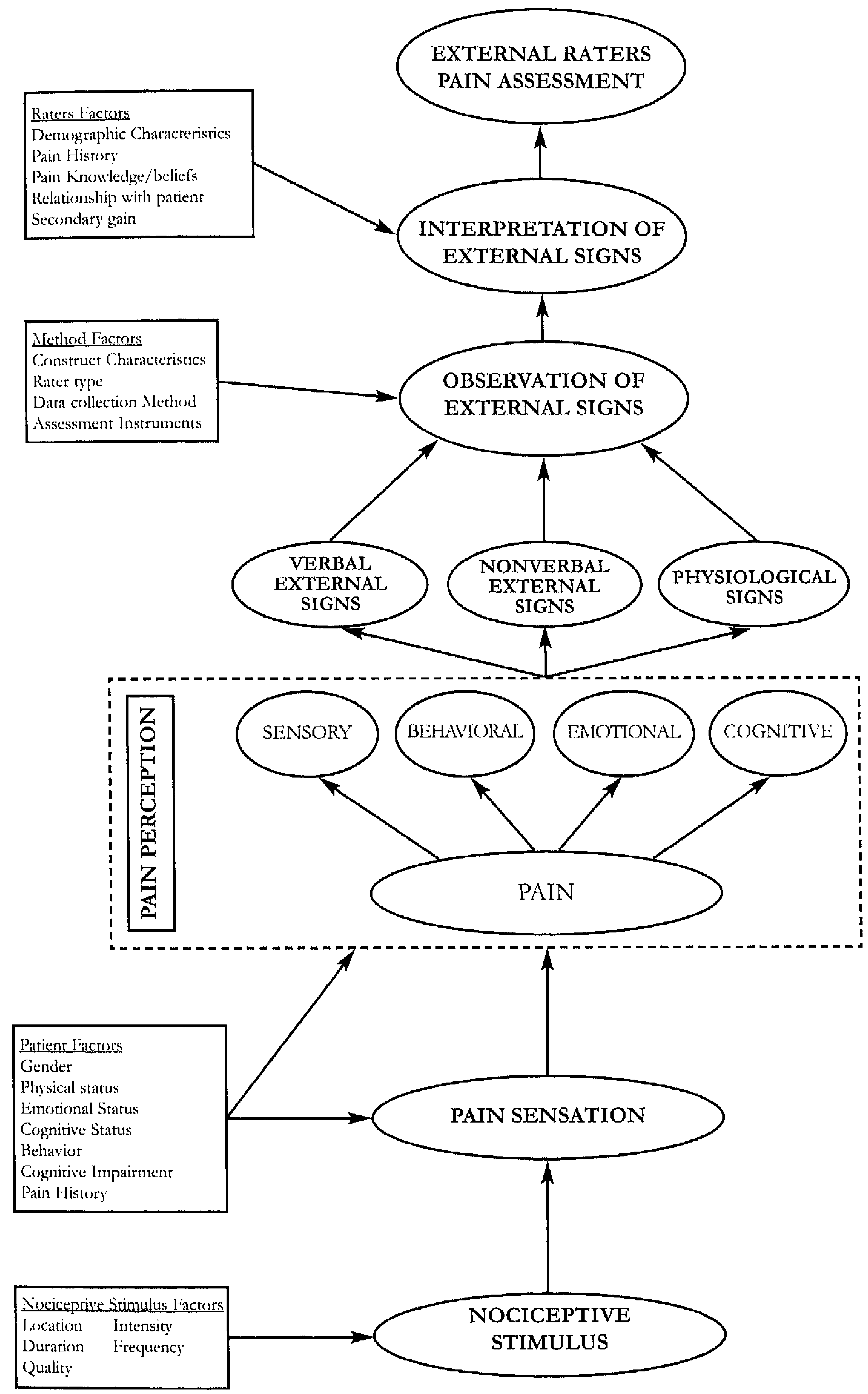




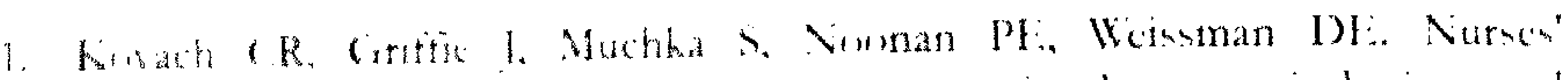

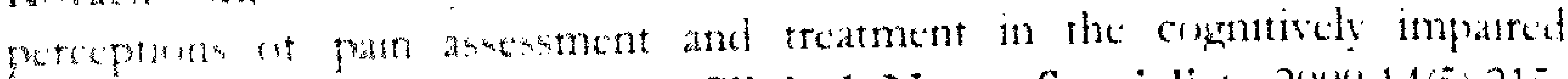

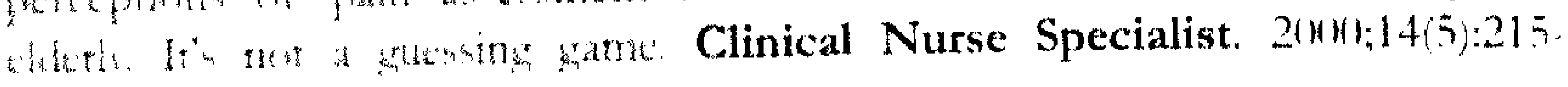
321

2. Shman R. Ahern M. Wright 1. Brown I. Nurses knowledge of pain in the k.t.th: Journal of Pain \& Symptom Management. 2(1)1:21(4):3177.322.

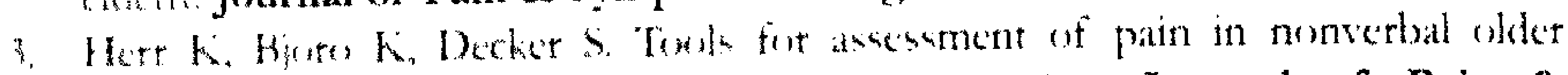
whitw weth dementia: a watenethe-science review: Journal of Pain \& Symptom Management. 2116(3)31(2):1711.192.

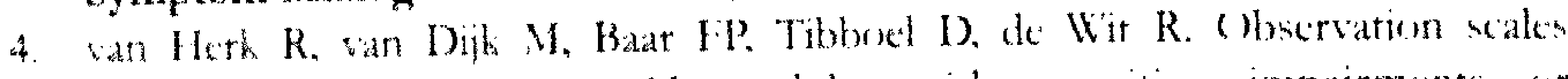
tor pam adesement in oklet adults with congnitive impaiments ot communumation difficulties. Nurs Res. Jan-Feb 21k17:56(1):34-43.

3. Xes Panel in Persistent Pain in (I)der Persons. The management of perustent pain in older persens. Journal of the American Geriatrics Society. 2612,506, Supply:S205-224.

6. Letng IV. Nue TH. Prevalence of pain in nursing home residents with ditferent congntwe and communicative abilities. Clinical Journal of Pain. $2(14: 23(2): 119 \cdot 12 \%$

- Hambleton RK. Swaminathan H. Item response theory: principles and applications. Beston: Kluwer Vrijhoff Publishing: 1985.

*. Win 1, Iapane K, Cambassi (;, Bernabei R, Mor V, I ipsitz IA. Correlates and managentent of nommalignant pain in the nursing home. SACiE: Stud: Group. Srstematic Assessment of Geriatric drug use via Epidemiology. Journal of the American Geriatrics Society. 1909;47(8):936-942.

9. Kamel HK, Phlawan M, Malekgoudarzi B, Gongel P, Norley Jf. Utilizing pain assessment scales increases the frequency of diagnosing pain among elderly nursing home residents, Journal of Pain \& Symptom Management. $2(3): 21(6): 45(1-455$.

16. Mulder WI. Farmacokinetiek en farmacologie bij ouderen. Pijn Info. 2(4); ()ktober:29-42.

11. Brunier $G_{n}$ Carson $M G$, Harrison DF. What do nurses know and believe abrut patients with pain? Results of a hospital survey. Journal of Pain \& Symptom Management. 1995;10(6):436-445.

12. Snu AL, OMalle KJ, Coly M, et al. A conceptual model of pain assessment for noncommunicative persons with dementia. The Gerontologist. 2(1) $4: 44(0): 80$ ? 817.

13. Cirol R, Grimshaw J. From best evidence to best practice: effective implementation of change in patients' cars. Lancet. $20033 ; 3(2(9) 391): 1225$. 1230 . 


\section{Chapter 8}

Summary

Samenvatting

Dankwoord

About the author 
SUMMARY

Dain assessment and its management in nursing home residents with dementia is a complex challenge for nursing home staff. This thesis aims to gain insight into pain assessment in elderly nursing home residents with dementia. The first chapter provides a general introduction and background to pain in elderly people with dementia. It specifies the overall aim and presents an overview of the thesis.

Chapter 2 shows the results of a questionnaire developed to measure possible deficits in nursing staff knowledge and beliefs about pain in elderly people with dementia, which may influence their behaviour in pain assessment and management. The 17-item questionnaire aimed to investigate differences between several categories of nurses (based on educational level and work experience) with respect to beliefs about pain. It comprised four components (knowledge of the pain experience of older compared to younger people, pain management in the ward, pain medication, pain and pain treatment in older adults) with an overall Cronbach's alpha of .782 . Results showed that nursing home staff respondents showed knowledge deficits about several aspects of pain - specifically pain treatment and medication - despite being satisfied about the way pain was assessed and treated in their wards. Staff educational level seemed to influence their beliefs; the more highly educated nurses had better knowledge (i.e. in better agreement with current literature) and seemed more aware of several issues related to pain. The knowledge gaps and negative beliefs identified in this could contribute to inadequate assessment and treatment.

Chapter 3 presents a systematic review of behavioural pain assessment tools. Awareness of the pain problem in this population has increased over the last decade. Therefore, valuable knowledge has come to light from researchers who have developed pain assessment scales for elderly people with dementia. The reliability, validity and usefulness of existing pain assessment tools is evaluated in this review. Overall, twelve pain assessment tools were identified using an extensive search strategy. Quality judgement criteria were formulated and used to evaluate the psychometric aspects of the scales. Most of the twelve scales included in this review were published after 2002, which demonstrates that the area has received more attention in recent years. Findings indicate that most observational scales are under development and show moderate psychometric qualities. Only four of the scales scored 11 points in our quality judgement, which has a scoring range from 0 to 20, viz. DOLOPLUS2, ECPA, PAINAD, PACSLAC. Based on the psychometric qualities and criteria regarding sensitivity and clinical utility, we conclude that PACSLAC and DOLOPLUS2 are the most appropriate scales currently available. Furthermore, that none of the behavioural pain assessment scales have been extensively tested in a variety of care settings for different types of pain limits their clinical utility. In view of the limited qualities of the scales, further research is essential for additional refinement, 
development and testing. Therefore, we decided to translate the highest-scoring observational scales into Dutch and test them for the first time outside their original research setting.

Chapter 4 reports on this psychometric testing of the translated versions of the PAINAD, PACSL AC, and DOLOPLUS-2 scales. Observations were carried out during potentially painful moments (influenza vaccination and care situations). In total, 128 nursing home residents of 12 psychogeriatric (PG) wards met the inclusion criteria and gave their informed consent. The findings of this study provide evidence of the validity and reliability of the three pain assessment scales. However, the PACSL_AC was judged the most useful scale: participating nurses described it as user-friendly and not overly time-consuming. Cronbach's alpha was high (>.80) for the total PACSLAC scale at T2 (influenza injection) and T3 (specific pain moment) and adequate for the 'facial expression' and 'social/personality/mood' subscales. IC scores for the 'activity/body movement' and 'physiological indicators/eating/sleeping changes/vocal behaviors' subscales were low. 'The scale demonstrated strong validity and reliability, though it should be further refined in order to increase homogeneity and further clinical usefulness. The PAINAD showed good psychometric qualities in terms of reliability, validity and homogeneity ( $\alpha$ ranged .69 to .74 at T2 and 'T3) (except for the 'breathing' item), but had lower scores for clinical usefulness in this sample. Approximately half of the participants were able to use the VRS. Higher VRS scores were consistent with higher total scores on the observational scales PAINAD and PACSLAC. The Dutch version of the DOLOPLUS-2 was considered more difficult to use but showed acceptable psychometric qualities in terms of the issues assessed, except for the 'psychosocial reactions' subscale. IC scores from the DOLOPLUS were adequate for the total scale ( $\alpha$ ranged .74 to .75) and almost all subscales ( $\alpha$ ranged .58-.80). In light of these findings, future studies need to focus on further refinement of the scale and additional testing, as well as examining the prevalence of pain by using an observational pain scale.

Chapter 5 describes the refinement of the PACSLAC. Mores specifically, this chapter reports on the process of item reduction as part of the construction of the PACSLAC-D scale, the shortened Dutch version to assess pain in older Dutch nursing home residents with dementia. In the previous study, the PACSLAC demonstrated overall acceptable psychometric qualities, with the exception of internal consistency. However, nurses found the 60-item scale overcomprehensive and simply too long. Therefore, internal consistency and Principal Component Analysis (PCA) were used to examine the psychometric quality and underlying factor structure of the scale in order to refine it. A brief and manageable version of the PACSLAC-D was developed, with a threecomponent solution consisting of 24 items. The results of the PCA show that the three factors explaining the underlying factor structure related to facial and vocal expressions, resistance/defence and social-emotional aspects/mood. This 
24-item version had high levels of internal consistency for the complete scale (Cronbach's alpha range .82-86) and for all subscales (alpha range .72-.82). Findings demonstrated that social-emotional items played a significant role in detecting pain. While facial expressions seem to be more universal pain cues, these social-emotional cues seem more specific and important for older people with dementia. It is very important for nurses and other healthcare workers to link these social-emotional behavioural cues to possible painful conditions. Now that a practical scale is available for the Dutch nursing home setting, further research should include the examination of the adequacy and effectiveness of the scale in daily clinical practice and their effects on pain management. The PACSLAC-D can be found in the appendix of this chapter.

Chapter 6 aims to explore the prevalence of pain in nursing home residents with dementia as measured by the PACSLAC-D, and to identify the associations between demographic parameters such as cognitive status, gender, analgesic use and co-morbidity, and the prevalence of pain. In an observational study design, 117 residents were observed and assessed for pain during personal morning care (e.g., washing, showering), which can be a possible provocative moment for pain. The PACSLAC-D was used to assess pain and the findings show that almost half of the participants $(47 \%)$ experienced pain to some extent. However, overall pain intensity scores were relatively mild. Of the 55 residents with clinically relevant pain (PACSLAC> $=4$ ), the mean pain score was 6.31 (SD 2.8; range 413) with a median of 5 . Findings showed, furthermore, that $40 \%$ of the residents who experienced pain as measured by the PACSLAC received no pain medication. Results from the regression analyses showed that among the independent variables, co-morbidities, analgesic use and the adjusted interaction term 'co-morbidities * analgesic use' were shown to be valid significant predictors that had the strongest associations with pain. We recommend that observational pain scales such as the PACSLAC-D are implemented in clinical practice. This should help health care workers recognize and evaluate pain cues in a more reliable, valid and simple manner.

Chapter 7 presents a general discussion of the studies described in this thesis, as well as a summary of the main findings. Methodological considerations are addressed, including their strengths and limitations, with a focus on the study and data collection procedure (scale development), external validity and the analyses used. The chapter ends by addressing some important clinical implications for nursing home residents, policy makers and health care professionals, as well as research implications. 


\section{SAMENVATTING}

Pijnbeoordeling en behandeling van verpleeghuisbewoners met dementie is 1 een complexe uitdaging voor het verplegend personeel in de verpleeghuizen. Het doel van deze studie is inzicht te krijgen in pijnbeoordeling bij verpleeghuisbewoners met dementie. De studie beschrijft onder andere het tot stand komen van een pijnschaal, PACSLAC-D genaamd, voor de Nederlandse verpleeghuissetting. In het eerste hoofdstuk, de introductie, wordt achtergrondinformatie verstrekt over pijn bij ouderen met dementie. Er wordt ingegaan op de doelstellingen die aan het onderzoek ten grondslag liggen en de hoofdlijnen worden weergegeven.

Hoofdstuk 2 beschrijft de resultaten van een vragenlijstonderzoek naar de kennis over pijn bij verpleeghuisbewoners, uitgevoerd in een steekproef van verpleeghuismedewerkers. Kennistekorten beïnvloeden mogelijk de inschatting en bestrijding van pijn bij ouderen met dementie. Kennistekorten over pijn zijn in kaart gebracht middels een hiervoor speciaal ontwikkelde vragenlijst. Vervolgens zijn de gegevens van de vragenlijst verspreid onder de medewerkers vergeleken met twee groepen hoogopgeleide verpleegkundigen. De ontwikkelde vragenlijst met 17 items is intern consistent gebleken met een Cronbach's alfa van .78. Op basis van een Principale Componenten Analyse zijn 4 componenten geïdentificeerd. Kennistekorten zijn met name aangetoond op het terrein van pijnbestrijding en medicatie. Daarnaast hebben de respondenten over het algemeen aangegeven tevreden te zijn over hoe pijn gemeten en behandeld wordt bij deze doelgroep. Lager opgeleide medewerkers blijken meer kennistekort te hebben dan hoger opgeleiden. Oftewel hoger opgeleiden zijn zich meer bewust van aspecten rondom pijn bij ouderen met dementie.

Hoofdstuk 3 geeft een systematisch overzicht van de literatuur betreffende observationele pijnbeoordelingsinstrumenten. De laatste jaren is men zich in toenemende mate bewust geworden van het probleem pijn bij ouderen met dementie. Deze toenemende bewustwording heeft geleid tot meer onderzoek en kennis op het terrein van pijnbeoordeling. De betrouwbaarheid, validiteit en bruikbaarheid van 12 getraceerde observationele pijnschalen zijn beoordeeld en met elkaar vergeleken in deze review. Deze 12 schalen zijn getraceerd door gebruik te maken van een uitgebreide zoekstrategie. Vervolgens is een psychometrische kwaliteitsmeting verricht aan de hand van vooraf opgestelde criteria. De meeste van de geselecteerde schalen zijn nog steeds in ontwikkeling. Meer dan de helft is na 2002 gepubliceerd. De psychometrische kwaliteit van de geselecteerde studies blijkt in de meeste gevallen matig te zijn. Slechts 4 van de schalen scoren 11 kwaliteitspunten tijdens de evaluatie (range 0-20), te weten DOLOPLUS-2, ECPA, PAINAD, PACSLAC. Gebaseerd op de psychometrische criteria sensitiviteit en de klinische bruikbaarheid concluderen we dat met name de DOLOPLUS en de PACSL $\Lambda$ C vooralsnog de voorkeur verdienen. De conclusie luidt verder dat geen van de schalen uitvoerig getest zijn 
buiten hun oorspronkelijke onderzoekssetting. Gezien de beperkte psychometrische kwaliteit lijkt verder onderzoek aan te bevelen waarin de psychometrische kwaliteit verder wordt getest.

Hoofdstuk 4 beschrijft de resultaten van deze verdere psychometrische evaluatie van de 3 vertaalde versies van de PAINAD, PACSLAC en de DOLOPLUS-2, uitgevoerd in een steekproef van 128 verpleeghuisbewoners van 12 psychogeriatrische afdelingen. Aan de hand van observaties, uitgevoerd tijdens de griepprik en tijdens een aanvullend individueel bepaald zorgmoment (bijvoorbeeld tijdens het wassen in de ochtend) werd de mogelijke aanwezigheid van pijn gemeten. De drie schalen tonen aan voldoende valide en betrouwbaar te zijn. Wat betreft de bruikbaarheid, scoort de PACSI AAC aanmerkelijk beter dan de andere schalen. De PACSLAC werd door de verpleegkundige en verzorgende gezien als gebruiksvriendelijk en niet tijdrovend, hetgeen voor de klinische bruikbaarheid van groot belang is. De Cronbach's alfa voot de totale PACSLAC bleek hoog $(>.80)$ te zijn. Dit was eveneens het geval voor twee van de vier subschalen, te weten 'gezichtsuitdrukkingen' en 'sociaal emotioneel/ stemming'. De twee andere subschalen, 'actitiviteit/ lichaamsbeweging' en 'fysiologische indicatoren etc' scoorden beduidend lager. Verder was er sprake van goede betrouwbaarheid en validiteit, alhoewel verder uitvoerig psychometrisch testen aan te bevelen is. Daarnaast is het van belang dat de schaal wordt ingekort, aangezien dit hoogstwaarschijnlijk een positief effect zal hebben op de bruikbaarheid en de homogeniteit van de schaal. De PAINAD werd als minder bruikbaar beschouwd maar scoorde wat betreft psychometrische kwaliteit goed. De interne consistentie was acceptabel met een alfa variërend van .69 tot .74 (met uitzondering voor het item 'ademhaling').

Opmerkelijk was verder dat maar liefst meer dan de helft van de deelnemers an het onderzoek in staat waren om een zelfrapportageschaal (Verbal Rating Scale) in te vullen. Een hogere score op de VRS bleek samen te hangen met een consistent hogere score op de observatieschalen PACSLAC en PAINAD. De Nederlandse versie van de DOLOPLUS werd gezien als de meest ingewikkelde schaal. De psychometrische kwaliteit van de DOLOPLUS was redelijk, met uitzondering van de subschaal 'psychosociale reacties'. Interne consistentie voor de totale schaal varieerde van .74 tot .75 en de subschalen varieerden van .58 tot .80. Toekomstige studies dienen zich te meer toe te spitsen op de verbetering van pijnschalen en het additioneel testen ervan.

Hoofdstuk 5 beschrijft het tot stand komen van een verkorte versie van de PACSLAC. Deze verkorte versie, PACSLAC-D genaamd, zal moeten resulteren in een schaal met een hoge mate van interne consistentie. Eerder onderzoek toonde verder aan dat medewerkers de 60-item schaal bruikbaar vonden, maar overcompleet. Dat duidt er op dat een groot aantal items niet of nauwelijks gebruikt worden in de dagelijkse klinische praktijk. Items zijn allereerst verwijderd indien ze niet of nauwelijks gescoord werden. Daarnaast zijn aanvullende criteria en analyses opgesteld op basis van een Principale 
Componenten Analyse en een interne consistentie analyse. Uiteindelijk resulteerde deze analyses in de PACSLAC-D. Een schaal bestaande uit 3 componenten die 24 pijnuitingen bevat. De 3 componenten hebben betrekking op 'gelaat', 'verzet/afweer', en 'sociaal emotioneel /stemming'. De 24 item versie vertoonde een hoge mate van interne consistentie voor de totale schaal (alfa >.82) en voor alle subschalen (alfa range .72-.82). Opmerkelijk is dat een groot aantal items in de uiteindelijke PACSLAC-D refereren aan sociaal emotionele uitingen van pijn. Verpleegkundigen en verzorgenden zullen dus alert moeten zijn op deze uitingen. Gelaatsuitdrukkingen daarentegen lijken meer een universele pijncategorie die bij allerlei doelgroepen van belang is. $\mathrm{Nu}$ een handzame praktische schaal beschikbaar is, zal toekomstig onderzoek moeten uitwijzen wat de effectiviteit is van de implementatie van een pijnschaal in de klinische praktijk. Het verdient aanbeveling dit nader te onderzoeken.

Hoofdstuk 6 onderzoekt de prevalentie van pijn bij verpleeghuisbewoners met dementie gemeten met behulp van de PACSLAC-D tijdens de ochtendzorg. Daarnaast hebben we gekeken naar de associatie tussen verschillende parameters zoals cognitieve status, geslacht, het gebruil van analgetica, co-morbiditeit en de aanwezigheid van pijn. In totaal werden 117 bewoners geobserveerd tijdens de ochtendverzorging, waarna de PACSLAC-D werd ingevuld. De resultaten beschreven in hoofdstuk 6 laten zien dat bijna de helft van de onderzoekspopulatie in meer of mindere mate pijn ervaart. Opgemerkt dient te worden dat de meeste pijnscores zich net boven het afkappunt bevonden (gemiddelde pijnscore 6.31 SD 2.8; range 4-13; mediaan 5). Verder werd aangetoond dat $40 \%$ van de mensen met een PACSLAC score van 4 of hoger geen pijnmedicatie ontving. De regressieanalyse toont aan dat onder andere comorbiditeit en het gebruik van analgetica significante voorspellers zijn en de sterkste associatie met pijn hebben. Het verdient aanbeveling om de PACSLAC$D$ te implementeren in de dagelijkse praktijk. Dit zou hulpverleners kunnen helpen om pijn beter te signaleren en te registreren.

$\mathrm{Na}$ een korte samenvatting worden in hoofdstuk 7 de belangrijkste resultaten uit het onderzoek besproken. Tevens worden methodologisch kanttekeningen gemaakt, waarbij wordt gekeken naar methodologisch sterke kanten en beperkingen van het onderzoek. Methodologische aandachtspunten zijn onder andere de procedure van data collectie (schaalontwikkeling), externe validiteit en de gebruikte analyses.

Het hoofdstuk wordt afgesloten met implicaties voor de verpleeghuisbewoners, beleidsmakers, gezondheidsmedewerkers en onderzoekers. 
"Each iteration you learn a little bit more; seldom do you learn the whole lesson at once. Just bits and pieces, incremental steps, incremental wisdom. Knowledge is revealed to us slowly.

The rate of knowing is a factor of our willingness, our abilities, our attention, our strengths and courage and desire our vision. The riddle we need to solve is the fullness of what we encounter on the outside and how we process it on the inside. The question is how far can we and do we want to progress in a life time".

(Dennis Dougherby, 2005)

Citation from the mail correspondence after the course 'Empower Yourself' at the Option Institute in Sheffield (MA) USA.

A special thanks to all participants for their empowering thoughts 


\section{DANKWOORD}

ank jullie wel allemaal.

Het doen van onderzoek kan zo op zijn tijd best solistisch zijn. Dit onderzoek en proefschrift hadden echter nooit tot stand kunnen komen zonder de inzet van zoveel gemotiveerde en betrokken mensen om me heen. Iedereen die zich daarvoor heeft ingezet wil ik hartelijk bedanken.

In het bijzonder wil ik graag alle mensen bedanken die op enigerwijze zelf hebben deelgenomen aan het onderzoek. Zij die woonachtig zijn op de verpleegafdelingen en veelal geen stem meer hadden maar vertegenwoordigd werden door hun mantelzorgers of wettelijk vertegenwoordigers. De mensen die voor het onderzoek onontbeerlijk waren en voor wie we het hele traject hebben afgelegd. Zij die met het beoordelinginstrument hopelijk een toekomst tegemoet gaan gericht op betere signalering en bestrijding van pijn. Ik dank u allen voor uw inzet en deelname aan het onderzoek.

Dankzij de bereidwilligheid en inzet van alle verpleegkundigen en verzorgenden heeft dit onderzoek een bulk aan data opgeleverd. De momenten van gegevens verzamelen waren vaak intensief en tijdrovend. Ik ben ontzettend dankbaar voor jullie inzet.

Uiteraard wil ik mijn twee promotoren bedanken, Jan Hamers en Martijn Berger. Beste Jan, ik dank je voor je betrokkenheid en de vele stimulerende en enthousiasmerende gesprekken tijdens het traject en in het bijzonder voor al het vertrouwen. Je gaf me de ruimte om te groeien en mijn eigen manier van onderzoek doen verder te ontwikkelen. Het is een voorrecht om met je samen te kunnen blijven werken aan de kwaliteitsverbetering van de ouderenzorg en ik kijk erg uit naar de toekomst.

Beste Martijn, je was niet alleen mijn statistische steun en toeverlaat vanaf de eerste dag. Als tweede promotor wist je als geen ander de begeleiding op afstand te coördineren en had je oog voor essentiële zaken in het onderzoek. Ik ben je zeer erkentelijk voor alle inbreng, ondersteuning en .... zorgzaamheid. Daarnaast wil ik ook Huda Huijer Abu-Saad bedanken. Huda zonder jou had ik hier vandaag nooit gestaan. Jouw enthousiasme en vasthoudendheid hebben me destijds overgehaald om de overstap te maken vanuit het management en de praktijk naar het onderzoek. En wie had er toen kunnen vermoeden dat dit ooit het resultaat zou zijn.

De leden van de beoordelingscommissie: Johan Vlaeyen, Ruud Kempen, Rianne de Wit, Erik Scherder en Riekie de Vet wil ik bedanken voor het kritisch beoordelen van dit proefschrift. De externe commissieleden wil ik in het bijzonder danken voor hun bereidwilligheid om deel te nemen in de commissie. Ik ben vereerd dat jullie zitting nemen in de commissie. Erik, je hebt als een van de eerste in Nederland pijn bij ouderen met dementie op de kaart gezet en jouw betrokkenheid is overweldigend. Riekie, je voorzag me ooit van advies tijdens de 
cursus klinimetrie en die bijdrage destijds heeft de basis yelegd voor het verdere verloop van het onderzoek. Jouw expertise heeft ons veel opgeleverd. Johan, ondanks alle drukke werkzaamheden wilde je toch het voorzitterschap op je nemen. Dank daarvoor. Ook een bijzonder dank je wel voor het feit dat ik deel uit mocht maken van de Somatoform club. Waarvoor natuurlijk ook alle dank dient te gaan naar Madelon Peters en Karolien van Gronsveld.

Dank ook aan mijn collega's bij de vakgroep die vaak indirect hun bijdrage hebben geleverd aan het tot stand komen van dit proefschrift. Een aantal van jullie wil ik bij naam noemen gezien de dagelijkse support, morele steun en de altijd even gezellige koffiemomentjes: Anna, Pascalle, Monique en Hilde. Dank ook aan al mijn (voormalig) kamergenoten waaronder Conny, Katinka, Mirjam en Hilde. Jullie waren (en sommige van jullie zijn nog steeds) gezellige kamergenoten in voor en tegenspoed. Attent en motiverend, waarvoor je graag even naar Maastricht rijdt. Katinka we hebben een hele poos samen op een project doorgebracht en je was mijn gids in de pijnwereld. Dank je voor alle fijne momenten samen.

Dank ook aan alle studenten die voor hun afstudeeronderzoek bij het project betrokken waren. In het bijzonder wil ik Rieneke Peijnenburg noemen, die een bijdrage heeft geleverd aan de dataverzameling en het tot stand komen van de pijnattitude vragenlijst van dit proefschrift.

Bijzonder waardevol was ook de inzet en betrokkenheid van de denktank van de werkgroep zorgonderzoek Meander. De maandelijkse bijeenkomsten hebben veel concrete ideeën en input opgeleverd voor het onderzoek, hetgeen van grote waarde is geweest.

Leerzaam was het traject van publiceren en zeker ook de samenwerking met coauteurs. Ik heb veel van jullie geleerd. Iedereen die heeft bijgedragen aan het tot stand komen van de wetenschappelijke publicaties wil ik nogmaals hartelijk danken, met name Paul Geels, en in het bijzonder Raymond Koopmans. Raymond, jouw enorme motivatie en inzet voor de verpleeghuisgeneeskunde zijn bijzonder inspirerend.

I have benefited from many discussions with students, course leaders and staff of the European Academy of Nursing Science. We first met in Bergen and during the course that lasted 3 years I experienced a wonderful learning and stimulating environment, which contributed to the project in a very positive way. It was a privilege meeting you all.

This study drew upon the knowledge and experience of other researchers in the area of pain research. Although too numerous to name, they are all appreciated for their contributions. However, a special thanks goes to Thomas Hadjistavropoulos and Shannon Fuchs-Lacelle.

Tot voor kort was dit boekje niet meer dan een aantal bij elkaar geraapte pagina's tekst, inhoudelijk misschien de moeite waard maar geen blik waardig. Nu enkele maanden later, dankzij de inzet van Hans en Inge Duimel is het 
waarachtig echt een mooi proefschrift. Inge en Hans, dank voor jullie creativiteit en vormgeving.

Gerda en Moon, ik ben er trots op dat jullie mijn paranimfen willen zijn. Gerda onze 'onderzoekscarrière' begon destijds bij het Centre for Nursing Research. Samen in hetzelfde schuitje, althans voor een korte tijd. Jij verliet het bootje voor psychologie terwijl ik naar VW verhuisde. Maar het 'wij' gevoel is gebleven (zelfde copingstrategie, zelfde achtergrond, zelfde soms onrealistische tijdsplanningen) en onze relatie groeide uit tot een vriendschap. Onze overlegmomenten duurden altijd langer dan gepland maar waren vaak zeer waardevol en vruchtbaar. Dank je wel voor alle steun. Ik begrijp soms niet hoe je het voor elkaar krijgt, duizend dingen tegelijk maar het lukt je telkens weer. Zo iemand wil je toch zeker als paranimf.

Lieve Moon, vanaf de HBO-V volgde je altijd vol belangstelling mijn kleine pasjes op weg naar deze voltooiing van dit proefschrift. Je bent een voorbeeld in mijn leven. Je bent mijn steun en toeverlaat, altijd een luisterend oor. Je hebt een relativerend en positief vermogen waar niemand tegen op kan. Met jou aan mijn zijde op 12 december, dan moet het wel goed komen.

Het is heerlijk om te kunnen praten over niet werkgerelateerde dingen. Over 'leuke' dingen in het leven die afleiding bieden. En dat, dat doe je met vrienden..... In het bijzonder wil ik noemen: Cindy, Jeanny, en Claudia, vanwege de bijzondere rol die ze in mijn leven vervullen. Dank voor jullie vriendschap en jullie steun. Lieve Cin, dank je voor alle gezellige afleidende momenten samen en de mooie uitdagingen en avonturen die we samen aangaan. Jeanny, jouw interesse is prijzenswaardig. Je bent zo begaan met mij en het onderzoek, alleen daarvoor zou je willen promoveren. Lieve Claudia, zielsverwant, al hebben we ieder onze eigen koers gevaren we weten elkaar altijd te vinden. Dat is altijd zo geweest en dat zal altijd zo blijven.

Pap, je hebt me geleerd om altijd door te gaan en vooral niet op te geven en dat is iets waar je als promovenda veel aan hebt. Ik herinner me dat ik een jaar of 16 was, op de HAVO zat en die dag voor de (zoveelste keer) wiskunde moest herkansen. Jij was al van huis om te gaan werken en op de keukentafel lag een briefje met daarop de woorden: GEEF NOOIT OP! De les was duidelijk......... En heeft me veel gebracht, nog steeds zoals je ziet. Dank je voor alle onvoorwaardelijke steun pap.

Mam, je zult er vandaag hoogstwaarschijnlijk niet bij zijn, maar in gedachten ben je er vaker wel dan niet. Je hebt bijgedragen aan mijn zelfstandigheid, een andere niet te missen eigenschap waarmee je als onderzoeker goed uit de voeten kunt. Ook jouw lessen des levens worden gewaardeerd en geleerd.

Martin, je was er altijd als ik je nodig had, deelde in blijdschap maar ook als er zorgen waren. Lief, ik ben voor jou zo bijzonder en mijn prestatie is zo uniek. En ook weet je soms niet precies waar het over gaat, het maakt niet uit. Je bent zo trots op me, dank je lief. 


\section{ABOUT THE AUTHOR}

S andra Zwakhalen was born on 25 December, 1973 in Naastricht, the $\mathcal{N}$ Netherlands. After graduating from high school in 1991, she began her studies in nursing at the Hogeschool Verpleegkunde (School of Nursing) in Sittard. In 1995 she obtained her bachelor's degree in nursing. Subsequently, she studied Health Sciences at Maastricht University (1995-1997), specialising in Mental Health Sciences. After graduating in 1997 she worked as a therapist at the Regional Ambulatory Centre for Mental Health Care (RIAGG) in Heerlen at the department of adult care and at the 'De Gezonde Zaak', a work reintegration centre. In 2000 she joined 'Drielanden Thuiszorg', a community healthcare service centre. Concurrently, she followed a sexual counselling training programme at the Erasmus Medical Congress Organization (EMCO) in Rotterdam.

Prior to her $\mathrm{PhD}$ project she participated in a research project on pain in children with intellectual disabilities. She started her $\mathrm{PhD}$ research at the Department of Health Care Studies at the Section of Nursing Science of Maastricht University in 2002, after receiving a grant from NWO, the Netherlands Organisation for Scientific Research. In 2004 she enrolled in the three-year summer school of the European Academy of Nursing Science, which she completed in 2006. In addition to her PhD project she currently holds a postdoctoral research position at the same department on a project called 'smallscale living in nursing homes'. Furthermore, she continues to conduct research into pain in elderly people with dementia.

Sandra Zwakhalen lives together with Martin Sanders, father of Robert (1991) and Iris (1994), in Hoogeloon, the Netherlands. 